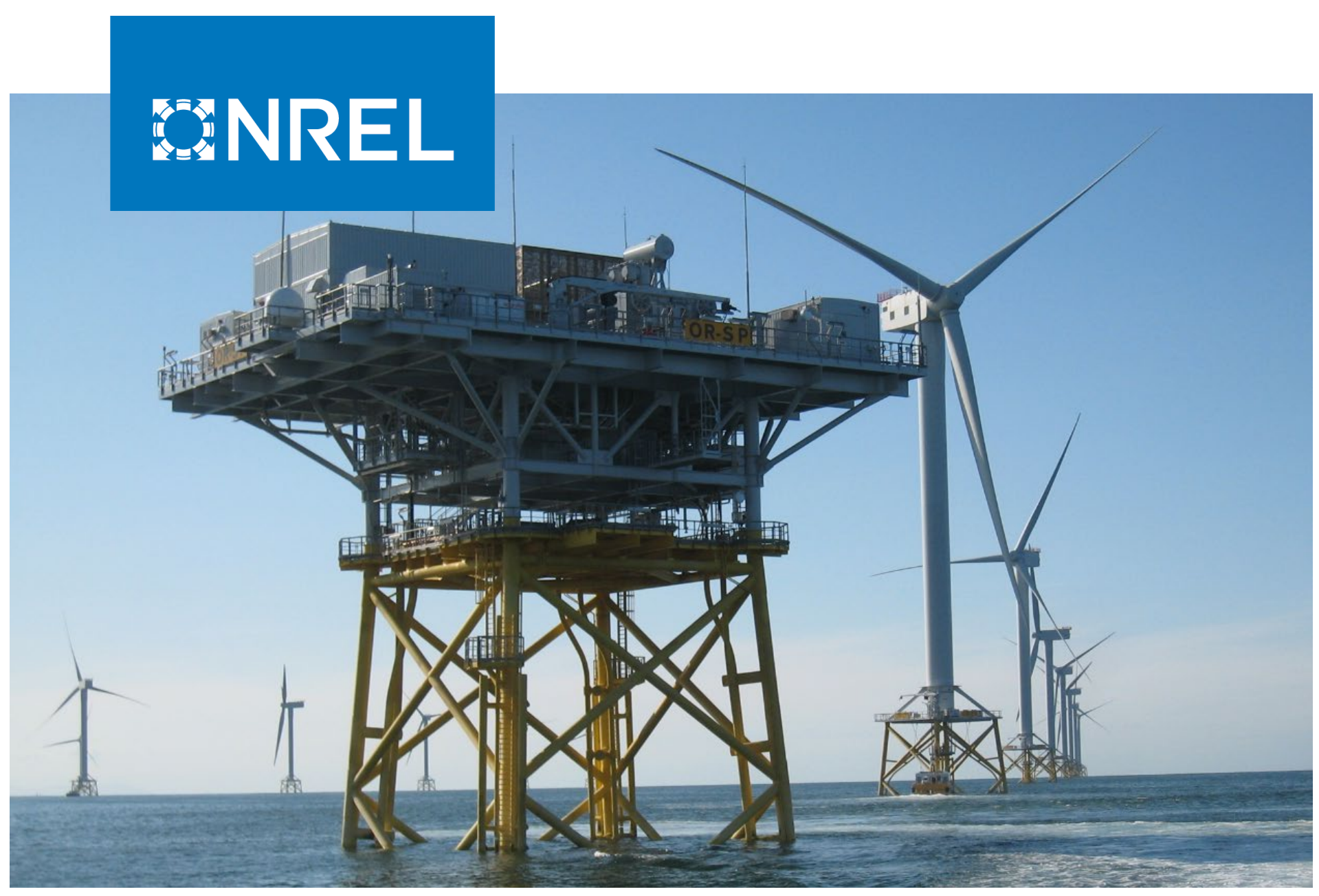

\title{
Offshore Wind Electrical Safety Standards Harmonization: Workshop Proceedings
}

\author{
Walter Musial, ${ }^{1}$ Chloe Constant, ${ }^{1}$ Aubryn Cooperman, ${ }^{1}$ \\ Michelle Fogarty, ${ }^{1}$ Emily J. Chambers, ${ }^{2}$ Brandon W. Burke,${ }^{2}$
} Edgar $\mathrm{DeMeo}^{3}$

1 National Renewable Energy Laboratory

2 Business Network for Offshore Wind

3 Renewable Energy Consulting Services, Inc.

NREL is a national laboratory of the U.S. Department of Energy Office of Energy Efficiency \& Renewable Energy Operated by the Alliance for Sustainable Energy, LLC

This report is available at no cost from the National Renewable Energy Laboratory (NREL) at www.nrel.gov/publications.

Contract No. DE-AC36-08GO28308
Technical Report

NREL/TP-5000-76849

June 2020

National Renewable Energy Laboratory 15013 Denver West Parkway Golden, CO 80401

303-275-3000 • www.nrel.gov 


\title{
Offshore Wind Electrical Safety Standards Harmonization: Workshop Proceedings
}

\author{
Walt Musial, ${ }^{1}$ Chloe Constant, ${ }^{1}$ Aubryn Cooperman, ${ }^{1}$ \\ Michelle Fogarty, ${ }^{1}$ Emily J. Chambers, ${ }^{2}$ Brandon W. \\ Burke, ${ }^{2}$ Edgar DeMeo ${ }^{3}$ \\ 1 National Renewable Energy Laboratory \\ 2 Business Network for Offshore Wind \\ 3 Renewable Energy Consulting Services, Inc.
}

\section{Suggested Citation}

Musial, Walter, Chloe Constant, Aubryn Cooperman, Michelle Fogarty, Emily J. Chambers, Brandon W. Burke, Edgar DeMeo. 2020. Offshore Wind Electrical Safety Standards Harmonization. Golden, CO: National Renewable Energy Laboratory. NREL/TP-5000-76849. https://www.nrel.gov/docs/fy20osti/76849.pdf.

NREL is a national laboratory of the U.S. Department of Energy Office of Energy Efficiency \& Renewable Energy Operated by the Alliance for Sustainable Energy, LLC

This report is available at no cost from the National Renewable Energy Laboratory (NREL) at www.nrel.gov/publications.

Contract No. DE-AC36-08GO28308
Technical Report NREL/TP-5000-76849 June 2020

National Renewable Energy Laboratory 15013 Denver West Parkway Golden, CO 80401

303-275-3000 • www.nrel.gov 


\section{NOTICE}

This work was authored [in part] by the National Renewable Energy Laboratory, operated by Alliance for Sustainable Energy, LLC, for the U.S. Department of Energy (DOE) under Contract No. DE-AC3608GO28308. Funding provided by the U.S. Department of Energy Office of Energy Efficiency and Renewable Energy Wind Energy Technologies Office. The views expressed herein do not necessarily represent the views of the DOE or the U.S. Government.

This report is available at no cost from the National Renewable Energy Laboratory (NREL) at www.nrel.gov/publications.

U.S. Department of Energy (DOE) reports produced after 1991 and a growing number of pre-1991 documents are available free via www.OSTI.gov.

Cover Photo courtesy of George Nichol, GE Renewable Energy

NREL prints on paper that contains recycled content. 


\section{Acknowledgments}

This study was funded by the U.S. Department of the Interior, Bureau of Safety and Environmental Enforcement (BSEE), and the Bureau of Ocean Energy Management (BOEM) through interagency agreement number M19PG00026 with the U.S. Department of Energy National Renewable Energy Laboratory (NREL). The authors would like to thank the many people who contributed to the content of this report, including Cheri Hunter (BSEE), David Nedorostek (BSEE), John Cushing (BSEE), Darryl Francois (BOEM), and Sid Falk (BOEM), as well as other Bureau team members for their thoughtful reviews, comments, and suggestions.

We also want to thank the NREL contributors including Tiffany Byrne, who coordinated the project schedule and deliverables, and Rebecca Green, who was instrumental in up-front planning and coordination. Cyndi Edgley coordinated the logistics for the workshop and provided support throughout the project. Technical editing was provided by Sheri Anstedt. Any errors or omissions are the sole responsibility of the authors.

Lastly, we would like to thank all the workshop participants who took time from their busy schedules to participate. The list of these participants is contained in Appendix A. 


\section{List of Acronyms}

$\mathrm{AC}$

AEIC

ANSI

API

ASTM

ATS

AWEA

BOEM

BS

BSEE

CFR

CIGRE

CSA

CVA

DC

DNV GL

DOE

EMSR

EPRI

EN

EMC

GFCI

GIS

GW

HVDC

ICEA

IEC

IECRE

IEEE

IP

ISO

ISO

$\mathrm{kV}$

LCOE

$\mathrm{MW}$

NEC

NESC

NERC

NETA

NEMA

NFPA

NREL alternating current

Association of Edison Illuminating Companies

American National Standards Institute

American Petroleum Institute

American Society of Testing Materials

Acceptance Testing Specifications

American Wind Energy Association

Bureau of Ocean Energy Management

British Standard

Bureau of Safety and Environmental Enforcement

Code of Federal Regulations

Conseil International des Grands Réseaux Électriques (International

Council for Large Electric Systems)

Canadian Standards Association

certified verification agent

direct current

Det Norske Veritas - Germanischer Lloyd

U.S. Department of Energy

Renewables Electrical and Mechanical Safety Rules (Avangrid internal)

Electric Power Research Institute

European norm

electromagnetic compatibility

ground fault circuit interrupter

gas-insulated switchgear

gigawatt

high-voltage direct current

Insulated Cable Engineers Association

International Electrotechnical Commission

IEC System for Certification to Standards Relating to Equipment for Use in Renewable Energy Applications

Institute of Electrical and Electronics Engineers

ingress protection

International Organization for Standardization

independent system operator

kilovolt

levelized cost of energy

megawatt

National Electric Code (U.S.)

National Electrical Safety Code

North American Electrical Reliability Corporation

International Electrical Testing Association

National Electrical Manufacturers Association

National Fire Protection Association (United States)

National Renewable Energy Laboratory (United States) 
NRTL

OCRP

OEM

OSHA

PES

PPE

PSCCC

RCD

RSSI

SDO

SGRE

SMS

S0

UL

UPS

USCG

$\mathrm{V}$

VAC

VDC nationally recognized testing laboratory (U.S. Department of Labor/Occupational Safety and Health Administration) Offshore Compliance Recommended Practices original equipment manufacturer Occupational Safety and Health Administration (U.S. Department of Labor)

Power \& Energy Society (part of IEEE)

personal protective equipment

Technical Committee on Power System Communications and Cybersecurity (part of IEEE PES)

residual current device

Renewables System Safety Instructions

standards developing organization

Siemens Gamesa Renewable Energy

safety management system

IEEE PES PSCCC Cybersecurity Subcommittee

Underwriters Laboratories

uninterruptable power supplies

United States Coast Guard

volt

volt alternating current

volt direct current 


\section{Table of Contents}

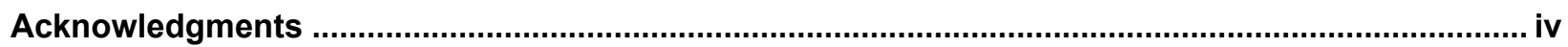

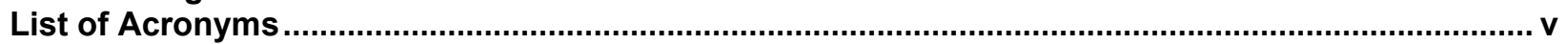

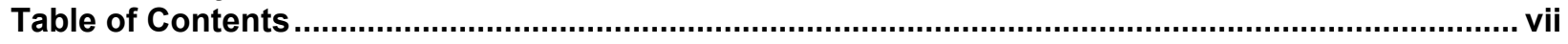

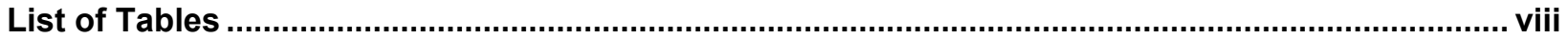

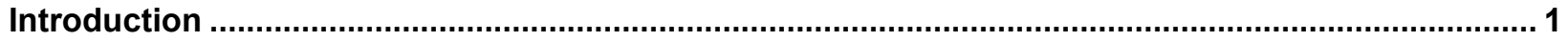

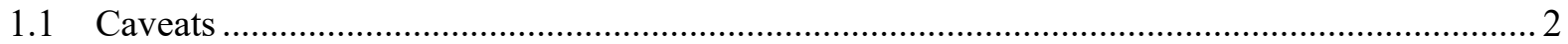

2 Key Findings

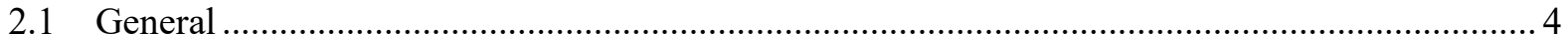

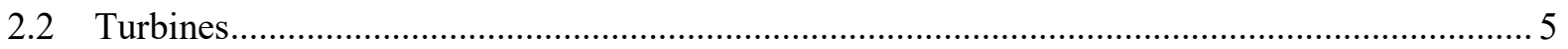

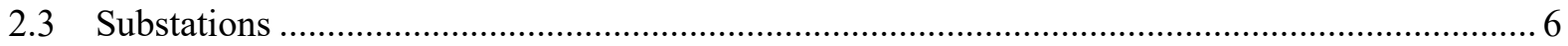

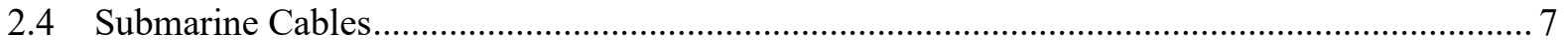

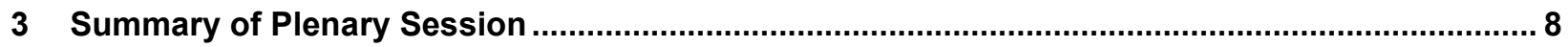

3.1 BSEE Perspective on U.S. Offshore Wind Electrical Safety Issues ......................................... 8

3.2 Overview of Offshore Wind National Standards Initiative .................................................... 9

3.3 U.S. Offshore Wind Recommended Practices Status............................................................ 11

3.4 Original Equipment Manufacturer Approach to Electrical Safety Standards ........................... 11

3.5 Assessment of Secondary System Issues ........................................................................... 12

3.6 Offshore Substations and Equipment Standards and Lessons Learned.................................... 13

3.7 Overview of Electrical Safety at RWE Windfarms During Construction and Commissioning.. 14

3.8 Assessment of U.S. Electrical Safety Regulations …........................................................... 14

3.9 Status of AWEA Working Group 5 Recommended Practices for Submarine Cables ............... 15

4 Assessment of Relevant Electrical Safety Standards for Offshore Wind Turbines .................... 17

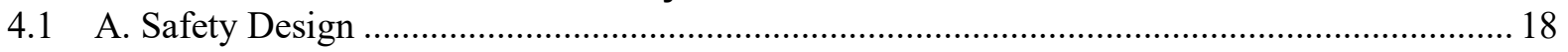

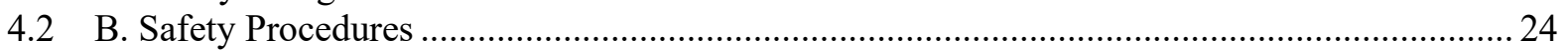

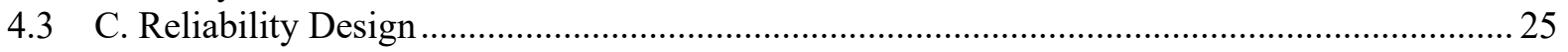

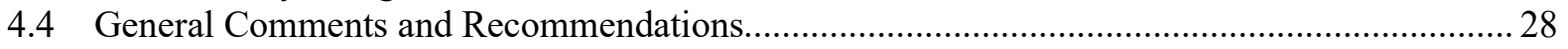

5 Assessment of Relevant Electrical Safety Standards for Offshore Substations......................................... 30

5.1 A. Safety Design (e.g., Lightning Protection, Switchgear, and Transformers).......................... 30

5.2 B. Safety Procedures (e.g., Personal Protective Equipment, Lockout/Tagout Procedures, and

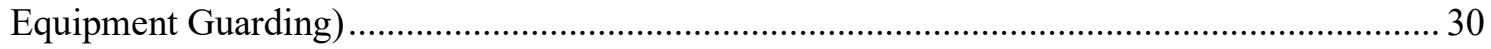

5.3 C. Reliability Design (e.g., Marine Cables and Uninterruptable Power Supplies) .................... 31

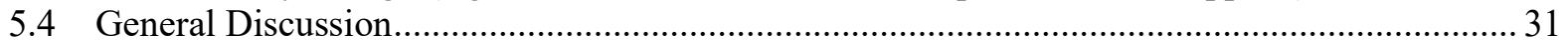

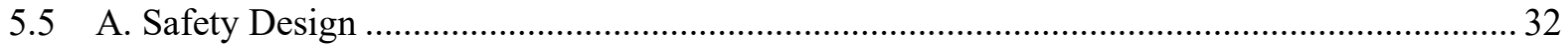

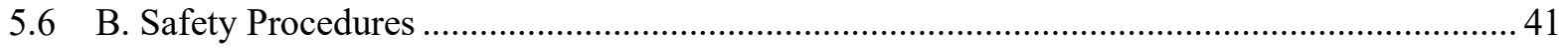

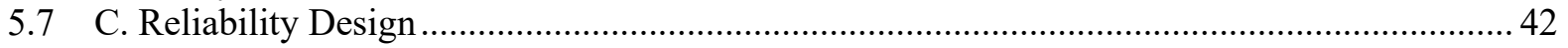

6 Assessment of Relevant Electrical Safety Standards for Submarine Cables..........................51

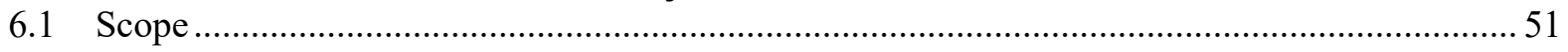

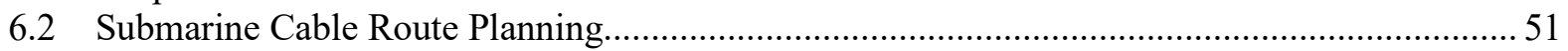

6.3 Submarine Cable Design, Manufacturing, and Testing .......................................................... 52

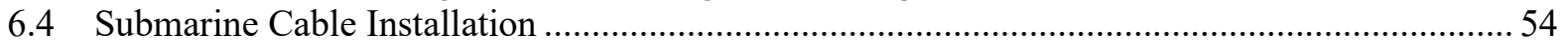

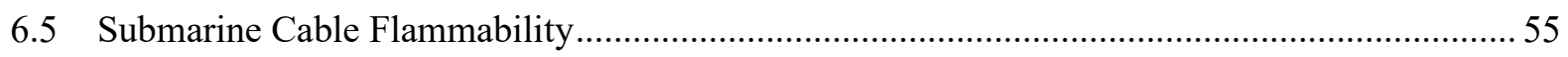

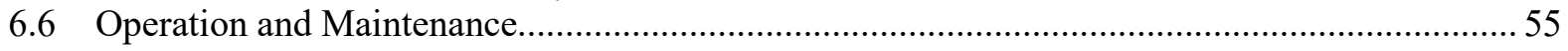

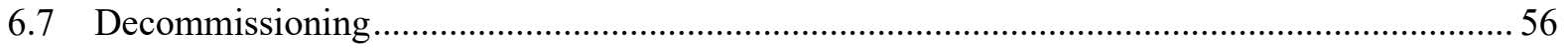

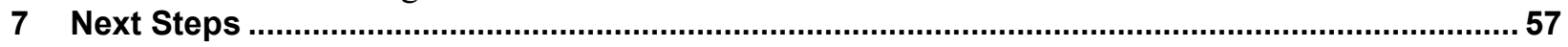

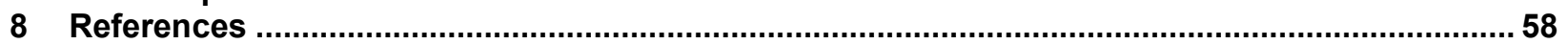

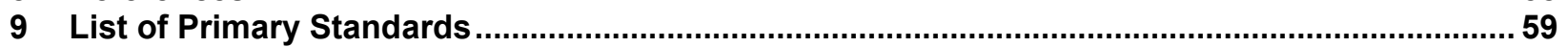

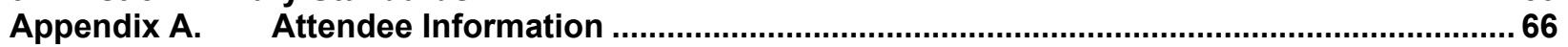

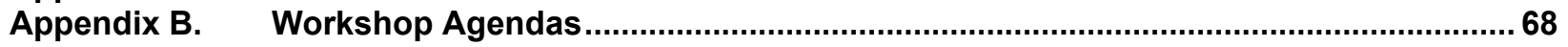

Appendix C. Workshop Presentation Materials .................................................................. 71

Appendix D. Standards Comparison Table ............................................................................. 109 


\section{List of Tables}

Table 1. List of Primary Standards Referenced in Report ...........................................................59

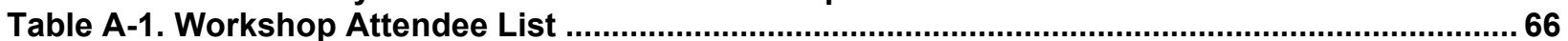

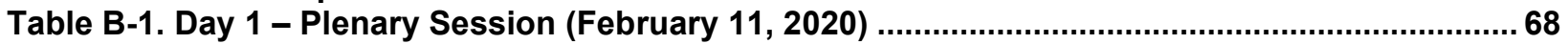

Table B-2. Day 2 - Breakout Group Discussions (February 12, 2020) .......................................... 70

Table D-1. U.S. and International Offshore Wind Electrical Safety Standards Comparison Table. 110 


\section{Introduction}

Offshore wind development activity is accelerating in the United States, with over 10 gigawatts (GW) of capacity likely to be installed on the Atlantic Coast before 2030. In addition, states have made commitments to procure over $29 \mathrm{GW}$ of offshore wind. Experienced European offshore wind energy developers are beginning to make large investments in offshore wind projects in American waters, and some U.S. developers have submitted key design documents for regulatory review. European offshore wind developers possess extensive experience in other geographic markets, which greatly increases confidence that the U.S. offshore wind industry will be successful. Nonetheless, existing U.S. electrical standards and European electrical standards are significantly different. If not addressed, these differences could impact worker safety.

To date, there has not been a comprehensive effort to compare U.S. electrical standards to European electrical standards in the offshore wind context. The Bureau of Ocean Energy Management (BOEM) and the Bureau of Safety and Environmental Enforcement (BSEE), both part of the U.S. Department of the Interior, are obligated to address these differences as part of a safe and efficient project approval process.

The federal regulations governing the development of offshore wind facilities, 30 Code of Federal Regulations (CFR) $\S 585$, were published in 2009. These regulations outline the development process for an offshore wind project in U.S. waters. However, because the U.S. offshore wind industry was less mature in 2009, adequate U.S. standards did not exist. For this reason, no specific standards were incorporated by reference into 30 CFR $\S 585$. Rather, the regulations prescribe that "best practices" be used, with the expectation that these practices would evolve as the U.S. offshore wind industry gained experience.

The formal process of defining "best practices" for the U.S. offshore wind industry has been undertaken by the U.S. wind industry (sponsored jointly by the U.S. Department of Energy (DOE), BOEM, and BSEE) through the development of recommended practices under a standards development process established by the American Wind Energy Association (AWEA), pursuant to an agreement with the American National Standards Institute (ANSI). This formal AWEA/ANSI approval process is critical for the acceptance of standards by the regulators. U.S. ANSI-approved consensus standards and guidelines include vital procedural safeguards that guide regulators with respect to project design and approval. These consensus standards can also be referenced in potential future revisions to 30 CFR $\S 585$. If appropriate, they can also be explicitly quoted by BOEM/BSEE in $30 \mathrm{CFR} \S 585$ or other regulations.

This AWEA/ANSI U.S. offshore wind standards initiative began in September 2017. The AWEA Wind Standards Committee formed an offshore wind subcommittee to oversee the development of five working groups to address deficiencies in the current suite of U.S. offshore wind standards, including electrical safety. This new suite of recommended practices will (a) help clarify design requirements for developers, and (b) enable BOEM/BSEE to create regulations that better reflect industry best practices; but publication is not expected until late 2021. For the near term, there is insufficient guidance in the public domain to establish best practices for U.S. offshore projects. 
The electrical infrastructure of an offshore wind power plant is extremely complex. To adequately cover all the electrical subsystems, a broad range of skills from varying disciplines is required. In the interest of minimizing delays to offshore wind project approvals, BOEM/BSEE commissioned the National Renewable Energy Laboratory (NREL) to convene a group of technical experts and conduct a workshop to help identify relevant issues. The workshop proceedings (this report) are intended to document these matters, such that regulators can use this report as guidance while the formal consensus recommended practices are being developed through the AWEA/ANSI U.S. Standards Initiative.

To execute the workshop and write these proceedings, NREL formed a team including internal staff, technical staff from the Business Network for Offshore Wind, and NREL consultant Ed DeMeo, who is an experienced wind technology expert. The NREL team identified the world's most qualified subject matter experts possessing specific skills vital to our understanding of offshore wind facility electrical design and safety, and the harmonization of European and U.S. standards. These experts were drawn from the membership of the AWEA/ANSI Offshore Compliance Recommended Practice (OCRP) working groups, relevant AWEA wind standards committees, recommendations from BOEM and BSEE, and the U.S. offshore wind supply chain and developer community. More than 50 technical experts from a diverse range of organizations gathered on February 11-12, 2020, at NREL's Flatirons Campus near Boulder, Colorado. During the course of the workshop, these experts shared their knowledge of the constituent electric systems that together comprise an offshore wind power plant - from the turbines and offshore substations (i.e., electric service platform) to the subsea electric cables and grid connections.

The workshop organizers compiled input received from workshop presentations and verbal discussions into this set of proceedings, with the primary goal of publishing these proceedings as a near-term reference to inform project design and approvals. In addition, we envision that these proceedings may help inform U.S. industry recommended practices, which are under development by the AWEA Wind Technical Standards subcommittee.

\subsection{Caveats}

This document represents the viewpoints of a wide variety of subject matter experts on the topics of electric safety in offshore wind plant design, installation, and operation. Although the authors made every attempt to document and translate the views expressed during the workshop and peer review process, the interpretations are those of the authors and may not convey the intentions of the attendees in all cases.

The complexity of the design and operation of the electrical systems of an offshore wind farm are immense, requiring the application of dozens of standards. Therefore, the recommendations made herein represent a first step toward reducing the conflicts that may arise during these processes; however, the authors make no claim that these recommendations will eliminate conflicts or safety concerns. All projects must engage certified verification agents as required by BOEM and BSEE to oversee project development, and, where appropriate, retain the services of a third-party owner's engineer.

It is important to note that there are several instances in which more than one group at the workshop addressed the same topic but may not have identical guidance. In some instances, the 
recommendations may conflict. In these cases, we attempted to provide both viewpoints to allow for the possibility that there may be multiple pathways to achieving the necessary levels of safety. In other cases, these viewpoints may not be conflicting but may address separate issues on the same topic. For the full scope of the workshop proceedings on a specific topic, reference the topic within each of the sections for the corresponding discussion and recommendations from the turbine, cables, and substations groups, respectively. In all cases where two different viewpoints were offered, we recommend considering both opinions and the developer and its certified verification agent (CVA) conduct their own thorough investigation of the issue. 


\section{Key Findings}

The workshop's presentations and discussions benefitted from the extensive breadth and depth of expertise of the workshop participants. Major findings and key insights from the workshop include the following, which are organized into four categories that parallel the section headings: General, Wind Turbines, Substations, and Subsea Cables.

\subsection{General}

- The U.S. offshore wind industry is progressing toward construction and operations sooner than the availability of supporting standards, guidelines, and regulatory frameworks. For that reason, interim regulatory guidelines are needed until comprehensive consensus standards can be finalized. The Offshore Wind Electrical Safety Standards Harmonization workshop delivered informed input to provide this preliminary guidance. Workshop attendees commended BOEM/BSEE for convening this meeting and recommended continuing interactions among BOEM, BSEE, the industry, and those pursuing standards harmonization. Ongoing engagement is important, as guidelines and best practices will need to be updated and refined as the domestic offshore wind sector advances. Recognizing that more formal guidance for U.S. projects may not be available until late 2021, the overall aim is to provide guidance to help proposed offshore wind projects move forward in the absence of definitive U.S. standards.

- A standards comparison table provided to participants in advance of the workshop helped focus workshop discussions. This table was drafted by BSEE technical staff and reviewed by several members of the offshore industry prior to the workshop. The table, along with initial feedback from the industry, gave rise to a number of questions considered by the workshop participants both during and after the workshop. Through discussion of the table, a number of standards - both U.S. and European - were added or deleted, and appropriate commentary was added to offer interim guidance. That table, amended to reflect the workshop deliberations, is included in Appendix D (Table D-1).

- An initial objective of the workshop was to identify and resolve inconsistencies (harmonizing) among U.S. and European standards addressing similar topics. However, the workshop discussions generally revealed differences rather than inconsistencies. In many cases, the differing standards may achieve essentially the same objective (i.e., a similar level of personnel and equipment safety). See Section 2.2 for further discussion.

- Strong support was broadly expressed for performance-based as opposed to prescriptive standards. The attendees generally felt that applying prescriptive standards may impose costs without increasing safety.

- Workshop participants were highly qualified in the topical areas being considered, ranging from experts in equipment and safety to certification, with a variety of technical and cultural workplace perspectives.

- In general, worker safety protocols and technical design decisions inform each other; they cannot be separated without compromising one or the other. Therefore, we recommend ongoing and expanded communication between technical design engineers and safety cultures. Both perspectives need to be well-represented and considered together in deliberations on project economics.

- In general, a consensus emerged that U.S. standards, if or where applicable, should be applied. However, if adherence to an International Electrotechnical Commission (IEC) 
standard results in the same level of safety, then the IEC standard should also be acceptable. Code mixing should be avoided and ensuring consistency in the use of codes, standards, and practices across the complete electrical system (e.g., the onshore substation, offshore substation, and wind turbine electrical interface) is paramount. It will be incumbent upon project developers to demonstrate to the CVA and regulatory bodies that an adequate level of safety will be achieved. Workshop participants indicated that the use of an IEC standard in place of a corresponding U.S. standard is more likely to occur in the case of wind turbines that already have IEC-type certification, or for submarine cable systems, for which no U.S. standard exists, than for substations, which are project-specific, custom-designed installations.

- Competition among standards organizations (e.g., Institute of Electrical and Electronics Engineers [IEEE], IEC, AWEA) impedes standards harmonization. These standards developing organizations (SDOs) appear increasingly reluctant to defer to similar standards developed by another SDO. In the past, standards bodies collaborated on producing standards, but this has become less common. Workshop participants would welcome greater cooperation and less competition.

- The terms "high," "medium," and "low" voltage are subjective and prone to misinterpretation. The terms refer to different voltage ranges in various standards and can also vary across jurisdictions. Workshop participants emphasized that when referencing a standard or procedure, it is important to verify that the range of voltages covered by that standard or procedure is appropriate.

- Wiring systems and nonsubmarine cables should not be overlooked. BOEM/BSEE or AWEA should identify a group to be responsible for reviewing wiring and cabling topics and determining which standards are most applicable.

- Although grid integration was not the focus of this meeting and is itself a separate and significant topic, it is important to realize that, with injections of $1 \mathrm{GW}$ or more at the landbased point of interconnection, offshore wind power plants will be subject to the North American Electric Reliability Corporation's (NERC's) jurisdiction. Offshore wind facilities will impact system reliability of the land-based receiving independent system operator (ISO) or utility. As a result, additional requirements and regulatory standards on offshore wind systems may be imposed because Federal Energy Regulatory Commission/NERC and regional organizations like the Northeast Power Coordinating Council define regulatory requirements focused on the bulk energy system and bulk power system, reliability, and cybersecurity.

- The industry should move away from IEC 61400-22, which is superseded by IEC System for Certification to Standards Relating to Equipment for Use in Renewable Energy Applications (IECRE) OD-501 and -502. Many turbine suppliers have already adopted the new IECRE system, and it is expected that most offshore turbines will be required to have IECRE certificates going forward. Therefore, IEC 61400-22 is an outdated standard. IECRE OD-501 and -502 are referenced in Section 2.2 and Section 2.3.

\subsection{Turbines}

The following statements summarize the notable, key findings from the turbines group workshop discussions: 
- Turbines are generally purchased "off the shelf," with a suite of components based on IECtype certification. Replacing components to meet U.S. standards is a design undertaking for each model and imposes costs for manufacturers. This practice of replacing components for compliance should not be required if the project developer provides justification that the turbine, as currently designed, meets the requisite level of safety. Some participants in the turbine group were more inclined to favor international standards, whereas others advocated for U.S. standards, as done in land-based wind. Participants also expressed that, if a component or subsystem has already been certified by a nationally recognized testing laboratory (NRTL) in the United States or as part of an IEC-type-certification process, it should not be required to undergo repeated evaluation and testing.

- To illustrate the previous finding, consider spacing of equipment cabinets with dangerous interior voltages. In the United States, the Occupational Safety and Health Administration (OSHA) - under the assumption that dangerous voltages are exposed when the cabinet is opened-requires clearances around cabinets. This requirement generally dictates larger clearances to aid maneuverability of service personnel. However, IEC standards do not allow dangerous voltages to be exposed within cabinets. For example, exposed voltages can be accessed with a suitable probe, but not with a finger. As a result, the hazard that is addressed by the OSHA standard does not exist in a system designed pursuant to IEC standards, so the spacing requirement can be relaxed.

- As a corollary to the two previous findings, applying an IEC standard rather than a corresponding U.S. standard simply to reduce costs should only be acceptable if it can be demonstrated that safety of personnel and equipment are not compromised.

- Offshore turbine technicians will require a higher level of training to enter and perform work on an offshore turbine than technicians that are trained for land-based turbines. This additional training should anticipate and cover specific differences between the offshore wind power plant's electrical design and the base training received by U.S. electrical workers.

\subsection{Substations}

The following statements summarize the notable, key findings from the substations group workshop discussions:

- Because of the similarity between offshore wind substations and offshore oil and gas platforms, on most issues, the substation group defaulted to American Petroleum Institute (API), ANSI, and IEEE standards. The rationale is that technicians involved in the construction and operation of substations will primarily have U.S. backgrounds, training, and experience. Also, major suppliers of electrical components are generally able to meet most global standards for multiple scenarios. Each substation is a custom product, so sourcing components that comply with U.S. standards should not impose undue hardship or costs.

- API Recommended Practice14F, "Design and Installation of Electrical Systems for Offshore Production Platforms" (see 30 CFR $\S 250.114(\mathrm{c})$ ), was frequently identified as an applicable U.S. standard because specific electrical safety requirements for electrical installations located offshore are covered. These include recommendations for low- and medium-voltage switchgear, heliports, weather decks, lighting, transformers, and all types of electrical equipment and installations for offshore applications. Other participants observed that the API electrical standards are relevant for some aspects of the offshore wind substation, but that they were originally intended for offshore oil extraction platforms, which may have 
different electrical design requirements than offshore wind substation platforms. Reference was also made to API RP 14C, "Analysis, Design, Installation, and Testing of Basic Surface Safety Systems for Offshore Production Platforms" (see 30 CFR § 250.1628(c)).

- Different approaches emerged concerning workforce utilization. Some companies use the same technicians to service land-based and offshore equipment, whereas others have separate specialized land-based and offshore workforces. A prescriptive standard may not be required in these instances, as this is more a question of operational strategy. However, it was emphasized during the workshop that inconsistencies (code mixing) across codes and standards can result in unintended safety-related consequences during operation/maintenance.

- U.S. and international standards differ on the need for visual confirmation of contact status (i.e., open or closed) for switchgear. This difference needs to be addressed to inform substation design and construction. In general, offshore wind electrical installations and switching equipment must be designed and installed with the appropriate arc flash protection and facilities to comply with OSHA lockout/tagout requirements.

\subsection{Submarine Cables}

The following statements summarize the notable, key findings from the cables group workshop discussions:

- Submarine cables for voltages up to 60 kilovolts $(\mathrm{kV})$ are covered by IEC 63026 , which was recently published.

- Existing U.S. standards apply to components of submarine cables, but there is no comprehensive U.S. standard for the entire submarine cable system. IEC standards describe methods for testing and type-certifying complete cable systems but need to be combined with Conseil International des Grands Réseaux Électriques (CIGRE) recommendations for electrical and mechanical testing of submarine cables. Acceptance of the relevant IEC standards is recommended. 


\section{Summary of Plenary Session}

This section summarizes the information exchanged during the plenary session of the workshop, which took place on February 11, 2020. The purpose of the plenary session was to provide background on the workshop objectives, and to allow members from the industry to present their unique, and sometimes divergent, perspectives on the issues. During the plenary session, eight speakers presented their viewpoints on issues relevant to electrical design and safety standards for offshore wind facilities, and how they are adapting and attempting to comply with U.S. market conditions.

\subsection{BSEE Perspective on U.S. Offshore Wind Electrical Safety Issues}

A presentation was made by Cheri Hunter, BSEE renewable energy program coordinator, Darryl Francois, BOEM Office of Renewable Energy Programs, and David Nedorostek, BSEE senior electrical engineer. The purpose of this introductory presentation was to set the stage for the workshop, and to explain why it was not only necessary but urgent to develop interim regulatory guidelines for U.S. offshore wind installations. The presentation covered the federal regulatory background, noting that the Department of the Interior is the federal agency that will be principally responsible for regulating and enforcing safety and health requirements for renewable energy projects located on the Outer Continental Shelf.

Offshore wind projects traditionally follow international standards, but conflicts may arise if consideration is not given to the prevailing national and local standards. BSEE and BOEM have a due diligence requirement to ensure that the safest standards are used, and the public expects these agencies to conduct a robust comparison of U.S. standards with a focus on safety.

BOEM and BSEE are separate entities but work closely together to review industry submissions, such as construction and operation plans, facility design reports (FDRs), and fabrication and installation reports related to offshore wind project development within the approval process.

They noted that U.S. offshore wind recommended practices are currently under development through AWEA's Offshore Wind Standards Initiative, but it is expected that these ANSIapproved recommended practices will not be available until the end of 2021. As such, BSEE created a comparison of U.S. versus international electrical safety standards to assist

BSEE/BOEM engineers in performing a comprehensive assessment of project electrical designs for the first U.S. offshore wind projects. This resulted in the creation of the Electrical Safety Standards Comparison Table (hereafter "the table"), which included a list of standards that was edited and distributed by the NREL team prior to the February 2020 workshop. The original table was intended to be a starting point for establishing U.S.-specific expectations for offshore wind electrical safety. BSEE indicated that the table will continue to evolve through the feedback received from the February 2020 workshop proceedings and as BSEE, BOEM, and the offshore wind industry identify best practices through experience. As such, the table was updated by the authors of this report based on the feedback received through this workshop and is presented in Appendix D.

The table identifies available standards from the United States, Europe, Canada, and harmonized standards that may incorporate international- and U.S-specific requirements. It focuses on what 
BSEE and BOEM have initially identified to be the most safety-critical electrical equipment and procedures. The table is subdivided into the following three categories:

- Safety Design (e.g., arc flash, switchgear, and transformers)

- Safety Procedures (e.g., personal protective equipment, lockout/tagout procedures, and equipment guarding)

- Reliability Design (e.g., marine cables and uninterruptable power supplies).

Workshop participants reviewed the table and considered the following sample questions including, but not limited to:

- Does the list of standards focus on most safety critical electrical equipment?

- Is critical electrical equipment categorized properly?

- Are all the applicable electrical safety standards for each electrical component captured?

- Should certification be done by a NRTL for functionality and performance?

This initial BSEE/BOEM presentation helped frame the discussions throughout the remainder of the workshop. The presentation concluded that the next steps were to continue a peer review of international and U.S. electrical standards by the experts in attendance and to document these discussions. In this manner, these workshop proceedings can inform near-term U.S. project development and the ongoing development of ANSI-approved recommended practices for U.S. offshore wind.

\subsection{Overview of Offshore Wind National Standards Initiative}

Walter Musial is a principal engineer at NREL and is the chairman of the AWEA Offshore Wind Standards Subcommittee, which is also known as the Offshore Wind Technical Advisory Panel (OWTAP). He presented an overview of the history of U.S. offshore wind recommended practices and the current efforts to develop new ones under the AWEA/ANSI rules. The U.S. offshore wind standards development effort is jointly sponsored by BOEM and DOE and is further supported by the efforts of the Business Network for Offshore Wind and AWEA.

From 2009 to 2012, the U.S. offshore wind industry, in collaboration with BOEM, NREL, DOE, and AWEA, developed a roadmap from existing standards to facilitate the development of "best practices" for U.S. offshore wind installations, known as the AWEA OCRP 2012. Over 50 members of the offshore wind industry participated in the development of AWEA OCRP 2012, which covers all aspects of fixed-bottom offshore wind facility development, from design through to decommissioning (American Wind Energy Association. 2012). OCRP refers to over 100 standards, guidelines, and technical specifications. After its publication in October 2012, it became the de facto reference for offshore wind development in the United States and has been used as an informative framework for regulators, developers, and CVAs.

However, for several reasons, AWEA OCRP 2012 no longer satisfies the regulatory requirements for BOEM/BSEE and the offshore wind development community. First, when it was written, the formal process for review and approval by ANSI had not yet been adopted by AWEA; this approval process is critical for the acceptance of standards by the regulators, and allows the standards documents to be referenced by BOEM/BSEE if appropriate. In addition, the scope of AWEA OCRP 2012 was too narrow. It did not cover key aspects of the current U.S. offshore wind industry such as floating wind turbines. Finally, in addition to the noted missing elements in AWEA OCRP 2012, the document is over 8 years old and does not adequately 
reflect the knowledge gained through the installation of over $27 \mathrm{GW}$ of offshore wind globally, and does not capture the extensive U.S. project development experience that has occurred since it was written.

The AWEA Offshore Wind Standards Subcommittee was formed in 2017 to oversee the initiative to upgrade the U.S. offshore wind recommended practices. On October 23, 2017, the AWEA Offshore Wind Standards Subcommittee met for the first time, formed five working groups, and assigned two conveners to each working group. These groups and their conveners are:

- OCRP 1 - Working Group 1: AWEA OCRP Edition 2, under the leadership of Rain Byars and Graham Cranston

- OCRP 2 - Working Group 2: AWEA U.S. Floating Wind Systems Recommended Practices, under the leadership of Lars Samuelsson and Leif Delp

- OCRP 3 - Working Group 3: AWEA U.S. Offshore Wind Metocean Conditions

Characterization Recommended Practices, under the leadership of Mike Drunsic and Lorry Wagner

- OCRP 4 - Working Group 4: AWEA U.S. Recommended Practices for Geotechnical and Geophysical Investigations and Design, under the leadership of Matt Palmer and Mathieu Guinard

- OCRP 5 - Working Group 5: AWEA Recommended Practices for Submarine Cables, under the leadership of Georg Engelmann and Bob Hobson.

Each recommended practice will provide a roadmap for U.S. offshore wind development in its respective area, with a view toward adding transparency and consistency to the regulatory approval process, as this can provide benefits to developers, regulators, and the general public. These nationally focused recommend practice documents will account for the unique offshore conditions on the U.S. Outer Continental Shelf, but they will also be applicable to potential offshore wind installations in state waterways (e.g., the Great Lakes). They will provide reasonable requirements for commercial offshore development and will cover a range of project development activities_ project design, construction, and deployment practices; operations; safety; inspection; and decommissioning — while anticipating the new and quickly evolving nature of offshore wind technology. This suite of offshore recommended practices will help clarify the requirements for developers beyond what was provided by AWEA OCRP 2012 and will enable BOEM and BSEE to adopt regulatory requirements that better reflect industry best practices.

The recommended practice documents that will result from this effort will clarify the requirements for offshore wind in the United States. However, they will not be publicly available for reference or citation until late 2021. Therefore, the results of this workshop will serve, in part, as interim guidance until these OCRP documents are published. OCRP-1 and OCRP-5 cover particularly relevant parts of this offshore electrical safety compliance and were described in the plenary session later by members of those committees: Albert Fisas and Bob Hobson, respectively. 


\subsection{U.S. Offshore Wind Recommended Practices Status}

Albert Fisas, advanced technologies manager for offshore wind at GE Renewable Energy, presented an overview of the electrical content in the draft "Offshore Compliance Recommended Practices (OCRP)" maintenance document, which will be the second edition that supersedes and replaces AWEA OCRP 2012. This revision is currently underway, with over 100 members from the international offshore wind community contributing. Albert is a key member of the development team and was representing the working group in the absence of its conveners. The working group plans to release a draft for public review later this year. A draft of the current version of this OCRP-1 RP was distributed among the participants of the workshop for review.

Albert pointed out that electrical design and safety standards are covered in several parts of the revised draft OCRP document, including in some of the general sections (i.e., introductory content, design basis, standards hierarchy, terms and definitions, references). Additionally, major references reside in the design sections of Chapter 5 , including:

- Section 5.6 (Design of Offshore Wind Turbine)

○ Section 5.6.4 (Electrical Design)

○ Section 5.6.5 (Design for Occupational Health and Safety)

- Section 5.7 (Design of Offshore Substation)

○ Section 5.7.4 (Electrical Design)

○ Section 5.7.5 (Design for Occupational Health and Safety).

Note that submarine cables are addressed in OCRP-5, which is currently being developed by working group 5.

The intent of the OCRP-1 working group and the participants of the electrical safety standards harmonization workshop was to collectively align with the recommendations within OCRP-1. However, workshop participants were not constrained by the content of the OCRP-1 edition 2 draft, which is still under development. As such, the OCRP-1 working group may potentially benefit from the additional insights revealed during the 2-day workshop. We suggest that the ORCP-1 consider new references to documents recommended by workshop participants as appropriate for offshore wind facility installations.

\subsection{Original Equipment Manufacturer Approach to Electrical Safety Standards}

Samuel Hawkins, chief engineer for offshore wind emerging markets at Siemens Gamesa Renewable Energy (SGRE), gave a presentation titled, "OEM Approach to Electrical Safety Standards." SGRE is the world's offshore wind turbine leader in terms of total installed offshore capacity. A brief company overview was provided, which included a description of their new turbine, the SG 11.0-193 DD, which is scheduled for commercial deployment in 2022.

Samuel introduced the methods that SGRE uses for selecting design standards, which includes the definition of the company's global design basis, and a formal evaluation and adaptation for the U.S. market. The process commences early in the design phase, to develop and document the 
design basis for each module of the system. SGRE incorporates best practices from previous designs, and regularly updates the process to account for fleet performance, reliability, safety, changes and improvements in technology, and revisions and updates to design standards. They have a listing of standards applied to each product, which is used during the type certification process. These standards cover a wide range of topics, including electrical design and safety. Health, safety, and environmental design requirements are created, reviewed, and distributed to design teams.

In summary, for general global supply, SGRE takes the following actions for offshore wind turbines:

- Turbine designs comply with international codes and standards

- Turbine models are type certified against this design basis, in accordance with IECRE OD 501.

Additional actions taken for offshore wind turbines in the United States include:

- Evaluating the design basis relative to OSHA regulations, United States Coast Guard (USCG) regulations, and leading standards from IEEE, National Fire Protection Association (NFPA), and others to meet safety objectives

- Evaluating the gaps between the global design basis and U.S. codes and standards on a caseby-case basis. If safety can be improved with reasonable effort, design modifications are made.

The type certificate serves as confirmation that the turbine design is compliant with its design basis.

\subsection{Assessment of Secondary System Issues}

Steven Kunsman, director of product management and applications at ABB, delivered two presentations during the plenary session. This is a general summary of both.

$\mathrm{ABB}$ is a major global supplier of large electrical hardware components that are used in multiple parts of offshore wind farms. As a global supplier, they can comply with any standards requirement. In ABB's view, it is more important to have a transparent specification than to align with a given set of standards.

Steve covered several topics that are relevant to the offshore wind industry as it enters the U.S. market. Some of the key points indicated were:

- Offshore wind farms will need to comply with NERC critical infrastructure protection regulations. The design impacts of this necessity should be considered.

- Offshore substations will likely be maintained by U.S.-trained electricians and high-voltage electrical workers, the same as for land-based substations. As such, there is a strong need to standardize equipment and training around U.S.-based standards (e.g., National Electric Code $[\mathrm{NEC}]$ ) to avoid possible safety concerns.

- From ABB's experience, BSEE will likely use OSHA standards first if applicable. BSEE will consider international standards and codes if they are more applicable. 
- IEC 60255 series have been harmonized with IEEE C37.90 series standards, which is a positive step. However, this IEC/IEEE cooperation does not appear to be continuing in the future. IEC and IEEE are competing more, which is leading to less harmonization and more potential conflicts.

- Steve also chairs the IEEE Power \& Energy Society Technical Committee on Power System Communications and Cybersecurity (PSCCC) Cybersecurity Subcommittee (S0). He indicated that cybersecurity standards, such as CIP-013-1, will be enforceable commencing July 2020; he cautioned the group not to overlook or downplay the importance of this growing issue.

In 2015, Moffatt \& Nichol published a report (https://www.boem.gov/723AA), funded by BOEM, that recommended standards to be used for offshore substations. Prior to this workshop, there was considerable interest in understanding whether this report had merit and should be used as a guide. The presentation by Steve Kunsman and subsequent discussion indicated that this report contained a collection of lessons learned from the Cape Wind offshore substation development process. Although the report captured all of the standards that were (or should have been) used for Cape Wind, the general group discussion indicated that the report may be biased toward structural design elements, and that some portions pertaining to electrical design and safety may be outdated.

\subsection{Offshore Substations and Equipment Standards and Lessons Learned}

George Nichol, project director, Grid Solutions for GE Renewable Energy, gave a presentation focused on his experience with substation design and implementation, totaling $4.7 \mathrm{GW}$ of offshore wind grid connections. His presentation provided background information related specifically to offshore wind substations that GE has deployed in recent years in the United Kingdom. He elaborated on the project development steps, and provided an overview of the Galloper substation, a 336-megawatt (MW), 33/132-kV, offshore substation. This substation and land-based delivery system features a state-of-the-art dynamic reactive compensation system located at the land-based substation near Leiston, Suffolk, in the United Kingdom, which is representative of new project experience. The benefits of this system include appropriate voltage control and reactive power support for the Galloper Wind Farm in compliance with U.K. grid code requirements.

Although the substation represented only a fraction of the project's overall capital cost, the presentation stressed the importance of lowering cost to achieve competitive levelized cost of energy (LCOE) strike prices in the \$50/megawatt-hour range. Going forward, the research indicates that standards will continue to evolve as more offshore wind is connected to the grid. Grid codes will reflect changing requirements resulting from modeling, testing, and demonstrating the technology. Developers will need to pay more attention to the specification of nonstandard items and focus on efforts to continuously lower LCOE. In all cases, however, safety is essential and has the highest priority. 


\subsection{Overview of Electrical Safety at RWE Windfarms During Construction and Commissioning}

Hendrik Berends, senior electrical engineer at RWE, gave an overview about the electrotechnical project structure used for installation and commissioning of some selected RWE wind farms according to German electrical safety rules. He first provided some background on the recent merger between EoN and Innogy to form RWE, which is now the fourth largest developer of renewable energy projects worldwide. He reviewed RWE's internal commitments to health and safety. Henrik reviewed RWE's experience with two German offshore wind installations: Arkona, a 385-MW wind farm commissioned in 2019 using 6.0-MW Siemens turbines and located in the Baltic Sea; and Amrumbank offshore wind farm, which was commissioned in 2015, using Siemens 3.6-MW turbines and located in the North Sea. He noted that all substations are normally unmanned in accordance with DNV GL OS J-201/ST-0145 and were fully commissioned in the harbor prior to load-out.

\subsection{Assessment of U.S. Electrical Safety Regulations}

Joseph Cunningham, health \& safety compliance manager for ScottishPower (part of Avangrid Renewables), presented an overview of Avangrid's internal Renewables Electrical and Mechanical Safety Rules (EMSR), which were established in the United Kingdom, and then outlined the challenges for U.S. implementation. He began by describing their safety rules, which enable Avangrid to meet minimum legal obligations, but did note that the EMSR often exceed minimum legal requirements. These rules are mandatory for all work conducted on sites where voltage exceeds 1,000 volts $(\mathrm{V})$ alternating current (VAC), or 1,500 volts direct current (VDC). The EMSR are applied to ensure persons working on or near electrical $/$ mechanical equipment are safeguarded from inherent dangers arising from those systems. The EMSR provide an overarching "philosophy" handbook and are supported by renewables system safety instructions. The EMSR may have some parallels with the emerging U.S. federal regulatory system, but further comparisons are not made in this report.

Joseph's presentation identified the following challenges to U.S. implementation:

- Safety control boundaries between the developer and the contractor may vary. In the United States, The NEC classifies any use of electrical service less than $1,000 \mathrm{~V}$ as low voltage.

- Potential conflicts may arise between a developer's or operator's established EMSR and wind turbine contractor's safety system of work/safety rules. This may be especially true if BOEM/BSEE establish different requirements for their safety management system (SMS) as part of the permitting and approval process.

- Some conflicts might also be expected in establishing Safety Control Boundaries with a turbine supplier.

- Evaluation of competencies, training, and certification is needed for safety team members managing the developer's safety management system and should consider any union requirements.

- U.S. license requirements for high-voltage switching in offshore wind farms (including landbased assets) and time required to obtain them may present some conflicts.

- Compatibility issues may arise with the "host" ISO's safety rules at the connection boundary. 
- Other potential issues may arise as a result of differences in the regulations, such as the use of U.S. ground fault circuit interrupters (GFCI), which are more sensitive than the European residual current devices (RCDs).

\subsection{Status of AWEA Working Group 5 Recommended Practices for Submarine Cables}

Bob Hobson, principal designer at NKT HV Solutions and a co-convener of the AWEA Offshore Wind Working Group on submarine cables, gave a presentation on the progress and content of the draft recommended practices document, titled "Recommended Practices for Design, Deployment, and Operation of Submarine Cables in the United States (OCRP-5)."

Bob recognized his co-convener Georg Engelmann, chief operating Officer at Excipio Energy, and Darin Lawton from Burns and McDonnell, who is the secretary for the OCRP-5 working group. The working group has deliberated over the correct framework to specify best practices for power cable systems in offshore wind farms. Cables are a critical part of an offshore wind installation; accordingly, they require proper attention over the entire lifecycle of the power plant, from conception to decommissioning.

Bob acknowledged that the OCRP-5 working group does not need to "reinvent the wheel," as there are ample existing global standards covering the relevant technical requirements. The working group need not write new standards but must simply provide a roadmap for the existing standards. The short-term approach of the working group is to adhere to functional performancebased standards.

For the following reasons, the working group has concluded that IEC standards should be preferred:

- IEC-based standards are based on performance and test the complete cable system.

- IEC requires prequalification testing of the entire cable system, and type testing of the entire cable system, both electrical and mechanical.

- IEC standards have an established track record of success in Europe for both submarine and offshore wind industries.

- IEEE and other U.S. standards are more prescriptive, and component-based, especially for power cables.

- The philosophy of U.S.-based standards is to allow interchangeability of components and manufacturers in a cable system.

- IEC standards are applicable for low-, medium-, and high-voltage systems based on years of development and implementation experience.

The OCRP-5 working group will provide a roadmap to best practices for export cables and interarray submarine cable systems. The working group identified more than 34 standards organizations and more than 127 standards that may apply to submarine power cables. The goal for the OCRP-5 recommended practice is to provide a roadmap, or reference, that leads the reader to the appropriate recommended standard. For example, "Cable Ampacity in Duct" designers should go to this standard as described by the OCRP-5 for details on how it should be applied. The OCRP-5 recommended practice will provide a list of standards with definitive useful information that can be directly referenced. It will also provide a list of standards that 
reference other standards containing instructive information. The recommended practice has approximately 100 subject headings related to the "cradle to grave" of an offshore wind facility's submarine power cable system. The OCRP-5 working group has more than 100 members contributing from a diverse group of users, of which approximately 20 attend their biweekly calls.

The working group expects to have a draft for AWEA Offshore Wind Technical Advisory Panel internal review by summer of 2020, with the final document ready to go out for public comment later in 2020 following the AWEA/ANSI consensus standard development approach.

Bob then discussed more general trends and challenges associated with offshore wind submarine power cables. He noted that offshore wind project sizes are growing at a rapid rate and the cable system designs will be challenged to keep up. For example, the Block Island Wind Farm, the only operating offshore wind project in the United States, is a 30-MW project. Projects are now being bid between 800 and 1,100 MW. Even larger projects are being planned, with the world's largest offshore wind farm being Dominion Energy's 2,640-MW proposed array. In addition, bigger turbines, $12 \mathrm{MW}$ and larger, are being developed; these machines will challenge conventional array cable systems. Floating wind turbines with dynamic cables and deeper water are also on the horizon and require additional testing and development. Higher-voltage AC array cables are moving quickly to market at $66 \mathrm{kV}$ currently. Future DC array cables are possible at even higher voltages. As distances from shore continue to increase, we will need longer export cables. New high-voltage alternating current and high-voltage direct current (HVDC) offshore transmission grid systems will also be needed. We will need standards that work for both the developer and U.S. regulators, like BSEE and BOEM.

With over $29 \mathrm{GW}$ of U.S. state-level offshore wind commitments, U.S. demand in 2030 is predicted to be $691 \mathrm{~km} /$ year (430 miles/year) to $1,113 \mathrm{~km} /$ year (692 miles/year). European demand for offshore cables in 2030 is estimated at 1,800 to 2,000 km/year. Lloyd Warwick International Claims Database (2002-2019) reports that $83 \%$ of the total value of offshore wind insurance claims concern cable failures, so it was stressed that the U.S. offshore wind regulatory system take steps to ensure this record of cable failures is improved upon for U.S. installations. 


\section{Assessment of Relevant Electrical Safety Standards for Offshore Wind Turbines}

The Turbines Breakout group's (hereinafter, "the group") approach was to discuss selected topics in depth. Because of time constraints, only topics A-1, A-3, A-6, A-13, C-1, and C-6 were addressed during the Turbines Breakout session. Group members were willing to provide insights where they felt competent, but some were generally hesitant to endorse or exclude specific standards. Postworkshop individual correspondence between Turbine Breakout session members and the Turbine Breakout session chair yielded additional feedback on already-covered topics and additional topics.

This section details the topics from the Electrical Safety Standards Comparison Table (hereinafter "the table") that were discussed either: (a) during the Turbines Breakout session of the February 2020 workshop, or (b) via postworkshop correspondence between a session participant and the session chair.

Note that in the text boxes associated with each of the upcoming subsections, when the word "add" appears next to a particular standard it indicates that the standard was added to the table found in Appendix D (Table D-1). When "remove" appears in a text box, it indicates that the standard in question was removed from the table and is no longer recommended.

Please also note that the questions and discussion issues raised herein may not always represent the most pertinent issues for a given topic and may not characterize the remaining issue(s) completely. Nevertheless, they are addressed in the section to best reflect the discussion as it was recorded and interpreted. The topics considered are as follows:

- A. Safety Design (e.g., arc flash, switchgear, and transformers)

- A-1, Arc Flash/Arc Blast Analysis

- A-3, Spaces Around Cabinets and Compartments and Equipment

- A-5, Adjustable Speed Drives

- A-6, Switchgear (High Voltage)

- A-7, Switchgear (Medium Voltage)

- A-9, Transformers

○ A-10, Safety of Machinery

- A-13, Wind Turbine Electrical Systems

○ A-15, Converter/Inverter

- A-16, Fixed ladder inside wind turbine.

- B. Safety Procedures (e.g., personal protective equipment, lockout/tagout procedures, and equipment guarding) 
○ B-1, Working on or near live equipment

○ B-3, Lockout/Tagout.

- C. Reliability Design (e.g., wiring methods and uninterruptable power supplies)

○ C-1, Safety (Testing/Fit for purpose) - Acceptance Testing

○ C-6, Cable Flammability Testing

○ C-10, Slip Rings

○ C-11, Alternators, Generators, and Motors

○ C-13, Wiring Within the Turbine

○ C-15, Pitch, Yaw, Other Control Panels

○ C-19, Lighting.

\subsection{A. Safety Design}

\section{A-1 Arc Flash/Arc Blast Analysis, Arc Flash Labeling}

The Turbines Breakout group indicated IEEE 1584 and NFPA 70E are the most appropriate standards for the U.S. market. NFPA 70E and Canadian Standards Association (CSA) Z462 are essentially the same document (CSA is the Canadian standard and is harmonized with NFPA $70 \mathrm{E}$ ). The group suggested that there was no harm in retaining CSA Z462 in the table since it is harmonized with NFPA 70E.

Discussion Issue: "Arc flash labeling requirements are new in the U.S."

Clarification was provided to indicate this labeling effort is standard for U.S. land-based wind but may be new to offshore vendors with more experience in other markets. For example, in European markets, hazards are addressed in design, lockout/tagout, or via instructions. Application of an arc flash sticker is not standard practice in those markets. The suggested solution is to rephrase as follows: "Since IEC standards will yield the same safety, use of IEC standards should constitute compliance; in addition, the arc flash label can be applied per IEEE 1584/NFPA 70E."

Discussion Issue: "What is needed to have a compliant Safety Management System?”

The developer shall establish an SMS that complies with 30 CFR 585 and is approved by BOEM/BSEE.

Discussion Issue: "Should BSEE recommend that developers utilize NFPA 70E or IEEE approaches on arc flash labeling requirements?"

The group reviewed the draft of OCRP Working Group 1 (OCRP-1) "5.6.4.7 Arc Flash" and agreed with the manner in which arc flash is addressed. BSEE should use the draft as guidance on this topic until the OCRP-1 process is completed through ANSI. 
Discussion Issue: "Are the following approaches for switchgear sufficient?"

The group concluded that the issue concerns switchgear design and suggested that it be addressed in A-6 switchgear (high voltage).

Discussion Issue: "Should the IEC standards listed in the A-1 section of the table in Appendix D, IEC 61482-2, IEC TR 61641, IEC 62271-200, IEC 60909-0, be followed for wind applications?"

The suggested solution is to rephrase as follows, "With proper justification, these IEC standards could be followed for wind applications."

It should be noted that some participants believe that the IEC standards will yield the same level of safety as the U.S. standards. Others believe this statement is too broad and that it has not been shown that the arc flash requirements and definitions of the two standards approaches are the same at all levels. If a sticker is used on IEC-tested and rated equipment, the boundary statement and other critical details should correlate to the IEC-defined levels. While either system could be acceptable for safety, the boundary or class definitions should not be mixed. Mixing of requirements from various IEC and U.S. standards should not be allowed.

The following questions, although discussed, still remain open issues:

- Regarding NFPA 70E, which is addressed in OCRP-1, will this standard still be an issue if OCRP-1 interpretation is utilized?

- Does using IEEE 1584 for the topic of arc flash conflict with the use of this standard in the OCRP-1 document?

Standards addressed:

\section{A-1}

- Recommended standards: IEEE 1584, NFPA 70E, OCRP-1 "5.6.4.7 Arc Flash"

- IEEE 1584: arc flash analysis and methodology for calculating arc flash boundary

- NFPA 70E: arc flash safety guidance procedure.

\subsubsection{A-3 Spaces Around Cabinets and Compartments and Equipment}

The group indicated IEC 60364-7-729 is less stringent than OSHA. IEC 62271-200 does not cover working spaces around cabinets and is perhaps irrelevant to this section.

Discussion Issue: "Requirements from IEC 60364, IEC 60204-1, IEC 60204-11, and IEC 61936-1 require measures to protect from electric shock, such as isolation of hazardous energy and the use of protective barriers. Are these the best standard to eliminate the shock hazard?"

These standards are more relevant to A-13 and do not need to be included in the list for A-3. However, if they are used, the hazard is eliminated.

The group thought it important to clarify that exposed live voltage is not necessary in turbine cabinet design. In fact, IEC standards prohibit exposed live voltage, whereas OSHA and 
IEEE/National Electrical Safety Code (NESC) standards require increased space around electrical cabinets based on the possibility of exposed live voltages.

It is suggested that BSEE ask the turbine original equipment manufacturer (OEM) if the turbine cabinets have exposed voltage. If yes, then A-3 should be pursued in detail; if not, these standards may not be as important or relevant.

It is also suggested that BSEE consider the safety ensured by the IEC standard to be equal to or greater than the IEEE standard. The group reviewed OPRC-1 draft, "5.6.4.6 Working Space around cabinets with exposed live voltages," and found it addresses only cabinets with exposed live voltages. The group agreed the minimum distance requirements should only be relevant to cabinets with exposed voltage.

\section{A-3}

Standards addressed:

- Recommended standards: none explicitly identified

- IEC 60364-7-729 is less stringent than OSHA

- IEC 62271-200 does not cover working spaces around cabinets and is perhaps irrelevant to this section

- IEC 60364, IEC 60204-1, 60204-11, and IEC 61936-1 are more relevant to A-13 and do not need to be included in the list for A-3. However, if they are used, the hazard should be eliminated.

\section{A-5 Adjustable Speed Drives}

This topic was not addressed by the group; the individual that provided feedback indicated that the standard Underwriters Laboratories (UL) 508C should be removed and replaced by UL 61800-5-1.

\section{A-5}

Standards addressed:

- Remove UL 508C and replace with UL 61800-5-1. 


\section{A-6 Switchgear (High Voltage)}

The group suggested adding "turbines" to the 'relevance' column, adding IEC 62271-203 because it addresses $>52 \mathrm{kV}$, and noting that IEEE 1547 refers to grid code compliance and is not specific to switchgear design.

\section{A-6}

Standards addressed:

- Recommended standards: none explicitly identified

- Add IEC 62271-203 because it addresses $>52 \mathrm{kV}$

- IEEE 1547 refers to grid code compliance and is not specific to switchgear design.

\section{A-9 Transformers}

Discussion Issue: "Which standards are acceptable?"

The original standards table listed NFPA 70B. A turbine-group member with extensive certification experience indicates that this is not a product certification standard. Therefore, NFPA 70B has been removed from the table.

Discussion Issue: "When installed inside the tower or nacelle, should a dry transformer with nonflammable liquid be used? Should a transformer with "less-flammable" liquid rather than "nonflammable" liquid be used?"

The term "less flammable" appears to be subjective. However, as defined in NEC 450.23, a liquid is considered less flammable if its ignition point is $300^{\circ} \mathrm{C}$ or higher. This is equivalent to a Class K liquid according to IEC 61039.

\section{A-9}

Standards addressed:

- Recommended standards: none explicitly identified.

\section{A-13 Wind Turbine Electrical Systems}

The group suggested adding IEC 61936-1 and UL 6141, and that EN 61400-3 is outdated and should be replaced by IEC 61400-3-1 and IEC 61400-3-2.

The following clarifications were provided:

- IEC 61400-1 covers the initial design to be type certified

- IEC 61400-3-1 covers fixed offshore turbines and is used to assess the suitability of the type certificate 
- IEC 61400-3-2 covers floating turbines and is used to assess the suitability of the type certificate

- IECRE OD-502 is an operational document describing a method of approving a design for a particular project (i.e., similar to the CVA process)

- CAN/CSA-C22.2 No. 272 is similar to UL 6141

- CAN/CSA-C61400-3 is harmonized to an older version of IEC 61400-3 and is not updated to harmonize with the 2019 version of IEC 61400-3 that includes 61400-3-1 and 61400-3-2.

The group suggested this section should list preferred U.S. standards and international standards with a caveat that "these international standards may be used with justification."

Discussion Issue: "Are the following standards acceptable: CAN/CSA C61400-3, UL 6141, and CAN/CSA-C22.2 No. 272?"

The group provided a response and justification for each:

- CAN/CSA C61400-3 is redundant with the outdated version of the IEC 61400-3 and is not acceptable.

- UL 6141 is acceptable and should be added.

- CAN/CSA-C22.2 No. 272 is similar to UL 6141 and therefore is acceptable.

Discussion Issue: "How should EN 61400-3 be used? Significant revision and expansion of the Electrical Systems section is included in the 2019 revision of the 61400-01 wind turbine design standard."

It is recommended that in general a European norm (EN) version should not be used when an IEC version exists.

Discussion Issue: "Regarding certification, should there be no requirement for repeated evaluation and testing by an NRTL? Wind turbine electrical system is type tested and certified as part of the type certification process (IECRE OD-501)."

The suggested solution is to rephrase as follows: "Regarding certification, there should be no requirement for repeated evaluation. Wind turbine electrical system is type tested and certified as part of the type certification process (IECRE OD-501 or e.g., UL 6141)." If something is certified, no reevaluation is needed unless it changes or if there are details beyond what is certified. 
The group reviewed the draft of OCRP-1 "5.6.4.1 General Requirements" and finds the statements acceptable, although not necessarily complete.

\section{A-13}

Standards addressed:

- Recommended standards: IEC 61400-3-1, IEC 61400-3-2, IEC 61936-1, UL 6141, CAN/CSA-C22.2 No. 272, and OCRP-1 "5.6.4.1 General Requirements"

- Add IEC 61936-1 and UL 6141

- CAN/CSA C61400-3 is redundant with the outdated version of IEC 61400-3 and should be removed

- EN 61400-3 is outdated and should be replaced by IEC 61400-3-1 and IEC 61400-3-2

- An EN version should not be used when an IEC version exists.

\section{A-15 Converter/Inverter}

Discussion Issue: "Should a low-voltage converter comply with IEC 62477-1 and a mediumvoltage converter with IEC 62477-2?"

The terms low voltage and medium voltage need to be quantified. IEC 62477-1 is suitable for voltages no greater than 1,000 VAC or 1,500 VDC. IEC 62477-2 is suitable for voltages from $1,000 \mathrm{VAC}$ or $1,500 \mathrm{VDC}$ up to $36 \mathrm{kV}$ AC or $54 \mathrm{kV}$ DC.

\section{A-15}

Standards addressed:

- Recommended standards: none explicitly identified.

\section{A-16 - Fixed Ladder Inside Wind Turbine}

An offshore industry safety manager offers this recommendation: fixed ladders should comply with OSHA standards inside the United States and its waters. European standards have not provided enough clearances for personnel and in the land-based industry, and OSHA will not give a variance for noncompliant ladders from Europe. AWEA has lobbied on this point for years and OSHA will not budge. The fixed ladder standard in OSHA is well-established and should be utilized in the United States. A participant from a different breakout group also expressed support for this recommendation. 
Additional input from an OEM suggested the following: OSHA requirements are prescriptive and must accommodate general industry, where the level of personal protective equipment (PPE) is not consistent. OSHA's reluctance to provide a variance on their rules for land-based wind was necessary to maintain a precedent that rules, as written, must be adhered to for workplaces where OSHA is the agency having jurisdiction. OSHA has not, to date, adopted a performance-based approach to safety regulation that permits the use of additional risk-reduction measures to achieve a desired safety level. For offshore wind, a developer's SMS should include basic PPE guidance and the use of a helmet when working in a wind turbine, especially when traversing fixed ladders. The mandatory use of a helmet significantly lowers the risk of harm as a result of encroachment into the area around the fixed ladder. It is recognized that the clearance requirements from ISO standards are less than those prescribed by OSHA. However, when the application of the ISO standards is combined with appropriate PPE, the level of safety meets or exceeds what would be accomplished through the OSHA requirements alone.

\section{A-16}

Standards addressed:

- Recommended standards: OSHA 29 CFR 1910.23, OSHA 29 CFR 1910.269(h), ISO 14122-1, and ISO 14122-4.

\subsection{B. Safety Procedures}

\section{B-1 Working on or Near Live Equipment}

An offshore industry safety manager offers this recommendation: OSHA and NFPA 70E should be the only allowable standards for the U.S. market. American technicians and personnel across all industries are already trained to, and familiar with, these regulations. These are wellestablished in the United States and manufacturers should not be allowed to dictate safety procedures. A participant from a different breakout group also expressed support for this recommendation.

Additional input from an OEM suggested the following: work on live equipment is generally prohibited in offshore wind. Instead, written isolation procedures are put in place to ensure that hazardous energy is removed from a system before work commences. Technicians are duly trained and evaluated on their competence in understanding these energy isolation procedures and the application of isolations. This training is a mandatory component of becoming a qualified person capable of performing work in an offshore wind turbine. The regime for evaluating and enforcing this competency is a necessary part of a developer's SMS. IEC and ISO design standards include strict requirements on the provision of energy isolation points for both electrical and fluid power systems, so that such energy isolation procedures may be created and followed. 


\section{B-1}

Standards addressed:

- Recommended standards: OSHA 29 CFR 1926.960, OSHA 29 CFR 1910 Subparts R,S, and NFPA 70 E Ch1 Art.100-130.

\section{B-3 Lockout/Tagout}

An offshore industry safety manager offers this recommendation: only U.S. lockout/tagout standards and practices should be followed. Project owners will not allow anyone who does not follow NFPA $70 \mathrm{E}$ and OSHA standards for control of hazardous energies and lockout/tagout to work on a project site. A participant from a different breakout group also expressed support for this recommendation.

Additional input from an OEM suggested the following: international standards include requirements for the design of equipment for lockout/tagout, which should be considered compatible with the process requirements from OSHA and NFPA 70E. These standards include IEC 60204-1 (e.g., Section 5.4) for electrical installations, as well as ISO 12100 (e.g., Section 6.2.11.1) for general machine safety and ISO 4413 (e.g., Section 5.4.7.2.1) for fluid power systems (hydraulics). The expression "isolation of hazardous energy" is a commonly used reference to lockout/tagout internationally.

\section{B-3}

Standards addressed:

- Recommended standards: NFPA 70E, NFPA 70B, NFPA 70, and OSHA 29 CFR 1910.

\subsection{Reliability Design}

\section{C-1 Safety (Testing/Fit for Purpose) - Acceptance Testing}

The group suggested:

- IEC 61400-22 be replaced with IECRE OD-501

- 'BS' (British Standard) be removed from EN 61400-22

- BS PD IEC WT 01 be removed from the table

- $\quad$ ISO 9001 be added to the table.

Clarification was provided that IEC 61400-1 and IEC 61400-3-1 include commissioning testing requirements, whereas other standards include (such as IEC 60204-1) verification and testing requirements. CSA SPE-1000-13 is used for field evaluation of electrical equipment.

Discussion Issue: "Are the following standards most acceptable? DNV GL, CSA, or ANSI/International Electrical Testing Association (NETA) standards?” 
The group was not familiar enough with the DNV GL, CSA, or ANSI/NETA standards to determine which are most acceptable.

Discussion Issue: "Should BSEE recommend that developers conduct tests on electrical equipment to determine if it is fit for service before going live?"

The group suggests acknowledging this is already being done.

\section{C-1}

Standards addressed:

- Recommended standards: IECRE OD-501 and ISO 9001

- Replace IEC 61400-22 with IECRE OD-501

- Remove 'BS' from EN 61400-22

- Remove BS PD IEC WT 01

- $\quad$ Add ISO 9001.

\section{C-6 Cable Flammability Testing}

The group suggests adding smoke visibility EN 61034-2 (e.g., IEC document 61034-2-2005) to the table, and suspects additional relevant standards need to be added to the table as well.

The distinction was made that the United States and Europe prioritize different hazards. The United States is more concerned about smoke than the toxicity of the emissions, so it makes cables with halogen. By contrast, Europe prioritizes reduction of the toxicity of emissions and requires a halogen-free design.

Discussion Issue: "Are all listed standards acceptable?"

The group noted the standards are not equivalent. The group's understanding from conversation with BSEE is that if OEMs use the U.S. standard, that will be acceptable. Alternately, if OEMs elect to use the IEC standard instead, the OEM must justify it.

The following question, although discussed, is still an open issue: The group's understanding from conversation with BSEE is that if OEMs use the U.S. standard, that will be acceptable. Alternately, if OEMs elect to use the IEC standard instead, the OEM must justify it.

\section{C-6}

Standards addressed:

- Recommended standards: none explicitly identified

- $\quad$ Add EN 61034-2 (e.g., IEC document 61034-2-2005). 


\section{C-10 Slip Rings}

The table states that UL 6141 references IEC 60204-1 as compatible. However, the word "compatible" could oversimplify the issue, because equipment evaluated to the separate standards is not certain to be compatible. UL 6141 explains that testing of the slip ring must consider the ratings and certifications of upstream overcurrent protection. A slip ring evaluated to UL508 may not be compatible with upstream equipment evaluated to IEC 60204-1.

UL 6141 states: Typical U.S. overcurrent devices have a 135\% overload rating, and IEC overcurrent devices often have a 1.45 overload rating. The maximum clearing time permitted for most overcurrent protective devices is commonly 1 or 2 hours and depends upon the device type, current rating, and applicable standard.

It is suggested the table comment be changed from "The UL 6141 standard references these as compatible" to "The UL 6141 standard accepts either IEC 60204-1 or UL 508 compliance."

\section{C-10}

Standards addressed:

- Recommended standards: none explicitly identified.

\section{C-11 Alternators, Generators, and Motors}

Similar to C-10, the original standards table states that UL 6141 references the IEC series as compatible. Again, the word "compatible" is misleading.

It is suggested the table comment should be changed to: "UL 6141 accepts compliance with either the UL 1004 series or the IEC 60034 series.”

\section{C-11}

Standards addressed:

- Recommended standards: none explicitly identified.

\section{C-13 Wiring Within the Turbine}

Although both IEC and U.S. standards are acceptable, a preference was expressed for use of the NFPA standards because U.S. technicians will be trained to those standards.

In the initial review of this report, another participant suggested there be consistency across the turbine, land-based and offshore substation electrical system because the electrical technician could work in all areas. Lack of consistency across the entire electrical system could result in safety issues. For example, the color coding of wires is inconsistent between IEC wiring tables and IEEE wiring diagrams.

Additional input from an OEM suggested the following: the developer's SMS should include requirements for minimum levels of training for technicians to be considered as qualified persons 
and competent to carry out work on electrical systems. This training must include the ability to read and interpret wind turbine manufacturer electrical diagrams and follow written electrical isolation procedures. This basic level of training can be used to ensure that wind turbine designs that include the use of international standards can be safely installed and maintained. To reinforce this, it is necessary that the electrical systems of the wind turbines are fully documented, including electrical schematics that match the specific designs installed at a project.

An additional participant emphasized U.S. wind turbine technicians know that wind turbine wiring can be in accordance with international standards and consistency, good training, and documentation are essential.

\section{C-13}

Standards addressed:

- $\quad$ Recommended standards: NFPA 70 (NEC) and NFPA 79.

\subsubsection{C-19 Lighting}

It is suggested the U.S. safety certification standard for luminaires, UL 1598, be added to the table.

\section{C-19}

Standards addressed:

- $\quad$ Add UL 1598.

\subsection{General Comments and Recommendations}

Regarding the turbine standards overall, if an offshore wind project is following codes and regulations that require NRTL testing, an NRTL should be used. Likewise, if using IEC standards, testing should be done with an accredited lab appropriate for those standards. This was the general sense of the group's breakout discussion, but additional input received after the workshop indicated differing views on the degree of required testing by an NRTL. These views are reflected in the following italicized statement, which, with appropriate variations, has been added to a number of the items in the Appendix D Standards Comparison Table: regarding certification, components normally come with type-testing documentation from the supplier. Some participants recommend against a requirement for repeated testing by an NRTL. However, others recommend the following approach: if using U.S. codes and regulations that require NRTL certification, then an NRTL should be used to certify. If using IEC standards, then tests with alternative accredited labs for those standards may be acceptable.

In general, the group encourages the use of performance-based, rather than prescriptive, standards. This common-sense approach will facilitate achieving the shared goal of project and worker safety. 
It should be expected that deviations from a standard are permissible, but deviations need to be justified to BOEM/BSEE. When an OEM deviates from a standard, there should be a mechanism to justify the deviation and explain why it achieves an equivalent or better result.

The group cautions against using vague "high," "medium," and "low" terms for voltage (e.g., in A-3, A-6, A-7). These terms are subjective and are often defined differently. The group recommends that standards be designed for a clearly stated voltage. Regardless of the terminology used (low, medium, high), a standard should be applied only when it is applicable for the actual voltage range of a component, subsystem, system, or technology in question.

The group suggests changing the statement in the "Certification" column in A-10, A-13, A-15, and C-15 from "Intertek certifies wind turbines to the listed UL and CAN/CSA standards" to "There are organizations to evaluate wind turbines to the listed UL and CAN/CSA standards." This change removes identifying a specific company, and uses proper terminology, as these organizations "evaluate" rather than "certify."

Regarding the development of BSEE's guidelines for electrical safety, the group provided several suggestions to accelerate progress. The original Electrical Safety Standards Comparison Table, which was disseminated in advance of the conference, included irrelevant standards, and was missing relevant standards. The group expressed that, while the February 2020 workshop was a productive exercise, there was not enough time to conduct a complete review of the table. Therefore, BSEE should consider all input to make the table as complete as possible.

Because the U.S. offshore wind industry is moving quickly, the group recommends that BOEM/BSEE support more workshops like this one while OCRP recommendations are being finalized. Additionally, BOEM/BSEE should engage with the land-based wind community and NRTLs to incorporate their experience integrating the international land-based wind industry into the U.S. market.

Finally, BOEM/BSEE should engage in face-to-face meetings with individual industry/stakeholder representatives to learn more and gather information. These face-to-face events will facilitate a more effective and efficient transfer of knowledge than emails and documents. They are also likely to yield more candid sharing of information than in a group setting. Once BOEM/BSEE collect information in individual meetings and identify common concerns, a group meeting should be convened to achieve consensus within the OSW industry.

A question for BSEE: Do the turbines and substations groups need to come to consensus on the standards? The philosophy of OCRP is that turbines are generally mass-produced and consistent with IEC-type certifications, whereas substations are project-specific custom designs. Consequently, standards language regarding turbines uses more permissive suggestions (i.e., "should"), whereas standards language relevant to substations employs more prescriptive requirements (i.e., "shall").

One OEM indicated it is following the same process for their offshore work as for their landbased work in the United States and uses an IEC-type certificate + NEC-UL base design. 


\section{Assessment of Relevant Electrical Safety Standards for Offshore Substations}

The following topics from the Electrical Safety Standards Comparison Table (hereinafter "the table"), found in Appendix D (Table D-1), were discussed during the substations breakout session of the February 2020 workshop. Additional input from the substations breakout group (hereinafter 'the group') was sought via correspondence subsequent to the workshop.

Note that in the text boxes below, when the word "add" appears next to a particular standard it indicates that the standard was added to the table. When "remove" appears in a text box it indicates that the standard in question was removed from the table.

Please also note that the questions and discussion issues raised herein may not always represent the most pertinent issues for a given topic and may not characterize the remaining issue(s) completely. Nevertheless, they are addressed in the section to best reflect the discussion that was recorded. The topics considered are listed as follows.

\subsection{A. Safety Design (e.g., Lightning Protection, Switchgear, and Transformers)}

- A-1, Arc Flash/Arc Blast Analysis

- A-2, Emergency Stop - Design

- A-3, Spaces Around Cabinets and Compartments and Equipment

- A-4, Electrical Safety Equipment (GFCI - RCD)

- A-6, Switchgear (High Voltage)

- A-7, Switchgear (Medium Voltage)

- A-8, Switchgear (Low Voltage)

- A-9, Transformers

- A-10, Safety of Machinery

- A-11, Lightning Protection

- A-12, Electrical Enclosures/Control Panel (Degrees of Protection)

- A-14, Fire Prevention and Fire Protection

- A-15, Converter/Inverter

- A-16, Fixed Ladder Insider Wind Turbine.

\subsection{B. Safety Procedures (e.g., Personal Protective Equipment,} Lockout/Tagout Procedures, and Equipment Guarding)

- B-1, Working on or Near Live Equipment

- B-2, PPE

- B-3, Lockout/Tagout

- B-4, Equipment Guarding (Energized Component). 


\subsection{Reliability Design (e.g., Marine Cables and Uninterruptable Power Supplies)}

- C-1, Safety (Testing/Fit for purpose) - Acceptance Testing

- $\mathrm{C}-2$, Wiring Methods (High Voltage)

- C-3, Wiring Methods (Medium Voltage)

- C-4, Wiring Methods (Low Voltage)

- C-5, Wiring Methods

- C-7, Harmonics

- C-9, Uninterruptable Power Supplies (UPS)

- C-11, Alternators, Generators, and Motors

- C-14, Surge Protection/Suppression Component

- C-19, Lighting

- C-20, Illumination Levels for Emergency Evacuation

- C-21, Emergency and Standby Power Systems

- C-22, Power Sockets and Plugs

- C-23, Cable Trays

- C-24, Cable Cleats for Electrical Installations

- C-25, Cathodic Protection

- C-26, Grounding and Bonding.

\subsection{General Discussion}

The substations breakout group began by identifying topics that group members deemed most pressing, or controversial, regarding offshore substations. The group identified the following topics as most pressing:

1. IEC vs. IEEE

2. A-1: Arc flash/arc blast

3. A-3: Space around equipment (low voltage) and working online equipment

4. Standards for drawings/schematics and associated worker training

5. A-6: High-voltage and low-voltage switchgear (personnel and equipment)

6. NRTL certification for offshore substations.

After identifying the previously mentioned key topics, the substations breakout group discussed all standards applicable to substations in the Electrical Safety Standards Comparison table. A total of 32 standards were discussed. Remaining standards were not addressed for different reasons, some because they were more appropriately considered by the turbines or cables breakout groups, and some because more clarification or information was necessary to comprehensively address the applicable standards. For example, the category name for that standard may have been too vague or broad to be able to determine which standards are applicable for that topic.

Standards C-3, C-4, and C-5, regarding wiring methods, were one exception to this process. 
At the outset of the workshop, the substations group delegated these standards to the cables group for consideration. After the cables group reviewed C-3, C-4, and C-5, it was determined that the substation group was better suited to address these topics.

The requirements for NRTL certifications were discussed frequently during the workshop. References to these discussions can be found in greater detail in the upcoming discussions for each topic. However, one participant commented that, in general, NRTL certifications do does not appear to be a requirement for engineered systems, such as fire protection systems, or for some components within the system (e.g., the regulators). The following recommendations were noted but further discussion may be required:

- NRTL certification of individual components shall be required only if there is a commonly used certification standard for that component.

- The entire system does not need to be NRTL certified, only the individual components.

- Systems can be comprised of components certified by different NRTLs.

Note that in general, the substations breakout group defaulted to answer the question: "Are the standards listed in the Standards Comparison Table (Appendix D) applicable and or acceptable for this topic?" (in terms of substation electrical safety), but other discussion issues were considered on a case-by-case basis, especially if an issue was specifically listed in the table.

\subsection{A. Safety Design}

\section{A-1 Arc Flash/Arc Blast Analysis}

The group agreed that arc flash is a critical issue. There was consensus that the small spaces in offshore substations make arc flash challenging to address. The group agreed that the substation design must account for the arc flash boundary for worker safety. It was noted that the arc flash boundary would be lower for offshore substations because of the space constraints.

The appropriate PPE would be dictated by the equipment used and space needed, which is unique to each substation design. Some participants recommended that land-based standards for arc flash should be used; universal agreement on this point could not be reached.

The group expressed that IEEE 1584 has already addressed this issue in the OCRP document. Some members of the substation group expressed concern that relying upon IEEE 1584, for arc flash in particular, may conflict with the revised OCRP document. This still remains an open issue.

The group also recommended referring to the general requirements for NFPA 70E and ANSI specifications for both equipment and PPE. Additionally, it was noted that within NFPA 70E, IEEE 1584 is referenced for the calculation of arc flash/blast risks. It is important to note the distinction that IEEE 1584 is the evaluation and calculation methodology for arc flash, whereas the practice of arc flash mitigation and personnel protection is in NFPA 70E.

Additionally, other participants recommended that API RP 14F be utilized for the working clearances around electrical equipment as defined in this standard. 
The group was in agreement that the purpose of this standard is for arc flash safety guidance procedure and workplace safety guidance. There was agreement that the outlined procedure should be followed, as it directs the user toward ANSI standards.

There was no discussion regarding CSA Z462, other than the fact that it remains applicable to this topic.

\section{A-1}

Standards addressed:

- Recommended standards: IEEE 1584, NFPA 70E, and CSA Z462

- IEEE 1584: arc flash analysis and methodology for calculating arc flash boundary

- NFPA 70E: arc flash safety guidance procedure and personal protection guidance

- Add: API RP 14F: working clearances around electrical equipment.

\section{A-2 Emergency Stop - Design}

The group debated the precise definition of emergency stop, and how far this process may extend. It was agreed that emergency stop can be defined as de-energizing the system. Some participants from this group went so far as to recommend that "emergency stop" be replaced by "remote de-energization," stating that a system should be in place to open all the line-side breakers in an offshore substation from a land-based location. Additionally, it was noted that the resolution to the definition of "emergency stop" has already been addressed in DNV GL standards; although, these standards were not specified by the group discussion.

It was also debated whether or not an emergency stop system includes emergency evacuation systems, and if manned or unmanned facilities should be addressed. This discussion did not reach a clear resolution.

The group agreed that every facility must have an emergency stop system in place. Although the issue was not fully resolved, the group made progress in asking questions to help define what an emergency stop means, such as:

- What equipment in the offshore substation needs to be shut down to maximize safety for the personnel and the environment?

- When personnel return to the substation facility, what equipment needs to be de-energized to ensure safety?

Overall, there was general agreement that the purpose of an emergency stop system is for the protection of the environment and personnel. No standards were specifically recommended to be added or removed from the list in Table D-1.

\section{A-2}

No standards were explicitly addressed during the discussion. Appendix D applies. 


\section{A-3 Spaces Around Cabinets and Compartments and Equipment}

The group decided it was necessary to agree on a definition for low, medium, and high voltage. The group agreed with the NEC definition, which defines voltage classes as follows:

- Low voltage: $<1 \mathrm{kV}$

- Medium voltage: $1-52 \mathrm{kV}$

- High voltage: $52+\mathrm{kV}$.

All participants in the electrical safety standards workshop generally agreed that the voltage for equipment should always be specified, rather than relying on subjective low-, medium-, or highvoltage language.

Upon addressing the voltage classification, the substation group also discussed the difference between troubleshooting exposed versus unexposed live (i.e., energized) parts. There was a difference of opinion regarding troubleshooting of live system components. A participant argued that one cannot troubleshoot a de-energized component, whereas others agreed that the part must be de-energized and grounded when troubleshooting for safety. Another participant recommended that in either case, whether energized or de-energized, the electrical equipment should be tested per the manufacturer's recommendations.

The group generally agreed that spaces around cabinets, compartments, and equipment are primarily an issue for low-voltage panels. This is because high-voltage components are typically not exposed. Regarding egress and ingress, the group recommended that the offshore substation health, safety, and environmental plan should address the voltage class. There was general agreement that, during the design phase, the full lifecycle of the project and equipment should be considered, including the location for installing the switchgear.

A concern was raised about whether the battery room would be considered a classified zone if API $14 \mathrm{~F}$ is mandated, knowing that classifying the battery room would greatly increase costs. The question still remains as to which standard should be used for calculating acceptable hydrogen levels without leading to a classified zone.

The group did not fully address which standards are applicable for medium voltage.

\section{A-3}

Standards addressed:

- Recommended standards: NEC NFPA 70E Articles 110.26, 110.34

- Low-voltage NEC (NFPA 70)

○ NFPA 70: national electric code for low-voltage and high-voltage gear

○ NEC: smaller distances.

- Add: API RP 14F, as this allows smaller distances for low and medium voltages than required by NFPA 


\section{A-4 Electrical Safety Equipment (GFCI - RCD)}

The group acknowledged that offshore locations are not formally within OSHA's jurisdiction (as a result of earlier agreements made bilaterally between BSEE and OSHA) but that BSEE will enforce OSHA regulations offshore to ensure personnel safety. With respect to using GFCI versus RCD, it was recommended that the NEC requirements be followed. It was noted that additionally, NEC could also be used for PPE. Another participant recommended that NEC be applied to all electrical systems in the offshore substation of $600 \mathrm{~V}$ or less.

\section{A-4}

Standards addressed:

- Recommended standards: NFPA 70E

- NFPA 70E: for low voltage and safety

- Add: API RP 14F.

\section{A-6 Switchgear (High Voltage)}

The group reinforced the need to precisely define the low-, medium-, and high-voltage classes before discussing high-voltage switchgear because various jurisdictions where offshore wind turbines might be installed often define voltage classes differently. Some countries have different voltage specification brackets for these voltage terms, whereas other countries do not distinguish the voltage with the terms low, medium, and high at all.

The group ultimately reached a general agreement that, from a safety perspective, low and high voltage is recognized. By contrast, for operating equipment, the terms low, medium, and high voltage are recognized. It was not clear to the substations group whether this "safety vs. equipment" distinction exists only in the United States.

There was some alignment among the substation participants to accept IEC standards for switchgear and associated equipment. It was, however, noted that U.S. and European standards differ regarding the need for visual confirmation of contact status (i.e., open or closed) for switchgear. This difference needs to be addressed relative to substation design and construction. However, one participant disagreed and stated that ANSI and UL switchgear and Merchant Category Code standards are preferred over IEC standards.

There was additional conversation regarding using IEC's gas-insulated switchgear (GIS) (e.g., viewing windows). It was noted that the IEEE C37.122 standard does not appear to be fully implemented by any vendors of GIS above $52 \mathrm{kV}$. All available GIS at the high voltages required for an offshore substation are built and tested to IEC 62271. Therefore, vendors can customize IEC's GIS to meet additional requirements of IEEE but the Factory Acceptance Tests are performed according to IEC and the tests are different from IEEE.

One participant noted that there are gaps in IEEE C37.122 and recommended using this standard in conjunction with IEEE C37.21. It was suggested to allow the use of fully IEC-compliant local control cabinets or hybrid local control cabinet designs that are built to IEC standards, but that they should also meet all of the practical requirements of IEEE C37.21. 
Additionally, it was suggested by one participant that if LCCs are fully IEC compliant, then IEC cables should be used between GIS and LCCs. If a hybrid IEC/IEEE LCC is used, then type/colors of cables used will ensure a consistent design.

Finally, there was discussion of NRTL testing of switchgear. Two participants of the substations group provided input on NRTL testing as follows: for systems at $600 \mathrm{~V}$ or less, the NEC should be followed. Higher than $600 \mathrm{~V}$, the NESC should be followed. NRTL testing is not required. The basis for this is that NRTL testing for components above $34.5 \mathrm{kV}$ does not appear to exist. NESC does not require NRTL certification. There are limited manufacturers of components up to $34.5 \mathrm{kV}$, so adding this additional requirement would be too restrictive for substation designers and may have negative unintended consequences on cost and safety. At $600 \mathrm{~V}$ and below, NRTL certified components are common, and NRTL certification demonstrates compliance with NEC. One can also use components that are not NRTL certified, but in these cases demonstration of NEC compliance must be made.

\section{A-6}

Standards addressed:

- Recommended standards: IEEE C37.122

- Add: IEEE C37.122, for gas-insulated switch gear, specific to high voltage

- Add: IEC 62271

- Remove: IEEE C37.20.2: for medium voltage only.

\section{A-7 Switchgear (Medium Voltage)}

The group's consideration of medium voltage switchgear was brief, and mainly led to a NRTL discussion. The substations group concluded that, if IEC standards are used, the equipment must still be NRTL certified.

Similar to the argument made in A-7, the same comment on NRTL certification was made for MV switchgear. For systems at $600 \mathrm{~V}$ or less, the NEC should be followed. Higher than $600 \mathrm{~V}$, the NESC should be followed but NRTL testing is not required. At $600 \mathrm{~V}$ and below, NRTLcertified components are common, and NRTL certification demonstrates compliance with NEC. One can also use components that are not NRTL certified, but then demonstration of NEC compliance must be made.

One participant noted that as the tests for IEC-type switchgear are different, the previous IECtype tests may be not applicable and the National Electrical Manufacturers Association

\section{A-7}

Standards addressed:

- Add: IEEE C37.20.2, IEEE C37.20.09: for ANSI MV

- Add: IEEE C37.20.7: if using arc gear for LV and MV; must be NRTL certified as well. 
(NEMA)/ANSI tests will need to be performed to comply with the requirements of the ANSI, IEEE, and UL standards.

\section{A-8 Switchgear (Low Voltage)}

The low-voltage switchgear conversation led to questions about the scope of the term. For example, should motor control equipment and exhaust fans be considered low-voltage switchgear? Some participants stated that motor control equipment is covered by the UL 845 standard and is not switchgear, and that it does not have the same requirements as ANSI C37.20.1 (i.e., it does not have a short time short circuit withstand rating, wherein low-voltage switchgear requires a 1-second withstand rating.) At the conclusion, there was still some question about whether motor control equipment should be classified as low-voltage switchgear. It remains unclear whether switchgear for exhaust fans should be included in this category.

The group came to a consensus that NEMA standards will be included with the other recommended standards. However, a path should be made for acceptance of IEC standards as well, as it was noted that IEC low voltage takes up considerably less space, and conserving space is important for offshore substations in particular. Additionally, the group acknowledged that UL has adopted many of the IEC standards, specifically IEC 947.

\section{A-8}

Standards addressed:

- Recommended standards: UL 891 (for low-voltage switchboard)

- Add UL 508: enclosed protection systems and enclosed cabinets

- Add UL 845: motor control

- Add UL 1558

- Add UL 1053: safety covering ground fault protection

- Remove: IEEE C37 series - all does not apply.

\section{A-9 Transformers}

The group first agreed on the scope of what equipment and accessories would be considered within the term "transformers" for the purpose of addressing this standard. From this discussion, there was alignment that the transformer and its accessories including reactors, circuit breakers, GIS equipment, and lightning protection would be considered. It was not unclear if shunt reactors should also be included in this list of transformer accessories. Although, it was recommended by one participant that the use of IEC transformers and shunt reactors, including IEC control cabinets, should be permitted.

The group came to a general agreement that the consideration of flammable liquids, open or closed systems, and other issues depends upon the substation design specifications. There was agreement that most offshore components are located in enclosed indoor spaces, though some transformers are outside. This is a function of the "semiclosed" versus "semiopen" design, which is often country-specific. Structural design of the transformer was discussed. All of the design 
questions are left to the developer to address as design specifications, including the "nonflammable" or "less flammable" liquid issue.

One participant recommended that if IEEE transformers are specified, special attention must be given to the following: a) plug-in bushings b) oil-SF6 bushings (if used), and c) control cabinet interfaces.

Additionally, another participant recommended using IEC 62271-211 for interfaces between a gas-insulated busbar and transformer bushing (oil-SF6), and that special attention is required when using IEEE transformers to ensure there are no IEC/IEEE interface issues.

\section{A-9}

Standards addressed:

- Recommended standards: IEEE/ANSI C57 series

- C57 series: for low-voltage transformers and reactors.

Other participants addressed the standardization between European and U.S. standards regarding transformers. One participant added that until harmonized standards between IEC and IEEE become available, n-load tap changers should be designed and tested to meet IEC standards. Yet another participant noted that until there are more U.S. suppliers of high-voltage transformers accessories, compliance with European standards should be permitted.

\section{A-10 Safety of Machinery}

For the purposes of this workshop, the group limited the term "machinery" to substations only, and specifically excluded turbines from the discussion. The group agreed that it would be beneficial to classify machinery as either necessary or backup systems. There was alignment that backup systems include air compressors; heating, ventilation, and air conditioning systems and ventilation systems; backup generators (diesel); and other ancillary systems. Fire detection, gas detection, and fire suppression systems are considered necessary machinery. Although this was the majority of the group's definitions for classifying machinery, there were differing opinions that separated machinery into ancillary systems, and emergency response or emergency shutdown systems. The classification of machinery for the purpose of this discussion remains an open issue.

The substations group was challenged in addressing the standards listed because different standards apply for different types of equipment.

\section{A-10}

No standards were explicitly addressed, discussion only. 


\section{A-11 Lightning Protection}

Some members of the group noted that offshore oil and gas platforms generally include limited lightning protection measures. For offshore wind substations, the group recommended the following standards.

\section{A-11}

Standards addressed:

- Recommended standards: consider IEC 61400-24 and NFPA 780 (sparing standards)

- Add: IEEE 998 - lightning protection for (land-based) substations.

\section{A-12 Electrical Enclosures/Control Panel (Degrees of Protection)}

The group reached consensus that this category refers to low-voltage electrical enclosures and control panels only. The Ingress Protection (IP) rating of these enclosures and control panels was discussed, in addition to the incorporation of any fiber optic cables within these fixtures. The substations group was not aware of any ANSI standards concerning integration of fiber optic cables into power cables.

\section{A-12}

Standards addressed:

- Recommended standards: UL 508A, NEMA ANSI/IEC 60529, NEMA 250

- UL 508A: enclosed assembled equipment

- NEMA ANSI/IEC 60529

- NEMA 250: rating.

\section{A-14 Fire Prevention and Fire Protection}

The substations group addressed who is responsible for fire protection, prevention, and suppression. The group generally agreed that fire suppression is driven by insurance company requirements, whereas fire protection is overseen by BSEE. In both cases, the substation's emergency response plan outlines these responsibilities, and outlines the contractor's responsibilities in the event of an offshore substation fire. The group agreed that it is the substation operator's responsibility to ensure that an emergency response plan is in place, and that the emergency response contractors are properly informed as to what regulatory documents need to be submitted regarding the fire protection and prevention plan. One participant recommended that fire detection should be required, but the installation of fire suppression systems be provided only after a proper "As Low As Reasonably Possible" analysis, thereby demonstrating the need and value of such a system.

The group also discussed NRTL certification with respect to fire protection and prevention and agreed that NRTL certification is required for fire protection. When and how to follow manufacturer's certifications was also considered. The group reached consensus that the manufacturer's certification can generally be relied upon. However, if the manufacturer does not 
operate in the country where the equipment is installed, then the equipment in question must be re-certified to adhere to local requirements. For example, offshore wind equipment manufactured in Germany would be required to obtain NRTL certification before it could be used in a U.S. offshore wind installation.

It is important to note that in Europe, fire protection/suppression is generally incumbent upon insurance companies. Regarding fire alarm system control, one participant commented that NFPA 2001 calls for a local logic controller for a fire extinguishing system controller. For typical European projects, the control of this system is under the fire alarm system, which minimizes the installation cost as well as the size/weight of the equipment installed on the offshore substation, and maintenance requirements. Therefore, it was suggested to allow the fire alarm system to control the fire extinguishing system equipment directly rather than using a separate fire extinguishing system controller. Another participant also recommended to allow European fire ratings for walls and penetrations for passive fire protection design.

Regarding helideck firefighting systems, one participant added that the U.S. standard for the helideck firefighting system, NFPA 418, requires a duration of a 10-minute (min) discharge; thus, a larger, heavier skid than CAP 437 (10 min in NFPA 418 vs. 5 min in CAP 437). The USCG has recognized CAP 437 as an acceptable alternative to the helideck deck firefighting system with respect to CFRs. Therefore, it was recommended that both CAP 437 and NFPA 418 are acceptable, while noting the differences in discharge timing.

\section{A-14}

Standards addressed:

- Add: NFPA 2001, “clean agent”/inert-gas fire suppression standard

- Add: API RP 14C

- Add: DNV GL ST 145, for passive/active suppression

- Add: NFPA 16, for water-based foam systems.

\section{A-15 Converter/Inverter}

The substations group did not address this standards category in depth. One participant commented that there are specific requirements for inverters to be operated and integrated into the U.S. power grid. It was therefore recommended to add the standard UL 1741, which is the Standard for Inverters, Converters, Controllers and Interconnection System Equipment for Use With Distributed Energy Resources for inverters for U.S.-based installations. 
The following question arose during the discussion: Would UPS systems be included in this category, or do DC UPS systems fall under this concern, within the substation? One participant recommended that UPS systems not be included in this category. Instead, it was recommended that UPS systems be addressed in the utilities and support systems, as they would be used to keep the control and communication systems functional during a brief power outage.

\section{A-15}

Standards addressed:

- Add: UL 1741: Standard for Inverters, Converters, Controllers and Interconnection System Equipment for Use With Distributed Energy Resources.

\subsection{B. Safety Procedures}

\section{B-1 Working on or Near Live Equipment}

The substation group agreed that this topic was fully covered by NFPA 70E and OSHA 29 CFR $\S 1910$ Subparts R, S.

\section{B-1}

Standards addressed:

- Recommended standards: NFPA 70E, OSHA 29 CFR § 1910, Subparts R, S.

\section{B-2 Personal Protective Equipment}

The group agreed that the American Society of Testing Materials (ASTM) F1506 provides the best reference for PPE requirements, and generally aligns with NFPA and OSHA standards, as listed in the corresponding recommended standards textbox (B-2). The group did not address whether or not NFPA 70B applies to PPE, or if this standard is only relevant to O\&M.

Standards addressed:

\section{B-2}

- Recommended standards: ASTM F1506, NFPA 70E, OSHA 29 CFR § 1910.137.

\section{B-3 Lockout/Tagout}

The substation group agreed that lockout/tagout is applicable for all voltages. There was consensus that the developer must define the lockout/tagout procedure and criteria within their design specifications, as these approaches can vary for different equipment. 
One participant recommended that that the IEC-based electrical equipment highlighted in the wind turbine section be provided with specific provisions for lockout/tagout that are compatible with the OSHA-mandated lockout/tagout requirements.

\section{B-3}

Standards addressed:

- Recommended standards: NFPA 70E

- Specify: OSHA 29 CFR $\S 1910$ is general, whereas OSHA 29 CFR $\S 1910.147$ is specific to lockout/tagout.

\section{B-4 Equipment Guarding (Energized Component)}

The group agreed that USCG rules do not require guardrails for fixed structures. The group also agreed that guarding for high-voltage GIS equipment is unnecessary. There was agreement that only energized equipment must be guarded. This is different than space around equipment, which is focused on permitting ingress and egress.

\section{B-4}

Standards addressed:

- Add: IEEE C2 (NESC)

- Add: API RP 14F.

The group agreed to exclude floating wind energy substations from this conversation, which will be addressed by other standards initiatives.

It remains an open issue whether or not USCG IEEE C2 Sub.J is applicable, although this issue may not represent the most pertinent issue(s) for this topic.

\subsection{Reliability Design}

\section{C-1 Safety (Testing/Fit for Purpose) - Acceptance Testing}

The substation group agreed that the question of safety acceptance testing should be deferred to the CVA. It was agreed that each OEM creates its own pre and postenergization inspection and test protocols. Additionally, developers have their own commissioning and execution plans.

The group further agreed that BSEE should recommend that developers test electrical equipment before energizing, but observed that this testing can vary by project, developer, or manufacturer. Proof-of-concept testing should be conducted by the OEM. The group generally agreed that commissioning activities are project- and equipment-manufacturer/type specific. The ANSI/NETA acceptance testing specifications (ATS) should still be considered for recommended guidelines. 
Generally, it is recommended that the industry move away from IEC 61400-22 and adopt IECRE OD-501 and -502. Work has been done so that it can result in certificates of higher quality and also allows for better mutual recognition. Many turbine suppliers have already adopted the IECRE system, and it is expected that in the future most offshore turbines will be required to have IECRE certificates. IEC 61400-22 is an outdated standard and is no longer recognized by IEC or the U.S. National Committee. IECRE OD-501 and -502 are referenced in both the turbines and substations sections.

\section{C-1}

Standards addressed:

- Remove: IEC 61400-22

- Remove: BS EN 61400-22

- Add: IECRE OD-501 and -502

- Add: CIGRE B3.26

- Add: ANSI/NETA ATS.

\section{C-2 Wiring Methods High Voltage}

The substations group did not discuss this topic in depth. One participant commented that there are high-voltage cables used in the platform that are not submarine cables(e.g., between the GIS and transformer). It is recommended that these cables also be built and tested to IEC standards rather than the Insulated Cable Engineers Association (ICEA) to avoid creating unnecessary IEC/ICEA interfaces that may require specialized IEC/ICEA cable joints and different types of cable terminations.

Another participant commented that European designs typically use plug-in termination for highvoltage cables (e.g., Pfisterer Connex). These can be dry type or oil-immersed. There are no equivalent U.S. standards for these types of terminations above $52 \mathrm{kV}$. It was recommended to allow the use of plug-in terminations (e.g., Pfisterer Connex) according to relevant IEC/EN standards.

\section{C-2}

No standards were explicitly addressed, discussion only.

\section{C-3 Wiring Methods Medium Voltage}

The substations group did not discuss this topic in depth but agreed to include API RP 14F and NEC NFPA 70 to the list of relevant standards.

\section{C-3}

Standards addressed:

- Add: API RP 14F

- Add: NEC NFPA 70. 


\section{C-4 Wiring Methods Low Voltage}

The substations group concluded that NFPA 70 is the recommended standard. The group agreed that additional information would be needed to properly address the topic of low-voltage wiring methods; either a submarine cable or interconnection cable.

The question arose during the workshop as to what a low-voltage submarine cable is. One participant commented that there is no such cable. They noted that [submarine cables] are intended for power transmission over some distance and can be available in medium-voltage or high-voltage applications. Rather, this participant suggested that low-voltage wiring methods specifically apply to the substation facility, with a focus on marine applications. Therefore, they recommend that API RP $14 \mathrm{~F}$ be added to the current reference to the NEC (NFPA 70) to be used for the recommended wiring methods for low-voltage applications for offshore facilities in the United States. This was added to address specific requirements for marine use and exposure to corrosive, salt-laden environments.

\section{C-4}

Standards addressed:

- Recommended standards: NFPA 70 (NEC)

- Add: API RP 14F.

\section{C-5 Wiring Methods}

The group felt it necessary to discuss and clarify the term "marine shipboard cable." The group questioned whether this term refers to actual "shipboard" cables (a special designation of cable), or if it was referencing any kinds of cables that are found onboard an offshore wind substation platform. The group agreed that it is important to clarify that for substations, marine shipboard cables are not the only cables to be used. Therefore, the group suggested removing "shipboard cable" from both the standard category column, and from the NRTL certification column. It was noted that IEEE 1580 should be allowed for marine shipboard cable to be used without being installed in accordance with IEEE 45, as this could be a viable option for armored cables installed outside on the platform. Also, it was recommended by one participant that all types of armored cables be allowed to be installed in a cable tray.

One participant recommended that "Type P cable" could replace "marine shipboard cable" in the category column of Table D-1, as this is the designation that is currently published in the 2020 version of the NEC (NFPA 70) that refers to the same type of cable design suitable for marinetype environments. Another participant suggested allowing all types of armored cable to be installed in a cable tray.

The question arose during the discussion to clarify the suggested wiring methods. One participant commented that in the United States, the term "wiring methods" refers to interconnection cables. Another participant suggested the following recommendations regarding the conflicting low-voltage wire coloring schemes within using the standards listed in the upcoming text box. The following color scheme should be used: protective ground (equipment grounding conductor) cables should be green or green with yellow strips. Neutral cables should be white or light grey. Both of these requirements are from NFPA 70. For DC cables, +ve should 
be red and -ve should be black. All other cables coloring (i.e., L1, L2, and L3 for $480 \mathrm{~V} / 277 \mathrm{~V}$ and $208 \mathrm{~V} / 120 \mathrm{~V}$, control wiring) should be at the discretion of the designer provided a consistent approach is used.

Another participant suggested to add low-smoke or halogen-free U.S. standards that align with the European ones, as low-smoke/low-halogen cables are preferred for an offshore substation. These standards are listed in the following text box.

\section{C-5}

Standards addressed:

- NFPA 70 and API RP 14F: wiring methods beyond marine shipboard cables

- Add: NFPA 70: allows the manufacturer to choose their own kind of wiring method

- Add: API RP 14F: wiring practices for offshore

- Add: IEC 60331-1, -2, -21 for fire resistivity

- Add: IEC 60754-1 and -2: halogen-free standard

- Add: IEC 61034-1 and -2: low-smoke standard

- Remove from category name column: "marine shipboard cable"

- Remove from certification column: "Cables should be listed as a marine shipboard cable by a NRTL"

- All other standards listed are for marine shipboard cables.

\section{C-6 Cable Flammability Testing}

There was consensus that cables are typically "flame retardant." The group found it necessary to distinguish between fire-rated cables, fire-retardant cables, and fire-resistant cables. One participant commented that submarine cables will not have flammability standards applied but will utilize external coverings applied at the substations to provide the degree of protection required by the standards. Another participant commented that the standards referenced within API RP $14 \mathrm{~F}$ will provide distinctions between the terms fire-rated, fire-retardant, and fireresistant.

It was recommended by one participant to add IEC 60331-1, -2, and -21 standards to accommodate a broader range of potential cable vendors.

Additionally, it was agreed that both the substations group and the cables group would address the issue of cable flammability testing. 


\section{C-6}

Standards addressed:

- Add: API RP 14F

○ Reveals which applications require low-smoke, low-halogen cables

- Defines where fire-related cables should be used

$\bigcirc$ Defines which kind of fire-related cables should be used

- Add: IEC 60331-1, -2, and -21.

\section{C-7 Harmonics}

The group agreed that the developer must address any harmonics issues within the offshore substation, whereas the grid operator must address onshore substation harmonics.

\section{C-7}

Standards addressed:

- Recommended standards: IEEE 519

- Applies at the point of interconnection

○ This standard is sufficient; not required inside of substation, but just at the point of common coupling.

\section{C-9 Uninterruptable Power Supplies}

The group agreed that UPS are a combination of DC and AC components. It was also agreed that it is necessary to establish a bridging system through the start cycle, and to establish power from the diesel system. It was noted that UL 62109-1 is a USCG requirement for Safety of Life at Sea.

\section{C-9}

Standards addressed:

- Add: IEEE 946

- Add: IEEE 44 or 484.

\section{C-14 Surge Protection/Suppression Component}

The group discussed switching operation surges and agreed that the IEEE C37 90.1 standard should be added. 


\section{C-14}

Standards addressed:

- Add: IEEE C37 90.1.

\section{C-19 Lighting}

The group recommended removing all of the information in the last column; the developer should define this, as it is not relevant to electrical safety.

It was recommended by one participant that lighting details for boat landings may not be addressed within these standards. It was recommended that the boat should provide emergency egress illumination without needing permanently installed lighting along egress ladders and boat landings.

\section{C-19}

Standards addressed:

- Recommended standards: IEEE C2 (NESC)

- Add: API RP 14F: minimal lighting levels for offshore locations, included servicing.

\section{C-20 IIlumination Levels for Emergency Evacuation}

The substation group briefly discussed this topic and recommended API RP 14F to address it.

\section{C-20}

Standards addressed:

- Add: API RP 14F.

\section{C-21 Emergency and Standby Power Systems}

The group discussed how to define "emergency power systems." There was consensus that usage of the term "emergency power" may trigger certain USCG regulatory requirements. The group instead recommended using the terms "standby" or "essential" power systems and added API RP $14 \mathrm{~F}$.

\section{C-21}

Standards addressed:

- Add: API RP 14F. 


\section{C-22 - Power Sockets and Plugs}

The group agreed that the listed standards are acceptable. It was recommended to remove "Receptacle NEMA 4x protection" verbiage in the table's certification column.

\section{C-22}

Standards addressed:

- Add: NEC (NFPA 70)

- Add: API RP 14F.

It was recommended by one participant to add the NEC (NFPA 70) and API RP $14 \mathrm{~F}$ to address the selection and installation for receptacles for offshore wind facilities. This would also cover the requirements for GFCI protection of these devices depending on their location and type of service.

\section{C-23 Cable Trays}

The group discussed the different materials - aluminum, stainless steel, and fiberglass—used to manufacture cable trays. There was consensus that the standards listed appropriately address the various materials used to create cable trays.

One participant recommended API RP $14 \mathrm{~F}$ for the design and installation of cable tray systems for offshore wind facilities in the United States because this standard covers the sizing, type, placement, and installation methods for cable tray systems to be used in an offshore marine environment.

\section{C-23}

Standards addressed:

- UL 2277: construction specifications

- Add: API RP 14F.

\section{C-24 Cable Cleats for Electrical Installations}

The group agreed that there was no manufacturer stipulation on this topic, and that the cable group should address it.

During the review of this document, a participant from the cables group commented that the group is addressing this topic only in relation to the clamping of the cables going to the first GIS connection. It was recommended that the clamps be tested according to IEC 61914 "Cable cleats for electrical installations" and spacing of clamps should be specified by cable manufacturer based in installation parameters. This international standard specifies requirements and tests for cable cleats and intermediate restraints used for securing cable in electrical installations. Cable cleats provide resistance to electromechanical forces where declared. This standard includes cable cleats that rely on a mounting surface specified by the manufacturer for axial and/or lateral retention of cables. 


\section{C-25 Cathodic Protection}

The substation group agreed that cathodic protection is a developer-implemented corrosion mitigation technique.

\section{C-25}

Standards addressed:

- Recommended standards: NACE RP-01

- NACE RP-01: corrosion protection.

\section{C-26 Grounding and Bonding}

This substation group agreed to add the standards API RP 14F , IEEE 837, and IEEE 80.

\section{C-26}

Standards addressed:

- Recommended standards: UL 467

- UL 467: grounding and bonding equipment

- Add: API RP 14F (covers grounding for offshore)

- Add: IEEE 837

- Add: IEEE 80.

\section{General Comments and Recommendations}

The substation breakout group discussions revealed that many of the identified standards pertain to the design of the substation itself. This was a common theme throughout the group discussion, because substations are generally individually designed to suit local site conditions. Accordingly, a developer's specifications tend to more heavily influence substation design than does an electrical safety perspective. For example, the lengthy discussion of arc flash/arc blast boundary ultimately resulted in the need for design specifications to further clarify the applicable standards.

In general, the U.S.-based IEEE or ANSI standards were considered to be defaults in many instances. When a U.S. standard was not available, IEC or other international standards were incorporated. This leads to the overarching question of how standards should be interpreted for worker training to ensure safety. Participants expressed different viewpoints regarding workforce utilization. Some companies use the same technicians to service on and offshore equipment, whereas others have separate specialized land-based and offshore workforces. A prescriptive standard may not be required in these instances, as this is more a question of operational strategy.

Additionally, it was recommended to not use the subjective low/medium/high descriptions for voltage; rather, voltage classes should be specifically stated in accordance with the NEC definitions, which was stated in the general key findings (Section 2.1). Across the board, greater 
specificity should reduce confusion and miscommunication, leading to safer offshore substations. 


\section{Assessment of Relevant Electrical Safety Standards for Submarine Cables}

Electrical safety standards for subsea cables are considered in the scope of work being completed by the AWEA OCRP Working Group (WG) 5, which is currently developing its recommendations. The cables breakout group included members of WG 5, as well as representation from submarine cable manufacturers, offshore wind project developers and operators, certification organizations, and BSEE. The organization of this section is intended to be consistent with the draft outline of the OCRP WG 5 document, which will have a similar structure.

\subsection{Scope}

The cables breakout group (hereinafter "the group") focused on array and export cables, with the scope defined in line with the WG 5 scope. Array cables are defined as extending between the terminations of the offshore wind facility structures, typically from the wind turbine to the substation. For export cables, the scope covers the cable between the termination on the offshore wind facility structure and where the submarine cable either terminates or transitions to a land cable design in a transition joint (splice).

Voltages for an offshore wind power plant array and export cables are generally $35 \mathrm{kV}$ and above. In Table D-1, array and export cables primarily fall in the "high-voltage" category, although standards listed under "medium voltage" may also be applicable to array or export cables with ratings at the lower end of the range. Although Europe and China are beginning to adopt HVDC systems for wind farms located far from shore, workshop participants do not anticipate any HVDC installations in the United States prior to the completion of the AWEA OCRP update that is scheduled for publication in 2021. Accordingly, standards for HVDC cables were not considered in detail during this workshop.

Electrical safety standards were discussed primarily in the context of reliability. There was broad consensus that a well-designed and properly installed cable should — barring external factors such as an anchor strike - not require any human interaction for the remainder of its lifetime. Ensuring reliability and minimizing the need for repairs is the best method for assuring safety. The other main approach to safety is having a repair plan in place in advance, in which all of the relevant standards and best practices are considered before they are urgently needed.

DNV GL-ST-0359 (Subsea power cables for wind power plants) and DNV GL-ST-0360 (Subsea power cables in shallow water) provide useful information relevant to submarine cables in all stages of the offshore wind plant lifecycle; however, they are recommended practices rather than U.S. or internationally recognized standards.

\subsection{Submarine Cable Route Planning}

Guidance from the AWEA OCRP 2012 recommended practice document remains relevant for cable route planning. A cable route should be planned based on data from the site characterization study and a desktop study of the seabed between the project site and proposed 
cable landing point. The North American Submarine Cable Association ${ }^{1}$ and the International Cable Protection Committee ${ }^{2}$ provide resources for identifying submarine cable locations and ownership. If other cables or pipelines are found to intersect the proposed route, the developer should, before construction begins, contact the owners of those facilities to negotiate the appropriate legal agreements regarding crossing and proximity. Documents that provide guidance for route surveys include:

- BOEM's guidelines for providing geological and geophysical hazards and archaeological information pursuant to $30 \mathrm{CFR} \S 585$

- Minimum requirements for the foundation of offshore wind turbines and power cable route burial assessments; Bundesamt für Seeschifffahrt und Hydrographie (Federal Maritime and Hydrographic Agency of Germany), August 2003

- International Cable Protection Committee Recommendation No. 3. Issue 9A: criteria to be applied to proposed crossings between submarine telecommunications cables and pipelines/power cables; Issue 2A: minimum technical requirements for a desktop study.

\subsection{Submarine Cable Design, Manufacturing, and Testing}

The application of standards to the design, manufacturing, and testing of export and array cables for offshore wind power plants is complicated by the absence of comprehensive standards for submarine power cables. Standards suitable for cables installed on land do not cover the additional requirements for submarine cables used in offshore wind systems, which typically include multiple cores, optical fiber, bedding, armor, and an outer jacket. IEC 63026 (Submarine power cables with extruded insulation and their accessories for rated voltages from $6 \mathrm{kV}$ up to 60 $\mathrm{kV}$ - Test methods and requirements) is the only internationally recognized standard covering both mechanical and electrical testing specifically adapted for submarine cable systems.

In the absence of standards specific to high-voltage subsea cables, the recommended practice is to follow standards for high-voltage land-based cables in combination with the guidance provided in CIGRE TB 490 (Recommendations for testing of long AC submarine cables with extruded insulation for system voltage above 30 to $500 \mathrm{kV}$ ) and CIGRE TB 623 (Recommendations for mechanical testing of submarine cables). CIGRE TB 496 (Recommendations for testing HVDC extruded cable systems for power transmission at a rated voltage up to $500 \mathrm{kV}$ ) provides guidance for HVDC cables. Examples of acceptable combinations of standards include:

- IEC 60840 (Power cables with extruded insulation and their accessories for rated voltages above $30 \mathrm{kV}$ up to $150 \mathrm{kV}$ - Test methods and requirements) and CIGRE TB 490

- IEC 62067 (Power cables with extruded insulation and their accessories for rated voltages above $150 \mathrm{kV}$ up to $500 \mathrm{kV}$ - Test methods and requirements) and CIGRE TB 490.

Participants in the cables group expressed different views regarding non-IEC standards. Some participants recommended using only IEC standards, whereas others believed that other standards should be allowed. A broad conclusion from the discussion was that if a relevant party,

${ }^{1}$ https://www.n-a-s-c-a.org/

2 https://www.iscpc.org 
such as a developer or interconnecting utility, requests cable core insulation wall thickness to be in compliance with standards issued by another SDO (such as the Association of Edison Illuminating Companies [AEIC] or ICEA), that could be acceptable as long as the cable system is type tested and prequalified following the procedures described in the relevant IEC and CIGRE standards documents. The added testing and potential increase in cable mass would likely increase costs and lead time associated with cable installation.

CIGRE TB 722 (Recommendations for additional testing for submarine cables from $6 \mathrm{KV}$ up to $60 \mathrm{kV}$ ) provides guidance on recommended testing for wet and semiwet cable designs.

Prequalification and type testing of a cable system for a given voltage can also qualify a lowervoltage cable system of the same design, as described in IEC 60840 and IEC 62067.

For the calculation of current ratings, IEC 60287 (Electric cables - Calculation of the continuous current rating of cables) is recommended. The method and process for ampacity calculation is explained and examples of the calculation process are given in the EPRI Underground Transmission Systems Reference Book-2016 Edition, Chapter 11. If the cable will be dynamically rated, site-specific data on wind speeds and proposed turbine capacity will be required to calculate the appropriate current rating. A conference paper, "CIGRE B1-303_2016: Systematic Description of Dynamic Load for Cables for Offshore Wind Farms. Method and Experience" outlines the methodology for reducing that data to calculate the current rating for dynamic loading. Appendix D4 in CIGRE TB 610 (Offshore generation cable connections) also provides information on dynamic loading calculations.

\section{C-2 (Wiring Methods High Voltage)}

Submarine cable standards addressed:

- Recommended standards:

○ IEC 63026

- Not specific to subsea cable, should be used in conjunction with CIGRE documents below: IEC 62067, IEC 60840, and IEC 60228

○ DNVGL-ST-0359

- CIGRE TB 490, CIGRE TB 496, CIGRE TB 610, CIGRE TB 623, and CIGRE TB 784.

- Other relevant standards (not specific to subsea cable; should be used in conjunction with CIGRE documents mentioned earlier):

- AEIC CS9, ICEA S-108-720

○ IEEE C2 (NESC), IEEE 404, and IEEE 1300. 


\section{C-12 (Cable Testing)}

Standards addressed:

- Recommended standards:

○ IEC 60230, IEC 60229, IEC 60287, and IEC 60811-501

- CIGRE TB 303, CIGRE TB 490, CIGRE TB 623, and CIGRE TB 722

- Other relevant standards (not specific to subsea cable):

- AEIC CS8 and AEIC CS9

○ ICEA P-32-382, ICEA P-45-482, ICEA S-94-649, ICEA T-24-380, ICEA T31-610, ICEA T-32-645, and ICEA T-34-664

○ IEEE 48.

\subsection{Submarine Cable Installation}

The installation process presents the highest risk for human error to impact cable performance. Careful planning and qualified personnel can mitigate some of the risks inherent to installation. Specific standards for cable installation are provided in the AWEA OCRP 2012.

Guidance for submarine cable joints and terminations can be found in:

- CIGRE TB 490 and CIGRE TB 610

- IEC 60859 (Cable Connections for Gas-Insulated Metal-Enclosed Switchgear for Rated Voltages of $72.5 \mathrm{kV}$ and Above - Fluid-filled and Extruded Insulation Cables - Fluid-Filled and Dry Type Cable - Terminations). Please note, however, that this standard has been withdrawn and replaced by IEC 62271-209 (High-voltage switchgear and controlgear - Part 209: Cable connections for gas-insulated metal-enclosed switchgear for rated voltages above $52 \mathrm{kV}$ - Fluid-filled and extruded insulation cables - Fluid-filled and dry-type cableterminations)

- IEEE 48 (Standard for Test Procedures and Requirements for Alternating-Current Cable Terminations Used on Shielded Cables Having Laminated Insulation Rated $2.5 \mathrm{kV}$ through $765 \mathrm{kV}$ or Extruded Insulation Rated $2.5 \mathrm{kV}$ through $500 \mathrm{kV}$ )

- IEEE 404 (Standard for Extruded and Laminated Dielectric Shielded Cable Joints Rated 2.5 $\mathrm{kV}$ to $500 \mathrm{kV}$ ); one participant stated that this standard is incompatible with the IEC/CIGRE submarine cable standards

- IEEE 1300 (Guide for Cable Connections for Gas-Insulated Substations); one participant noted that this is a copy of the IEC 60859 standard

- CIGRE TB 784 (Standard design of a common, dry type plug-in interface for GIS and power cables up to $145 \mathrm{kV}$ )

- Joining two different types of cable: CIGRE TB 303 (Revision of qualification procedures for high voltage and extra high voltage $\mathrm{AC}$ extruded underground cable systems). 


\subsection{Submarine Cable Flammability}

Although cable flammability is not a concern underwater, it should be considered for the portion of the cable that enters a wind turbine or substation and is exposed to air. The level of fire protection required depends on the classification of the offshore structure (e.g., manned, unmanned, not normally manned) and the corresponding risk that personnel could be exposed to a fire. CIGRE TB 720 (Fire issues for insulated cables in air) provides guidance on the selection of materials for fire safety as well as fire suppression techniques. Other standards relevant to cable flammability testing are listed under item C-6 in Table D-1.

Submarine cables will not be supplied with a coating over the individual cable cores that is flame resistant or retardant. Where the cable cores are broken out of the armor protection after the armor hang-off, the cable cores should be either placed in a metallic, nonmagnetic cable raceway or, alternately, continuously covered with a flame-retardant tape or covering material from the hang-off to the cable termination to protect the cable core jackets from flames and to contain a cable jacket fire. See CIGRE TB 720 for recommendations to protect cable. If halogen gas or smoke is of concern, the raceway or covering should be designed to route the gas or smoke away from the areas of concern and to vent to a safe exterior location in the case of a cable fire. Locating and/or pulling the cables into individual conduits or pipes will most likely not be practical and could be more of a safety hazard to the crew trying to pull the cables into pipes.

API RP $14 \mathrm{~F}$ was identified during the workshop as a potential source of information for determining the classification of the offshore structure. When examined in detail, however, the standard's references to umbilical cables are specific to the oil and gas industry and do not apply to offshore wind array and export cables.

\section{C-6 (Cable flammability testing)}

Standards addressed:

- Recommended standards:

- CIGRE TB 720.

\subsection{Operation and Maintenance}

Normal operation of submarine power cables should not require active intervention. Periodic inspection along the cable route should be carried out to detect any changes in the depth of buried cables - in particular, exposure as a result of scour, subsidence, sand waves, and so onor mechanical damage to the cable. Cables may also be designed with integrated fiber optic sensors that can detect changes in burial depth, strain, or temperature along the cable. If a cable becomes exposed, reburial or additional protection may be needed. Initial cable characterization using a method such as optical time domain reflectometry can provide a basis for comparison if a fault occurs.

Advance preparation of a repair plan is strongly recommended. After a fault has occurred, repair planning becomes time critical and mistakes or omissions that compromise safety are more likely. Guidance for developing a repair plan can be found in CIGRE TB 773 (Fault location on 
land and submarine links (AC \& DC)). The information in IEEE 1234 (Guide for Fault-Locating Techniques on Shielded Power Cable Systems) is similar, but its focus is primarily on power cables installed on land. Key elements of a repair plan include:

- Obtaining spare parts and cable

- Storing spare stock appropriately so that it achieves its expected shelf life and replacing it as needed

- Identifying local contractors with expertise and equipment available for cable locating, fault locating, and cable repair

- Establishing agreements with identified contractors to provide timely response and repair for any cable problem that may arise

- Specifying a safe operating plan for repair operations.

The safe operating plan should cover shutdown procedures, lockout/tagout procedures and communication, and induced voltage procedures. Acceptable standards for safe working practices near subsea cables are listed under item B-5 in Table D-1. IEEE 1727 (Guide for Working Procedures on Underground Transmission Circuits with Induced Voltage) and CIGRE B1-115_2018 (Safe Work on HV Extruded Insulation Cable Systems under Induced Voltages), which provide guidance on safety for working on a deenergized line in proximity to an energized line. Safety during diving operations is covered by the Association of Diving Contractors International Consensus Standards for Commercial Diving and Underwater Operations (6th Ed., Rev. 6.3, 2019) and the International Marine Contractors Association (IMCA) international code of practice for offshore diving (IMCA D 014 Rev. 2.1, 2019).

\section{B-5 (Work on Submarine Cables)}

Standards addressed:

- Recommended standards:

○ IEC 60204

○ CIGRE TB 773

○ IEEE 1727 and IEEE 1234.

\subsection{Decommissioning}

Current guidance from BOEM in 30 CFR $\S 585$ requires developers to include the cost of decommissioning (i.e., removing the cable and returning the site to its original condition, subject to an environmental impact assessment). Because of the disturbance to the seabed when removing a buried cable, the conclusion of the environmental impact assessment may be a recommendation to leave the cables in situ. 


\section{Next Steps}

Understanding the design and safety implications of the various proven European design methods and existing U.S. codes and standards is essential for the maturation of the U.S. offshore wind industry. The Offshore Wind Electrical Safety Standards Harmonization Workshop held on February 11-12, 2020, at NREL's Flatirons Campus near Boulder, Colorado, and this report, which documents the proceedings of the workshop, represent a major step in the process to implement safe design and safety practices for offshore wind facilities on the U.S. Outer Continental Shelf.

This publication can now serve as a near-term reference to inform project design and approvals, thereby leveraging these workshop proceedings to help inform U.S. industry-recommended practices, which are under development by the AWEA Wind Technical Standards subcommittee. The primary next step is to complete the current AWEA/ANSI U.S. offshore wind standards initiative and publish a suite of five offshore recommended practices documents. A formal AWEA/ANSI approval process for these recommended practices includes vital procedural safeguards that will allow BOEM/BSEE to reference them in future revisions to $30 \mathrm{CFR} \S 585$, and, if appropriate, explicitly quote them in regulations.

In the interim period, we recommend that work continue to update Table D-1 to reflect the most current thinking, as there was not enough time during the workshop to complete this discussion. This could be accomplished through additional workshops held while the more formal OCRP recommendations are being finalized. This would allow BOEM/BSEE to engage individually with industry representatives to gather more candid information.

Additionally, BOEM/BSEE could engage directly with the land-based wind community and NRTLs to incorporate their experience integrating the international land-based wind industry into the U.S. market.

Finally, a key component to the safety of workers employed during the construction and operation of U.S. offshore wind facilities will be proper workforce training. It is essential that the U.S. industry develop workforce training and health and safety protocols that integrate with the electrical safety standards discussed in this report, and which comply with and facilitate the BOEM/BSEE safety management system requirements. These activities should be initiated immediately and proceed in parallel with the development of the OCRP recommended practices. 


\section{References}

American Wind Energy Association. 2012. AWEA Offshore Compliance Recommended Practices. Recommended Practices for Design, Deployment, and Operation of Offshore Wind Turbines in the United States. https://offshorewindhub.org/sites/default/files/resources/awea 916-2012 oswrecommendedpractices.pdf.

Electric Power Research Institute. 2016. EPRI Underground Transmission Systems Reference Book: 2016, Chapter 11

CIGRE. 2016. Systematic description of dynamic load for cables for offshore wind farms. Method and experience. CIGRE B1-303_2016. https://e-cigre.org/publication/B1-303_2016

CIGRE. 2018. Safe Work on HV Extruded insulation Cable Systems under induced Voltages. CIGRE B1-115_2018. https://e-cigre.org/publication/SESSION2018 B1-115. 


\section{List of Primary Standards}

This list represents the standards that are referred to in the body of the report but is not a comprehensive list of the standards in Table D- 1 .

\section{Table 1. List of Primary Standards Referenced in Report}

\begin{tabular}{|c|c|}
\hline Standards \# & Topic Covered \\
\hline AEIC CS9 & $\begin{array}{l}\text { Specification for extruded insulation power cables and their accessories } \\
\text { rated above } 46 \mathrm{kV} \text { through } 345 \mathrm{kVAC}\end{array}$ \\
\hline $\begin{array}{l}\text { ANSI/NETA } \\
\text { ATS }\end{array}$ & $\begin{array}{l}\text { Standard for Acceptance Testing Specifications for Electrical Power } \\
\text { Equipment and Systems }\end{array}$ \\
\hline $\begin{array}{l}\text { ANSI C57 } \\
\text { Series }\end{array}$ & Standard for Low-Voltage Transformers and Reactors \\
\hline API RP 14C & $\begin{array}{l}\text { Analysis, Design, Installation, and Testing of Basic Surface Safety Systems } \\
\text { for Offshore Production Platforms; } 30 \text { CFR } 250.1628 \text { (c) }\end{array}$ \\
\hline API RP 14F & $\begin{array}{l}\text { Design and Installation of Electrical Systems for Offshore Production } \\
\text { Platforms; } 30 \text { CFR } 250.114 \text { (c) }\end{array}$ \\
\hline ASTM F1506 & $\begin{array}{l}\text { Standard Performance Specification for Flame Resistant and Electric Arc } \\
\text { Rated Protective Clothing Worn by Workers Exposed to Flames and Electric } \\
\text { Arcs }\end{array}$ \\
\hline $\begin{array}{l}\text { AWEA OCRP } \\
2012\end{array}$ & AWEA Offshore Compliance Recommended Practices 2012 \\
\hline $\begin{array}{l}\text { CIGRE B1- } \\
\text { 115_2018 }\end{array}$ & $\begin{array}{l}\text { "Safe Work on HV Extruded insulation Cable Systems under induced } \\
\text { Voltages" }\end{array}$ \\
\hline $\begin{array}{l}\text { CIGRE B1- } \\
\text { 303_2016 }\end{array}$ & $\begin{array}{l}\text { "Systematic description of dynamic load for cables for offshore wind farms. } \\
\text { Method and experience" }\end{array}$ \\
\hline CIGRE B3.26 & Guidelines for the Design and Construction of AC Offshore Wind Farms \\
\hline CIGRE TB 303 & $\begin{array}{l}\text { Revision of qualification procedures for high-voltage and extra-high-voltage } \\
\text { AC extruded underground cable systems }\end{array}$ \\
\hline CIGRE TB 490 & $\begin{array}{l}\text { Recommendations for testing of long AC submarine cables with extruded } \\
\text { insulation for system voltage above } 30(36) \text { to } 500(550) \mathrm{kV}\end{array}$ \\
\hline
\end{tabular}




\begin{tabular}{|c|c|}
\hline Standards \# & Topic Covered \\
\hline CIGRE TB 496 & $\begin{array}{l}\text { Recommendations for Testing DC Extruded Cable Systems for Power } \\
\text { Transmission at a Rated Voltage up to } 500 \mathrm{kV}\end{array}$ \\
\hline CIGRE TB 610 & Offshore Generation Cable Connections \\
\hline CIGRE TB 623 & Recommendations for Mechanical Testing of Submarine Cables \\
\hline CIGRE TB 720 & Fire issues for insulated cables in air \\
\hline CIGRE TB 722 & $\begin{array}{l}\text { Recommendations for additional testing for submarine cables from } 6 \mathrm{KV} \text { up } \\
\text { to } 60 \mathrm{KV}\end{array}$ \\
\hline CIGRE TB 773 & Fault location on land and submarine links ( $A C$ and $D C$ ) \\
\hline CIGRE TB 784 & $\begin{array}{l}\text { Standard design of a common, dry-type plug-in interface for GIS and power } \\
\text { cables up to } 145 \mathrm{kV}\end{array}$ \\
\hline $\begin{array}{l}\text { CAN/CSA- } \\
\text { C22.2 No. } 272\end{array}$ & Wind Turbine Electrical Systems \\
\hline CSA C22.2 & CSA C22.2 No. 0.4 - Bonding of Electrical Equipment \\
\hline CSA C22.2 & CSA C22.2 No. 41 - Grounding and Bonding Equipment \\
\hline $\begin{array}{l}\text { CSA SPE-1000- } \\
13\end{array}$ & Model Code for the field evaluation of electrical equipment \\
\hline CSA Z462 & Workplace Electrical Safety (Based on NFPA 70E) \\
\hline $\begin{array}{l}\text { DNVGL-ST- } \\
0359\end{array}$ & Subsea power cables for wind power plants \\
\hline $\begin{array}{l}\text { DNVGL-ST- } \\
0360\end{array}$ & Subsea power cables in shallow water \\
\hline DNVGL-ST-145 & Offshore substations \\
\hline EN 61034-2 & $\begin{array}{l}\text { Measurement of smoke density of electric cables burning under defined } \\
\text { conditions - Part 2: Test procedure and requirements }\end{array}$ \\
\hline ICEA S-108-720 & $\begin{array}{l}\text { Standard for Extruded Insulation Power Cables Rated Above } 46 \text { Through } \\
500 \mathrm{KV} \mathrm{AC}\end{array}$ \\
\hline
\end{tabular}




\begin{tabular}{|c|c|}
\hline Standards \# & Topic Covered \\
\hline $\begin{array}{l}\text { IEC } 60034 \\
\text { series }\end{array}$ & Rotating electrical machines \\
\hline IEC 60204-1 & $\begin{array}{l}\text { Safety of machinery - Electrical equipment of machines - Part 1: General } \\
\text { requirements }\end{array}$ \\
\hline IEC 60204-11 & $\begin{array}{l}\text { Safety of machinery - Electrical equipment of machines - Part 11: } \\
\text { Requirements for equipment for voltages above } 1,000 \mathrm{~V} A C \text { or } 1,500 \mathrm{~V} D C \\
\text { and not exceeding } 36 \mathrm{kV}\end{array}$ \\
\hline IEC 60287 & Electric cables - Calculation of the current rating \\
\hline IEC 60364 & Low-voltage electrical installations \\
\hline $\begin{array}{l}\text { IEC 60364-7- } \\
729\end{array}$ & $\begin{array}{l}\text { Low-voltage electrical installations - Part 7-729: Requirements for special } \\
\text { installations or locations - Operating or maintenance gangways }\end{array}$ \\
\hline IEC 60502-2 & $\begin{array}{l}\text { Power cables with extruded insulation and their accessories for rated } \\
\text { voltages from } 1 \mathrm{kV}(\mathrm{Um}=1,2 \mathrm{kV}) \text { up to } 30 \mathrm{kV}(\mathrm{Um}=36 \mathrm{kV})-\text { Part 2: Cables } \\
\text { for rated voltages from } 6 \mathrm{kV}(\mathrm{Um}=7,2 \mathrm{kV}) \text { up to } 30 \mathrm{kV}(\mathrm{Um}=36 \mathrm{kV})\end{array}$ \\
\hline IEC 60840 & $\begin{array}{l}\text { Power cables with extruded insulation and their accessories for rated } \\
\text { voltages above } 30 \mathrm{kV}(\mathrm{Um}=36 \mathrm{kV}) \text { up to } 150 \mathrm{kV}(\mathrm{Um}=170 \mathrm{kV})-\text { Test } \\
\text { methods and requirements }\end{array}$ \\
\hline IEC 60909-0 & $\begin{array}{l}\text { Short-circuit currents in three-phase a.c. systems - Part 0: Calculation of } \\
\text { currents }\end{array}$ \\
\hline $\begin{array}{l}\text { IEC 61034-2- } \\
2005\end{array}$ & $\begin{array}{l}\text { Measurement of smoke density of cables burning under defined conditions } \\
\text { - Part 2: Test procedure and requirements }\end{array}$ \\
\hline IEC 61039 & Classification of insulating liquids \\
\hline IEC 61400-1 & Wind energy generation systems - Part 1: Design requirements \\
\hline IEC 61400-3-1 & $\begin{array}{l}\text { Wind energy generation systems - Part 3-1: Design requirements for fixed } \\
\text { offshore wind turbines }\end{array}$ \\
\hline IEC 61400-3-2 & $\begin{array}{l}\text { Wind energy generation systems - Part 3-2: Design requirements for } \\
\text { floating offshore wind turbines }\end{array}$ \\
\hline IEC 61482-2 & $\begin{array}{l}\text { European equivalent to ASTM F1506 for the thermal hazards of an arc } \\
\text { flash. The standard includes requirements for material testing and } \\
\text { additional information for garments constructed from compliant materials. }\end{array}$ \\
\hline
\end{tabular}




\section{Standards \# Topic Covered}

This is required for selling garments for arc flash protection in the European Union.

\begin{tabular}{|c|c|}
\hline IEC 61936-1 & Power installations exceeding 1 kV a.c. - Part 1: Common rules \\
\hline IEC 61914 & Cable Cleats for Electrical Installations \\
\hline IEC 62067 & $\begin{array}{l}\text { Power cables with extruded insulation and their accessories for rated } \\
\text { voltages above } 150 \mathrm{kV}(\mathrm{Um}=170 \mathrm{kV}) \text { up to } 500 \mathrm{kV}(\mathrm{Um}=550 \mathrm{kV})-\text { Test } \\
\text { methods and requirements }\end{array}$ \\
\hline IEC 62271-200 & $\begin{array}{l}\text { High-voltage switchgear and controlgear - Part 200: AC metal-enclosed } \\
\text { switchgear and controlgear for rated voltages above } 1 \mathrm{kV} \text { and up to and } \\
\text { including } 52 \mathrm{kV}\end{array}$ \\
\hline IEC 62271-203 & $\begin{array}{l}\text { High-voltage switchgear and controlgear - Part 203: Gas-insulated metal- } \\
\text { enclosed switchgear for rated voltages above } 52 \mathrm{kV}\end{array}$ \\
\hline IEC 62477-1 & $\begin{array}{l}\text { Safety requirements for power electronic converter systems and } \\
\text { equipment - Part 1: General }\end{array}$ \\
\hline IEC 62477-2 & $\begin{array}{l}\text { Safety requirements for power electronic converter systems and } \\
\text { equipment - Part 2: Power electronic converters from 1,000 V AC or 1,500 } \\
\text { V DC up to } 36 \mathrm{kV} \mathrm{AC} \mathrm{or} 54 \mathrm{kV} \mathrm{DC}\end{array}$ \\
\hline IEC 63026 & $\begin{array}{l}\text { Submarine power cables with extruded insulation and their accessories for } \\
\text { rated voltages from } 6 \mathrm{kV}(\mathrm{Um}=7,2 \mathrm{kV}) \text { up to } 60 \mathrm{kV}(\mathrm{Um}=72,5 \mathrm{kV}) \text { - Test } \\
\text { methods and requirements }\end{array}$ \\
\hline
\end{tabular}

IEC TR 61641 Enclosed low-voltage switchgear and controlgear assemblies - Guide for testing under conditions of arcing due to internal fault

IECRE OD-501 Type and component certification scheme

IECRE OD-502 Project certification scheme

IEEE C2 $\quad$ (NESC)

IEEE C37.20 Guide for low-voltage and medium-voltage arc gear

IEEE C37 90.1 Standard for Surge Withstand Capability (SWC) Tests for Relays and Relay Systems Associated with Electric Power Apparatus 


\begin{tabular}{|c|c|}
\hline Standards \# & Topic Covered \\
\hline IEEE C37.122 & Guide for Gas-Insulated Switchgear, specific to High Voltage \\
\hline IEEE 1234 & Guide for Fault-Locating Techniques on Shielded Power Cable Systems \\
\hline IEEE 1300 & Guide for Cable Connections for Gas-Insulated Substations \\
\hline IEEE 1547 & $\begin{array}{l}\text { EEE Standard for Interconnection and Interoperability of Distributed Energy } \\
\text { Resources with Associated Electric Power Systems Interfaces }\end{array}$ \\
\hline IEEE 1584 & IEEE Guide for Performing Arc Flash Hazard Calculations \\
\hline IEEE 1727 & $\begin{array}{l}\text { Guide for Working Procedures on Underground Transmission Circuits with } \\
\text { Induced Voltage }\end{array}$ \\
\hline
\end{tabular}

IEEE 404 Standard for Extruded and Laminated Dielectric Shielded Cable Joints Rated $2.5 \mathrm{kV}$ to $500 \mathrm{kV}$

IEEE 519 Standard for Point of Interconnection

IEEE 946 Recommended Practice for the Design of DC Auxiliary Power Systems for Generating Stations

\begin{tabular}{l|l} 
IEEE 80 & Guide for Safety in AC Substation Grounding
\end{tabular}

IEEE 837 Standard for Qualifying Permanent Connections Used in Substation Grounding

IEEE 44 (or Recommended Practice for Installation Design and Installation of Vented 484) Lead-Acid Batteries for Stationary Applications

ISO 12100 Safety of machinery - General principles for design - Risk assessment and risk reduction

ISO 14122-1 Safety of machinery - Permanent means of access to machinery - Part 1: Choice of fixed means and general requirements of access

ISO 14122-4 Safety of machinery - Permanent means of access to machinery - Part 4: Fixed ladders

ISO $4413 \quad$ Hydraulic fluid power - General rules and safety requirements for systems and their components

ISO $9001 \quad$ Quality Management 


\begin{tabular}{|c|c|}
\hline Standards \# & Topic Covered \\
\hline NACE RP-01 & Corrosion Protection \\
\hline NEMA 250 & Enclosures for Electrical Equipment (1,000 Volts Maximum) \\
\hline $\begin{array}{l}\text { NEMA } \\
\text { ANSI/IEC } \\
60529\end{array}$ & $\begin{array}{l}\text { Degrees of Protection Provided by Enclosures (IP Code) (Identical National } \\
\text { Adoption) }\end{array}$ \\
\hline NFPA 70 & $\begin{array}{l}\text { Standard for Electrical Safety in the Workplace, Chapter 1, Articles 100-130 } \\
- \text { Working on or near live equipment }\end{array}$ \\
\hline NFPA 70B & Recommended Practice for Electrical Equipment Maintenance \\
\hline NFPA 70E & $\begin{array}{l}\text { Standard for Electrical Safety in the Workplace; Chapter 1, Articles 100-130 } \\
\text { - Working on or near live equipment }\end{array}$ \\
\hline NFPA 79 & Electrical Standard for Industrial Machinery \\
\hline NFPA 780 & Lightning Protection \\
\hline NFPA 2001 & Standard for Clean Agent/Inert Gas Fire Suppression \\
\hline $\begin{array}{l}\text { OSHA } 29 \text { CFR } \\
1910\end{array}$ & Occupational Safety and Health Standards \\
\hline $\begin{array}{l}\text { OSHA } 29 \text { CFR } \\
1910 \text { Subpart R }\end{array}$ & Special Industries \\
\hline $\begin{array}{l}\text { OSHA } 29 \text { CFR } \\
1910 \text { Subpart S }\end{array}$ & Electrical \\
\hline $\begin{array}{l}\text { OSHA } 29 \text { CFR } \\
1910.23\end{array}$ & Ladders \\
\hline $\begin{array}{l}\text { OSHA } 29 \text { CFR } \\
1910.137\end{array}$ & Personal Protection Equipment \\
\hline $\begin{array}{l}\text { OSHA } 29 \text { CFR } \\
1910.147\end{array}$ & Lockout/Tagout (LO/TO) \\
\hline $\begin{array}{l}\text { OSHA } 29 \text { CFR } \\
1910.269(h)\end{array}$ & $\begin{array}{l}\text { Electric Power Generation, Transmission, and Distribution - Fixed ladders } \\
\text { inside wind turbine towers }\end{array}$ \\
\hline
\end{tabular}




\begin{tabular}{|l|l|}
\hline \multicolumn{1}{|c|}{ Standards \# } & Topic Covered \\
\hline $\begin{array}{l}\text { OSHA 29 CFR } \\
\mathbf{1 9 2 6 . 9 6 0}\end{array}$ & Working on or near exposed energized parts (Construction) \\
\hline UL 1004 series & Standard for Rotating Electrical Machines \\
\hline UL 1598 & Luminaires \\
\hline UL 467 & Standard for Grounding and Bonding Equipment \\
\hline UL 508 & Standard for Industrial Control Equipment \\
\hline UL 508A & Standard for Industrial Control Panels \\
\hline UL 508C & Standard for Power Conversion Equipment \\
\hline UL 2277 & Standard for Construction Specifications \\
\hline UL 6141 & Standard for Wind Turbines Permitting Entry of Personnel \\
\hline UL 61800-5-1 & $\begin{array}{l}\text { Standard for Adjustable Speed Electrical Power Drive Systems - Part 5-1: } \\
\text { Safety Requirements - Electrical, Thermal and Energy }\end{array}$ \\
\hline UL 845 & Standard for Motor Control \\
\hline UL 1053 & Standard for Safety Covering Ground Fault Protection \\
\hline UL 1558 & Standard for Metal-Enclosed Low-Voltage Power Circuit Breaker Switchgear \\
\hline
\end{tabular}




\section{Appendix A. Attendee Information}

The table below provides a list of the attendees of the workshop who were the primary subject matter experts who guided the content of this report.

Table A-1. Workshop Attendee List

\begin{tabular}{|c|c|c|}
\hline Attendee Name & Attendee Affiliation & Break-Out Group \\
\hline Tom Buchal & Independent Consultant & Turbines \\
\hline Edgar DeMeo & Renewable Energy Consulting Services & Turbines \\
\hline Jens Brix Due & Siemens Gamesa Renewable Energy & Turbines \\
\hline Albert Fisas & GE Renewable Energy & Turbines \\
\hline Michelle Fogarty & $\begin{array}{l}\text { National Renewable Energy Laboratory } \\
\text { (NREL) }\end{array}$ & Turbines \\
\hline Jonas Gertz Jensen & $\varnothing$ rsted & Turbines \\
\hline Samuel H. Hawkins & Siemens Gamesa Renewable Energy & Turbines \\
\hline Cheri Hunter & $\begin{array}{l}\text { Bureau of Safety and Environmental } \\
\text { Enforcement (BSEE) }\end{array}$ & Turbines \\
\hline Geoff Neild & Vineyard Wind & Turbines \\
\hline Benjamin Palethorpe & GE Renewable Energy & Turbines \\
\hline Christian Pohl & Nexans & Turbines \\
\hline Christian Storbeck & UL LLC & Turbines \\
\hline Jack Arruda & Vineyard Wind & Substations \\
\hline Hendrik Berends & RWE Renewables GmbH & Substations \\
\hline Brandon Burke & Business Network for Offshore Wind & Substations \\
\hline Dave Burns & Shell & Substations \\
\hline Emily Chambers & Business Network for Offshore Wind & Substations \\
\hline Darryl Francois & Bureau of Ocean Energy Management & Substations \\
\hline Jonathan Howie & $\begin{array}{l}\text { Energie Baden-Württemberg North } \\
\text { America }\end{array}$ & Substations \\
\hline Svein Johansen & Equinor ASA & Substations \\
\hline Daniel Katz & $\emptyset$ rsted & Substations \\
\hline Steven Kunsman & ABB & Substations \\
\hline Nick Matone & Burns \& McDonnell & Substations \\
\hline Walt Musial & NREL & Substations \\
\hline
\end{tabular}




\begin{tabular}{|l|l|l|}
\hline George Nichol & GE & Substations \\
\hline Shane O'Sullivan & $\emptyset$ rsted & Substations \\
\hline Juan Luis Paredes Ortiz & Avangrid & Substations \\
\hline Stephan Schwab & WSP & Substations \\
\hline Hongbiao Song & GE & Substations \\
\hline Chloe Constant & NREL & Cables \\
\hline Aubryn Cooperman & NREL & Cables \\
\hline Joseph Cunningham & Scottish Power/Avangrid & Cables \\
\hline Georg Engelmann & Excipio Energy & Cables \\
\hline David Grassbaugh & $\varnothing$ rsted & Cables \\
\hline Robert Hobson & NKT & Cables \\
\hline Paul Knapp & UL LLC & Cables \\
\hline Darin Lawton & Burns \& McDonnell & Cables \\
\hline Sabrina Morelli & American Wind Energy Association & Cables \\
\hline David Nedorostek & BSEE & Cables \\
\hline Maxime Toulotte & Nexans & Cables \\
\hline Bill Wall & LS Cable America & Cables \\
\hline & & \\
\hline
\end{tabular}




\title{
Appendix B. Workshop Agendas
}

\author{
Offshore Wind Electrical Safety Standards Harmonization Workshop \\ Tuesday, February 11 through Wednesday, February 12, 2020, at the Flatirons Campus \\ National Renewable Energy Laboratory (NREL) \\ 18200 Highway 128 Boulder, CO 80303
}

Table B-1. Day 1 - Plenary Session (February 11, 2020)

\begin{tabular}{|c|c|c|}
\hline Time & Activity & Speaker \\
\hline 8:00-8:15 a.m. & $\begin{array}{l}\text { Flatirons Campus Arrival and Check- } \\
\text { In }\end{array}$ & NREL's Flatirons Guard Gate \\
\hline $8: 15-8: 45$ a.m. & Network/Lite Breakfast & All \\
\hline 8:45- 9:00 a.m. & $\begin{array}{l}\text { Welcome, Meeting Objectives, and } \\
\text { Introductions }\end{array}$ & $\begin{array}{l}\text { Walt Musial (NREL } \\
\text { Cheri Hunter (Bureau of Safety and } \\
\text { Environmental Enforcement [BSEE]) } \\
\text { Darryl Francois (Bureau of Ocean Energy } \\
\text { Management) }\end{array}$ \\
\hline 9:00-9:30 a.m. & $\begin{array}{l}\text { BSEE Perspective on U.S. Offshore } \\
\text { Wind Electrical Safety Issues }\end{array}$ & $\begin{array}{l}\text { Cheri Hunter and David } \\
\text { Nederostek/Darryl Francois } \\
\text { (BSEE/BOEM) } \\
\text { "Why are we here?" }\end{array}$ \\
\hline 9:30-9:45 a.m. & $\begin{array}{l}\text { Overview of Offshore and Offshore } \\
\text { Wind National Standards Initiative }\end{array}$ & Walt Musial (NREL) \\
\hline 9:45- 10:15 a.m. & $\begin{array}{l}\text { U.S. Offshore Wind Recommended } \\
\text { Practices Status - Offshore } \\
\text { Compliance Recommended Practice } \\
\text { (OCRP)-1 }\end{array}$ & $\begin{array}{l}\text { Albert Fisas (GE) Offshore Compliance } \\
\text { Recommended Practices - Maintenance } \\
\text { Team Delegate - "Status of OCRP-1" }\end{array}$ \\
\hline 10:15- 10:30 a.m. & Break & All \\
\hline 10:30-noon & $\begin{array}{l}\text { Session 1: Participant Presentations } \\
\text { on Wind Plant Electrical Safety and } \\
\text { Discussion }\end{array}$ & $\begin{array}{l}\text { Chair: Ed DeMeo-(NREL Consultant; } \\
\text { Workshop Chair) } \\
\text { Industry Speakers: } \\
\text { - Samuel Hawkins (Siemens } \\
\text { Gamesa) "OEM approach to } \\
\text { electrical safety standards" } \\
\text { - Steven Kunsman (ABB) } \\
\text { "Assessment of Secondary system } \\
\text { issues including protection, } \\
\text { control, automation, and cyber } \\
\text { security" } \\
\text { - George Nichol (GE) "Offshore } \\
\text { substations \& equipment } \\
\text { standards and lessons learned }\end{array}$ \\
\hline
\end{tabular}




\begin{tabular}{|c|c|c|}
\hline Time & Activity & Speaker \\
\hline & & $\begin{array}{l}\text { (gas-insulated switchgear and } \\
\text { high-voltage DC)" }\end{array}$ \\
\hline 12:00- 1:00 p.m. & Lunch (brought in) & All \\
\hline 1:00 2:30 p.m. & $\begin{array}{l}\text { Session 2: Participant Presentations } \\
\text { on Electrical Safety for Offshore } \\
\text { Substations and Discussion }\end{array}$ & $\begin{array}{l}\text { Chair: Ed DeMeo-Workshop Chair } \\
\text { Industry Speakers: } \\
\text { - Joseph Cunningham (Avangrid) } \\
\text { "Assessment of U.S. Electrical } \\
\text { Safety Regulations" } \\
\text { - Hugo Avila (presented by Steven } \\
\text { Kunsman) (ABB) "Assessment of } \\
\text { High Voltage Primary Equipment } \\
\text { Issues" } \\
\text { - Steven Kunsman } \\
\text { (ABB) "BOEM/Moffat and Nichols } \\
\text { Report" }\end{array}$ \\
\hline 2:30-2:45 p.m. & Break & All \\
\hline 2:45-3:45 p.m. & $\begin{array}{l}\text { Session 3: Participant Presentations } \\
\text { on Electrical Safety for Offshore } \\
\text { Subsea Cables and Discussion }\end{array}$ & $\begin{array}{l}\text { Chair: Ed DeMeo } \\
\text { Industry Speaker: } \\
\text { - Bob Hobson (NKT Inc.) "Status of } \\
\text { AWEA Working Group } 5 \\
\text { Recommended Practices for } \\
\text { Submarine Cables" }\end{array}$ \\
\hline 3:45- 4:00 p.m. & Break & All \\
\hline 4:00- 5:00 p.m. & $\begin{array}{l}\text { Introduce Breakout Groups } \\
\text { 1) Turbines } \\
\text { 2) Substations } \\
\text { 3) Subsea Cables }\end{array}$ & $\begin{array}{l}\text { Facilitation: Ed DeMeo; Breakout Groups } \\
\text { Will Briefly Assemble and Work Out } \\
\text { Reporting, Facilitation, and Protocols. } \\
\text { Create a List of Key Issues to be Discussed } \\
\text { on Day } 2\end{array}$ \\
\hline 5:00 p.m. & Adjourn for the Day & All \\
\hline 6:30 p.m. & No-Host Dinner (TBD) & Sign-Up at Registration \\
\hline
\end{tabular}


Table B-2. Day 2 - Breakout Group Discussions (February 12, 2020)

\begin{tabular}{|c|c|c|}
\hline Time & Activity & Speaker \\
\hline 8:00-8:15 a.m. & $\begin{array}{l}\text { Flatirons Campus Arrival and } \\
\text { Check-In }\end{array}$ & NREL's Flatirons Guard Gate \\
\hline 8:15-8:45 a.m. & Network/Lite Breakfast & All \\
\hline 8:45-9:00 a.m. & $\begin{array}{l}\text { Review Plenary Breakout Group } \\
\text { Objectives and Report-Out } \\
\text { Guidance }\end{array}$ & Ed DeMeo (NREL Consultant) \\
\hline 9:00-9:15 a.m. & $\begin{array}{l}\text { Break and Assemble into } \\
\text { Breakout Sessions }\end{array}$ & All \\
\hline 9:15-noon & $\begin{array}{l}\text { (Three) Facilitated Break-Out } \\
\text { Sessions Meet Concurrently: 1) } \\
\text { Turbines, 2) Substations, and 3) } \\
\text { Subsea Cables } \\
\text { Breakout Facilitators Will } \\
\text { Prescribe Their Own Coffee } \\
\text { Breaks When Convenient } \\
\text { Notetakers Will be Assigned to } \\
\text { Each Breakout Froup }\end{array}$ & $\begin{array}{l}\text { Breakout Organizers: } \\
\text { Facilitator/Chapter Lead } \\
\text { Turbines: Ed DeMeo/Michelle } \\
\text { Fogarty } \\
\text { Substations: Brandon Burke/Emily } \\
\text { Chambers } \\
\text { Subsea Cables: Chloe } \\
\text { Constant/Aubryn Cooperman }\end{array}$ \\
\hline 12-1:00 p.m. & Lunch (brought in) & All \\
\hline 1:00-2:30 p.m. & $\begin{array}{l}\text { Breakout Groups Report-Out ( } 30 \\
\text { min Each with Q\&A) }\end{array}$ & $\begin{array}{l}\text { Breakout Facilitators } \\
\text { Presentation: Hendrik Berends } \\
\text { (RWE) "Overview of Electrical Safety } \\
\text { at RWE Windfarms during } \\
\text { Construction and Commissioning" }\end{array}$ \\
\hline 2:30-3:00 p.m. & $\begin{array}{l}\text { Wrap-Up_-Steps Forward, } \\
\text { Assignments }\end{array}$ & Ed DeMeo (NREL Consultant) \\
\hline 3:00 p.m. & Adjourn & \\
\hline
\end{tabular}




\section{Appendix C. Workshop Presentation Materials}


Offshore Wind Electrical Safety Standards Harmonization Workshop

\section{Welcome and Opening}

Walt Musial

Principal Engineer, National Renewable Energy Laboratory (NREL)

Chairman, American Wind Energy Association (AWEA) Offshore

Wind Subcommittee

Offshore Wind Electrical Safety Standards Harmonization Workshop

Tuesday, Feb 11-12, 2020, at the Flatirons Campus,

National Renewable Energy Laboratory

National Wind Technology Center 


\section{Opening Comments}

- Welcome

- Introductions

- Call-in protocol

- Meals and refreshments

- Bureau of Ocean Energy Management (BOEM)/Bureau of Safety and Environmental Enforcement (BSEE) Opening Remarks

- NREL overview 


\section{Electrical Standards Project Objectives}

- Objective for the Overall Project:

- Develop and document published, publicly available "record of expert opinion" for application of relevant electrical safety standards in domestic offshore wind installations

- Inform Offshore Compliance Recommended Practices (OCRP)-1 to help deliver an American National Standards Institute (ANSI)-approved offshore wind electrical safety standard

- Project Approach

- Develop a list of relevant standards

- Compare and contrast relevant standards from both Europe and the United States

- Identify significant differences, and offer recommendations on resolution or acceptance of differences, based on understood real-world consequences (level of risk)

- Produce a public guidance report on Workshop outcome

- Objectives for the Workshop:

- Review recent efforts to identify relevant standards from both Europe and the United States

- Identify and assess commonalities and differences; highlight differences to understand magnitude of material consequences

- Discuss differences and propose resolutions for most significant discrepancies

- Summarize range of views in cases not amenable to immediate resolution

- Compile information from the discussions relevant to preparation of the guidance document 


\section{NREL Science Drives Innovation}

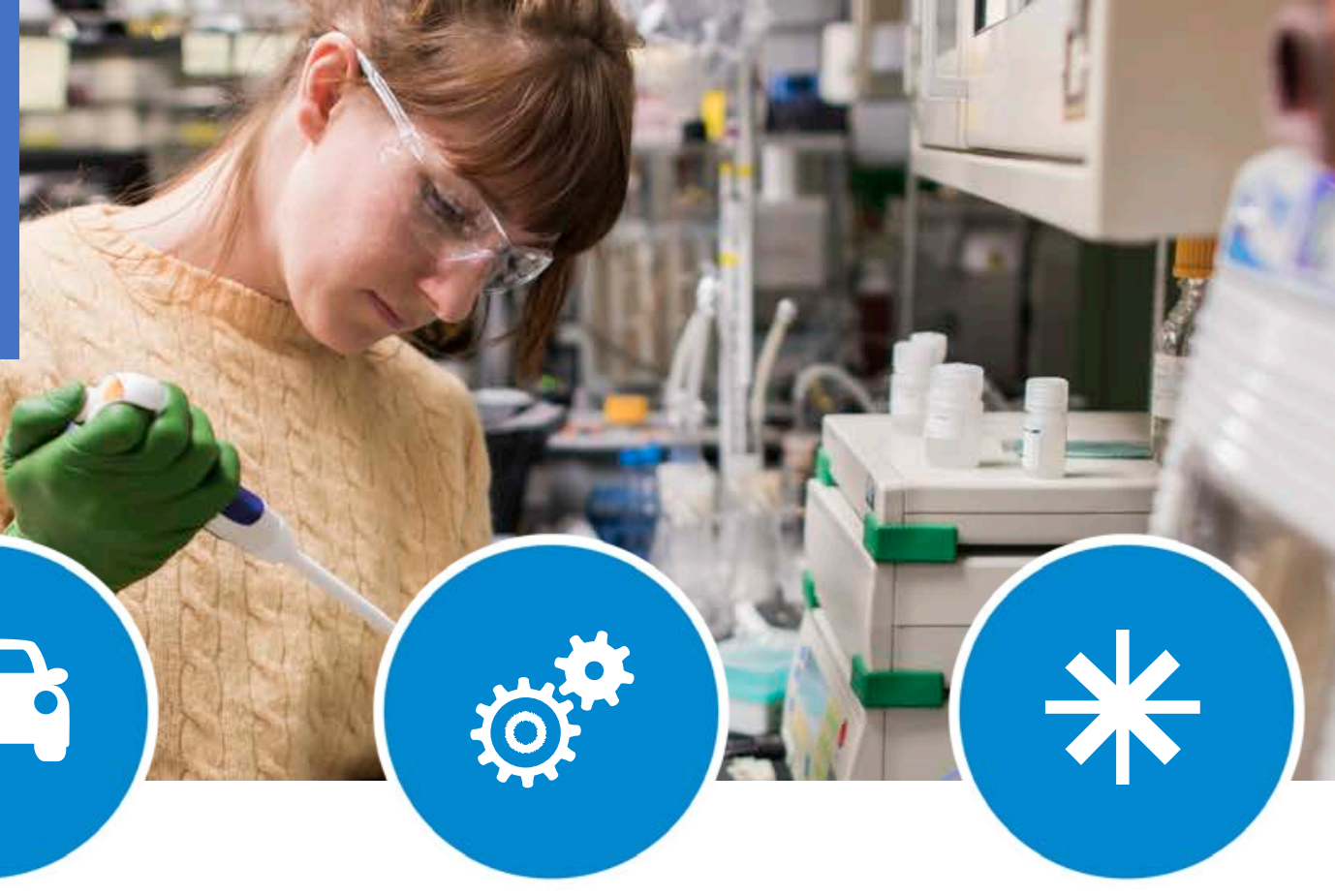

Renewable Power

Solar

Wind Water

Geothermal
Sustainable Transportation

Bioenergy

Vehicle Technologies

Hydrogen

\section{Energy} Efficiency

Buildings

Advanced Manufacturing

Government Energy Management
Energy Systems Integration

Grid Integration

Hybrid Systems 
NREL Quick Facts

- 2,685 Employees, Postdoctoral Researchers, Interns, Visiting Professionals, and Subcontractors

- Patents Issued for NREL Technologies to Date 571

- More than 1,700 Scientific and Technical Materials Published Annually

- 3 National Centers

- 16 Research Programs

- 871 Active Partnerships with Industry, Universities, Foundations, and Governments

- More than 70 Countries Represented by Staff

- 65 R\&D 100 Awards 


\section{NREL's Flatirons Campus}

- The National Wind Technology Center (NWTC) at the Flatirons Campus was established in 1977 and is an ideal setting for evaluating the reliability and performance of wind turbines. Approximately 150 staff work on-site in Wind and Marine Hydrokinetic technology.

- Key land-based and offshore wind research facilities:

Structural research

$>$ Dynamometer research

$>$ Controllable Grid Interface (CGI)

$>$ Energy storage
$>$ Field validation sites

> Composites Manufacturing Education and Technology (CoMET)

High-Performance Computing (HPC)

Integrated energy systems at scale

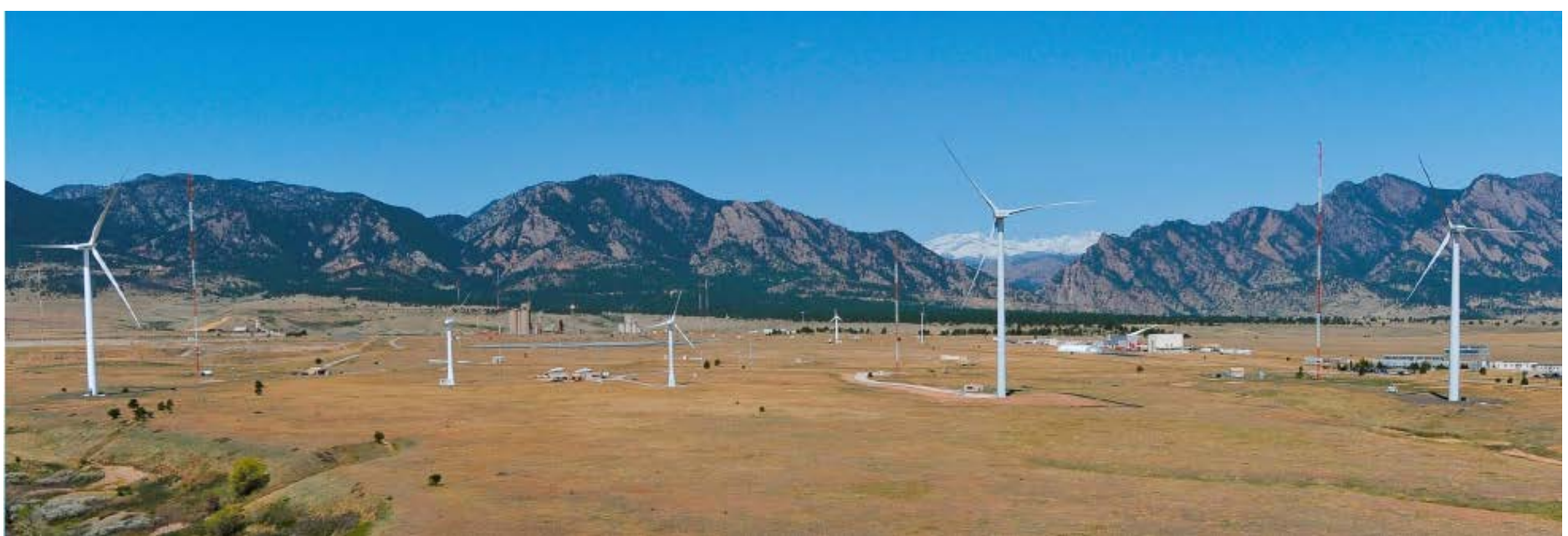




\section{Workshop Agenda-Page 1}

\begin{tabular}{|c|c|c|}
\hline Time & Activity & Speaker \\
\hline & Day 1 - Plenary Session; Feb 11, 2020 & \\
\hline $8: 00-8: 15 \mathrm{am}$ & Flatirons Campus arrival and Check-in & NREL's Flatirons Guard Gate \\
\hline $8: 15-8: 45 a m$ & Network/ Lite Breakfast & All \\
\hline $8: 45-9: 00 \mathrm{am}$ & Welcome, Meeting Objectives, and Introductions & $\begin{array}{l}\text { Walt Musial/NREL; Cheri Hunter/BSEE } \\
\text { Darryl Francois/BOEM }\end{array}$ \\
\hline $9: 00-9: 30 \mathrm{am}$ & $\begin{array}{l}\text { BSEE Perspective on U.S. Offshore Wind Electrical Safety } \\
\text { Issues }\end{array}$ & $\begin{array}{l}\text { Cheri Hunter and David Dederostek/Darryl Francois - } \\
\text { BSEE/BOEM - "Why are we here?" }\end{array}$ \\
\hline $9: 30-9: 45 \mathrm{am}$ & Overview of Offshore and OSW National Standards Initiative & Walt Musial - NREL \\
\hline $9: 45-10: 15 \mathrm{am}$ & U.S. Offshore Wind Recommended Practices Status - OCRP-1 & $\begin{array}{l}\text { Albert Fisas - GE - Offshore Compliance Recommended } \\
\text { Practices - Maintenance Team delegate - "Status of } \\
\text { OCRP-1" }\end{array}$ \\
\hline $10: 15-10: 30 \mathrm{am}$ & Break & All \\
\hline $10: 30-12: 00$ noon & $\begin{array}{l}\text { Session 1: Participant Presentations on Wind Plant Electrical } \\
\text { Safety and Discussion }\end{array}$ & Chair: Ed DeMeo - NREL Consultant (Workshop Chair) \\
\hline $12: 00-1: 00 \mathrm{pm}$ & Lunch (brought in) & All \\
\hline $1: 00-2: 30 \mathrm{pm}$ & $\begin{array}{l}\text { Session 2: Participant Presentations on Electrical Safety for } \\
\text { Offshore Substations and Discussion }\end{array}$ & Chair: Ed DeMeo - Workshop Chair \\
\hline $2: 30-2: 45 \mathrm{pm}$ & Break & All \\
\hline $2: 45-3: 45 \mathrm{pm}$ & $\begin{array}{l}\text { Session 3: Participant Presentations on Electrical Safety for } \\
\text { Offshore Subsea Cables and Discussion }\end{array}$ & Chair: Ed DeMeo \\
\hline
\end{tabular}




\section{Workshop Agenda-Page 2}

\begin{tabular}{|c|c|c|}
\hline $3: 45-4: 00 \mathrm{pm}$ & Break & All \\
\hline $4: 00-5: 00 \mathrm{pm}$ & $\begin{array}{l}\text { Introduce Breakout Groups } \\
\text { 1) Turbines } \\
\text { 2) Substations } \\
\text { 3) Subsea Cables }\end{array}$ & $\begin{array}{l}\text { Facilitation: Ed DeMeo -Breakout Groups will briefly } \\
\text { assemble and work out reporting, facilitation, and } \\
\text { protocols. Create a list of key issues to be discussed on } \\
\text { Day } 2 \text {. }\end{array}$ \\
\hline $5: 00 \mathrm{pm}$ & Adjourn for the day & All \\
\hline \multirow[t]{2}{*}{$6: 30 \mathrm{pm}$} & No Host Dinner (TBD) & Sign-up at registration \\
\hline & Day 2 - Breakout Sessions February 12, 2020 & \\
\hline $8: 00-8: 15 \mathrm{am}$ & Flatirons Campus arrival and Check-in & Guard gate \\
\hline $8: 15-8: 45 a m$ & Network/ Lite Breakfast & All \\
\hline $8: 45-9: 00$ & $\begin{array}{l}\text { Review Plenary Breakout Group Objectives and Report-out } \\
\text { Guidance }\end{array}$ & Ed DeMeo - NREL Consultant \\
\hline $9: 00-9: 15$ & Break and Assemble into Breakout Sessions & All \\
\hline $9: 15-12$ noon & $\begin{array}{l}\text { (Three) Facilitated Break-out sessions meet concurrently 1) } \\
\text { Turbines; 2) Substations; 3) Subsea Cables } \\
\text { Breakout facilitators will prescribe their own coffee breaks when } \\
\text { convenient. Chapter leads are assigned to each breakout group }\end{array}$ & $\begin{array}{l}\text { Breakout Organizers: Facilitator/Chapter Lead } \\
\text { Turbines: Ed DeMeo/Michelle Fogarty } \\
\text { Substations: Brandon Burke/Emily Chambers } \\
\text { Subsea Cables: Chloe Constant/Aubryn Cooperman }\end{array}$ \\
\hline 12 noon $-1: 00 \mathrm{pm}$ & Lunch (brought in) & All \\
\hline $1: 00-2: 30 \mathrm{pm}$ & Breakout groups Report-out (30 min each with Q\&A) & Breakout Facilitators \\
\hline $2: 30-3: 00 \mathrm{pm}$ & Wrap-up - steps forward, assignments & Ed DeMeo - NREL Consultant \\
\hline $3: 00 \mathrm{pm}$ & Adjourn & \\
\hline
\end{tabular}




\title{
Offshore Wind Electrical Safety Standards Workshop Roles
}

\author{
Plenary Session \\ Facilitator: Ed DeMeo \\ Chapter Leads: Brandon Burke and Emily Chambers
}

Turbine Breakout

Facilitator: Ed DeMeo

Chapter Lead: Michelle Fogarty

Medium/small conference room
Substations Breakout

Facilitator: Brandon Burke

Chapter Lead: Emily Chambers

Large conference room
Submarine Cables Breakout

Facilitator: Chloe Constant

Chapter Lead: Aubryn Cooperman

East Conference Room

\section{Logistics: Cyndi Edgley}

- Food and refreshments

- Site access

- Communication

- Badges and registration

- Social event planning

- Project meetings
Report: Walt/Ed (overall)

- Outline (Walt)

- Compile/post presentations

- Key findings

- Chapters - chapter leads

- Editing and oversight
Contracting: Tiffany

- Business Network for Offshore Wind (BNOW)

- BOEM/BSEE

- Reporting

- Ed DeMeo 


\section{Workshop Organizing Team}

- Walt Musial-Principal Investigator and host

- Ed DeMeo-Workshop lead moderator

- Brandon Burke-BNOW

- Emily Chambers-BNOW

- Michele Fogarty-NREL

- Chloe Constant-NREL

- Aubryn Cooperman-NREL

- Cyndi Edgley-NREL

- Rebecca Green-NREL 


\section{Workshop Sponsors-BSEE and BOEM}

- Cheri Hunter-BSEE

- David Nederostek-BSEE

- Darryl Francois-BOEM 


\section{Why We Are Here}

David Nedorostek, BSEE Senior Electrical Engineer

Cheri Hunter, BSEE Renewable Energy Program Coordinator

Darryl Francois, BOEM Office of Renewable Energy Programs

Offshore Wind Electrical Safety Standards Harmonization Workshop

Tuesday, Feb 11-12, 2020 at the Flatirons Campus,

National Renewable Energy Laboratory

National Wind Technology Center 


\section{Contents}

1 Workplace Safety

2 OCS Renewable Energy Authorization Process

3 Industry Plan Review

4 Comparison of Electrical Safety Standards

5 Next Step: Peer Review 


\section{Workplace Safety}

- The Department of the Interior (DOI) is the principal federal agency for the regulation and enforcement of safety and health requirements for outer continental shelf (OCS) renewable energy

- Offshore wind traditionally uses international standards

- BSEE/BOEM have due diligence requirement to ensure the safest standards are used

- Public expectation is a robust comparison to U.S. standards with a focus on safety 


\section{OCS Renewable Energy Authorization Process}

Planning \& Analysis

2 Years

- Intergovernmental task force

- $\quad$ Call for information \& nominations (Call)

- Area identification

- Environmental reviews
1-2 Years

- Auction

- Issue leases

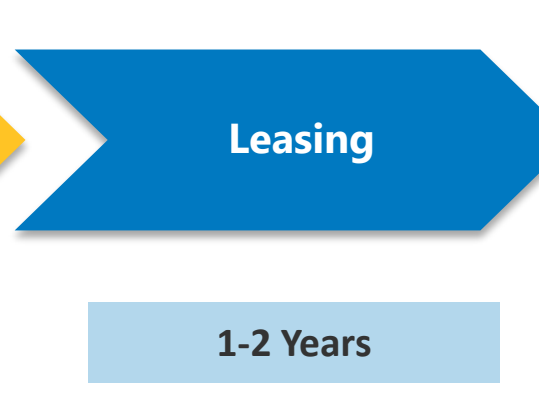

- Proposed sale notice

- Final sale notice

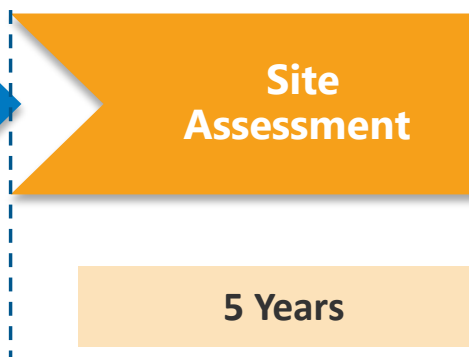

- $\quad$ Site characterization (i.e., geophysical and geological surveys, biological surveys, and so on)

- Site assessment plan

\section{Construction} 8 Operations

2 Years (+25)

- Construction \& operations plan

- $\quad$ Facility design report

- Fabrication and installation report

- Decommissioning 


\section{Industry Plan Review}

- BSEE partners with BOEM to review industry submissions (construction and operations plans, facility design reports, fabrication and installation reports)

- U.S. offshore electrical wind industry standards are under development

- BSEE created a comparison of U.S. versus international electrical safety standards to assist BSEE/BOEM engineers in performing a comprehensive assessment of a project's electrical design 


\section{Comparison of Electrical Safety Standards}

- The list of standards is a starting point for establishing U.S.-specific expectations for offshore wind electrical safety

- The list of standards will continue to evolve as BSEE/BOEM and industry identify best practices

- Purpose:

- Highlight available standards

- United States

- European

- Canadian

- harmonized

- (incorporating international and U.S-specific requirements) 


\section{Comparison of Electrical Safety Standards}

- Includes a list of electrical equipment subdivided into three categories:

- Design (lightning protection, switchgear, transformer)

- Procedures (personal protective equipment [PPE], lockout/tag-out [LO/TO], equipment guarding ) and

- Reliability design (marine cable, uninterruptable power supply (UPS)

The list focuses on what BSEE/BOEM have initially identified to be the most safety-critical electrical equipment and procedures. 


\section{Standards}

- Table review:

- Does the list of standards focus on most safety-critical electrical equipment?

- Is critical electrical equipment categorized properly?

- Are all the applicable electrical safety standards for each electrical component captured?

- Should certification be done by a Nationally Recognized Testing Laboratory for functionality and performance? 


\section{Comparison of Electrical Safety Standards}

\section{Why We Are Here}

Next step: Peer review

- International and U.S. electrical standards experts

- Members of Offshore Wind Technical Advisory Committee (U.S. industry consensus-based, ANSI-approved, recommended practice document) 


\section{U.S. Offshore Wind Standards Initiative}

Walt Musial

Principal Engineer, NREL

Chairman, AWEA Offshore Wind Subcommittee

Offshore Wind Electrical Safety Standards Harmonization Workshop

Tuesday, Feb 11-12, 2020 at the Flatirons Campus,

National Renewable Energy Laboratory

National Wind Technology Center 


\section{Organizers and Sponsors}

Walt Musial
Liz Burdock
Elizabeth Barminski




\section{BOEM/BSEE Authority to Regulate Offshore Wind}

$>$ The Energy Policy Act of $\mathbf{2 0 0 5}$ authorized BOEM to grant leases on the Outer Continental Shelf for offshore renewables and to promulgate any necessary regulations

$>30$ CFR 585 rule was issued in 2009, covering the offshore wind facility development process cradle to grave; does not specify standards and requires best practices to be used

> From 2009-2012, the industry developed AWEA OCRP 2012, a consensus-based roadmap to facilitate "best industry practices"

$>$ U.S. consensus standards and guidelines can be:

$>$ Adopted by developers to guide project design and approval

$>$ Referenced by BOEM in 30 CFR 585

$>$ Explicitly quoted in regulations 


\section{Project Objective}

To develop a comprehensive set of consensus-based roadmaps to navigate the existing standards and guidelines to:

- Facilitate safe designs and orderly deployment of U.S. offshore wind energy

- Account for the unique offshore conditions on the U.S. Outer Continental Shelf and state waterways

- Provide DOI with recommended practices of industry best practices with procedural protections provided by ANSI process 


\section{Why Do We Need U.S. Standards Roadmaps?}

- Enable a more efficient regulatory process

- Provide more confidence in design approvals by regulators

- Increase clarity in the regulatory requirements for developers and certified verification agents

- Create more transparency for the public

- Increase worker safety throughout the life of project

- Lower project cost 
AWEA Offshore Compliance Recommended Practice (OCRP) 2012

\section{Current Best Practices}

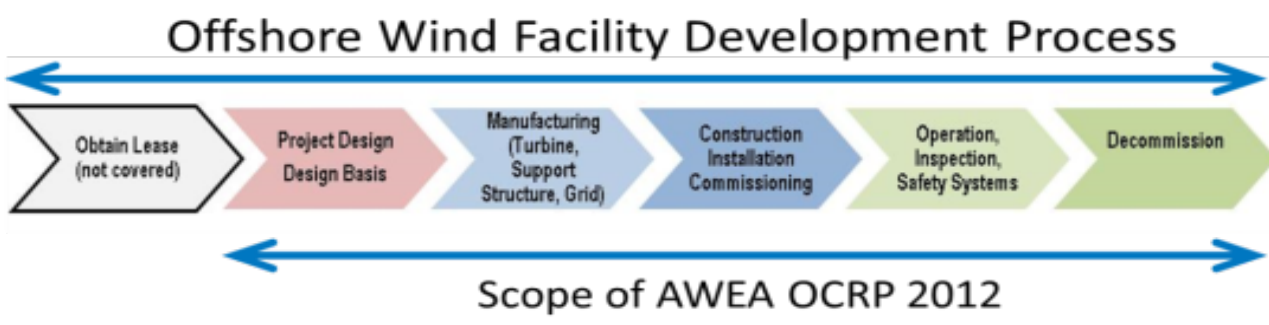

D AWEA OCRP 2012 is structured to mirror BOEM 30 CFR 585 "cradle to grave"

$>$ Dozens of standards and guidelines from various industries and certifying bodies are cited and mapped to development process

$>50+$ stakeholders/subject matter experts participated between 2009 and 2012

D AWEA OCRP published in October 2012 as a Recommended Practice

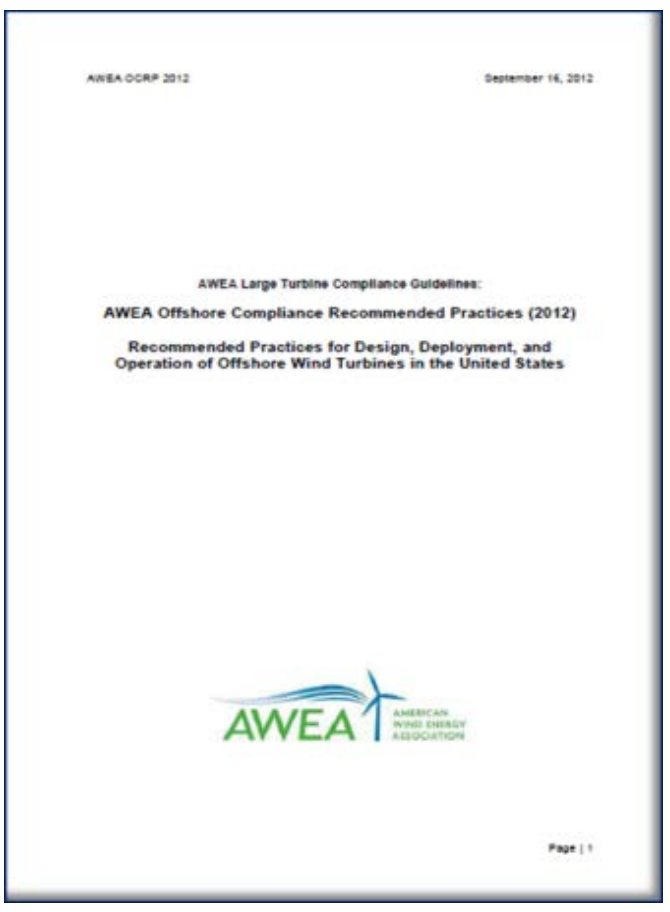




\section{Working Groups and Conveners}

(WG1) AWEA Offshore Compliance Recommended Practices (OCRP) Maintenance Working Group OCRP1

(WG2) AWEA U.S. Floating Offshore Wind
Systems Working Group OCRP2
Systems Working Group OCRP2

\begin{tabular}{l} 
(WG3) AWEA U.S. Offshore Wind \\
Metocean Conditions Characterization \\
Working Group OCRP3 \\
\hline \\
(WG4) AWEA U.S. Geotechnical and \\
Geophysical Investigations and Design \\
Working Group OCRP4 \\
\hline \\
(WG5) AWEA Offshore Wind Submarine \\
Cables Working Group OCRP5
\end{tabular}

Rain Byars - Shell Renewables

Graham Cranston-SG\&H Consultants

Lars Samuelsson-ABS

Leif Delp-Equinor

Michael Drunsic-WSP

Lorry Wagner

\section{Matt Palmer-WSP}

Mathieu Guinard-Atkins

Georg Engelmann-Excipio Energy Bob Hobson-NKT HV Cables AB 


\section{U.S Offshore Wind Standards Initiative Organizational Structure}

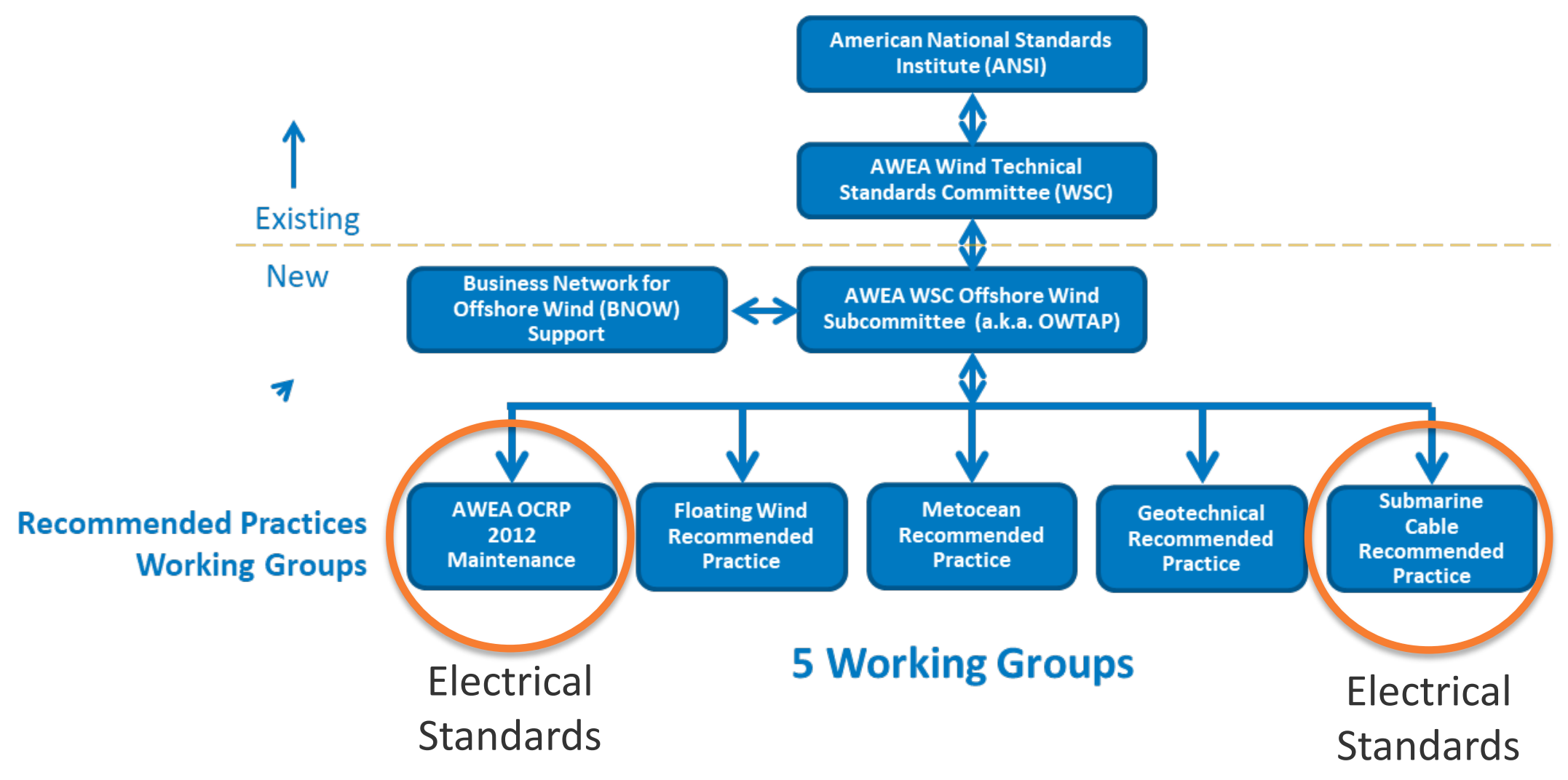




\section{Major Steps in Developing the Recommended Practices}

- Develop outline for recommended practice document

- Write first draft of recommended practice document

- Internal review of first draft (90 days)

- Internal working group draft

- Final draft submitted for OWTAP and working groups

- OWTAP review comment period (60 days)

- Resolve OWTAP comments

- Final committee draft

- Final draft submitted for approval by WTSC

- 30-day ballot period

- Working Group resolves comments

- AWEA staff submit BSR-8 to ANSI

- Public comment is open for 45 days

- Review and resolve public comments

- (Optional appeal process)

- AWEA staff submit BSR-9 to ANSI

- ANSI approval process and publication

External Working Group: About 12 months

Process to finalize guidelines under AWEA/ANSI process may take too long. 


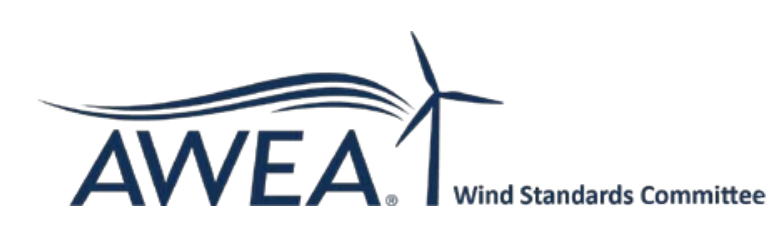

\section{Electrical Content in Draft Offshore Compliance} Recommended Practices (OCRP) 2nd Edition

Albert Fisas, GE Renewable Energy

Member OWTAP \&

OCRP Working Group

February 10, 2020

Boulder, $\mathrm{CO}$ 


\section{Overview of OCRP WG1 Effort}

The Working Group

- Offshore Wind Technical Standards Committee formed in Oct 2017 under AWEA Wind Standards Committee, Chaired by Walt Musial

- Working Groups kicked off April 2018

- All volunteer, wide industry representation

- Working Group 1 - OCRP second edition

\section{The OCRP}

- Serves as a Roadmap for application of international and US requirements to Offshore Wind in U.S. waters

- Addresses gaps, overlaps, and conflicts

- Does not intend to create new requirements

- Committee Draft on track for mid-2020

- Will be published as an American National Standard through AWEA/ ANSI

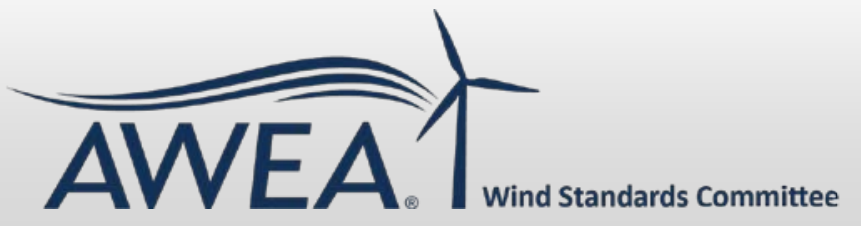




\section{Electrical Author Team}

- Electrical standards identified as one of the gaps in 2012 OCRP

- Electrical sections in $2^{\text {nd }}$ edition draft are written by a 28 member author team made up of volunteers from across the industry

- Regulators

- Developers

- OEMs

- CVAs
- Consultants

- Contractors

- Supply Chain

- Academics

- Author team has conducted monthly or bi-weekly web-meetings and bi-annual face to face meeting throughout 2018 and 2019 to reach consensus on structure, topics, content, and reference standards.

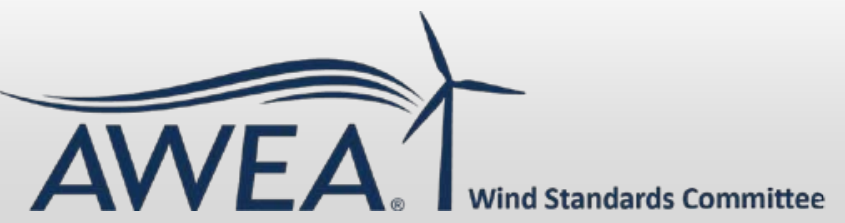




\section{Electrical Content in Draft OCRP ed. 2}

- General Sections

(introductory content, design basis, standards hierarchy, terms and definitions, references)

- Chapter 5 - Design

- 5.6 Design of Offshore Wind Turbine

- 5.6.4 Electrical Design

- 5.6.5 Design for Occupational Health and Safety

- 5.7 Design of Offshore Substation

- 5.7.4 Electrical Design

- 5.7.5 Design for Occupational Health and Safety

Note: Sub-sea cables are addressed in RP being developed by WG5 


\section{Standards referenced}

See Chapter 11 of Draft OCRP

Electrical Standards Include

- US Electrical Standards (NFPA, ANSI, IEEE, NEMA, UL, others)

- International Standards (IEC, ISO, CIGRE )

- US Offshore O\&G Electrical Standards (API) 


\section{Mapping - Workshop Topics/ Draft OCRP}

Workshop Topic

A. Safety Design

A-1 Arc Flash

A-2 Emergency Stop

A-3 Spaces Around Cabinets

A-6, A-7 Switchgear

A-9 Transformers

A-11 Lightning Protection

A-13 WTG Electrical Systems
OCRP Chapter

5.6.4.7 and 5.7.4.7

5.6 .4 .9

5.6.4.6 and 5.7.4.6

5.7 .9 .4

5.6.4.8 and 5.7.4.8

5.6.4.10 and 5.7.4.10

5.6.4.1 


\section{Mapping - Workshop Topics/ Draft OCRP}

Workshop Topic

B. Safety Procedures

B-3 Lock-Out Tag-Out

B-4 Equipment Guarding

C. Reliability Design

C-1 Safety Acceptance Testing

C-17 Wind Turbine Elevators

C-18 Hoist/ Winch/ Cranes

C-21 Emergency Power

C-22 Sockets and Plugs

C-25 Cathodic Protection

C-26 Grounding and Bonding $\underline{\text { OCRP Chapter }}$

5.6.5.6 and 5.7.5.5

5.6.4.5 and 5.7.4.5

5.6.4.3 and 5.7.4.3

5.6.5.4

5.6.5.5 and 5.7.5.4

5.6.4.13 and 5.7.4.13

5.6.4.11 and 5.7.4.11

5.6.3.4.2 and 5.6.3.4.3

5.6.4.10 and 5.7.4.10 


\section{Recommendations}

- Use recommended practices and reference standards from draft OCRP Ed 2

- Understand context of electrical sections within larger recommended practice (introductory sections, design basis approach, interfaces, different types of design oversight, acceptance testing, etc.) 


\section{Appendix D. Standards Comparison Table}

Over the past several years, the Bureau of Safety and Environmental Enforcement (BSEE) has been actively preparing for growth in applications for offshore wind power plants planned for the U.S. Outer Continental Shelf. To this end, BSEE technical staff have been compiling electrical safety standards to apply to domestic offshore installations. Recognizing that most existing offshore wind power plants have been built in Europe and certified to European standards, BSEE is examining similarities and differences among corresponding U.S. and European standards.

A key step in that process was BSEE's assembly of a table listing relevant standards applicable to major components, processes, and procedures associated with offshore wind construction and operation. Table items were organized into three categories: safety design, safety procedures, and reliability design. For each item, European and U.S. standards were listed side by side. ${ }^{3}$ In early 2019, with the aim of improving the accuracy of the table contents, BSEE sought and received feedback from several wind turbine original equipment manufacturers. That process elicited a number of suggestions and proposed changes.

In late 2019, BSEE engaged NREL's organizing team for the workshop covered in this report to shape the draft table and its contents into a form likely to engender discussion and feedback from a larger group of offshore wind industry participants. For each item in the table, the team posed a number of questions, based on comments from BSEE and the previous original equipment manufacturer reviewers. The revised table was sent to all participants prior to the workshop to prompt relevant discussion during the event. Subsequent to the workshop, the table was revised to reflect input from the meeting's discussions. In addition, many of the questions were restored to their original format as comments.

The revised postworkshop table was then sent to the members of the turbine breakout group for additional feedback. The table was subsequently refined, based on additional input received. Finally, the table was reviewed by all participants as part of their review of the entire workshop report and revised once again to reflect additional input. For many of the table's entries, there is broad agreement. For others, there are differing views. In those cases, the organizers have attempted to include the range of views expressed.

Through the iterative process described earlier, the organizing team believes that this table provides relevant and accurate guidance to offshore wind power plant regulators as they consider applications for offshore wind projects in the interim period before definitive regulatory guidelines become available. It should be viewed as a work in progress that will evolve as the offshore wind industry and BSEE engage over the coming months. Although the way forward is clear in many cases, significant questions remain. For those cases open questions, the organizing team's hope is that this table provides information helpful to regulators as they apply their best judgment to resolve any open issues.

The standards table in its current form follows.

\footnotetext{
${ }^{3}$ In some cases, particular standards are listed in the table with double or even triple designations (e.g., International Electrotechnical Commission (IEC) 61400-25-2 and DS/EN 61400-25-2 or IEC 60204-1, EN/IEC 60204-1, and BS EN 60204-1). Users of this table should be aware that there may or may not be material differences between versions of standards with the same numbers. In most cases, the IEC version would be most applicable for U.S. installations.
} 
Table D-1. U.S. and International Offshore Wind Electrical Safety Standards Comparison Table

\begin{tabular}{|c|c|c|c|c|c|c|}
\hline \multicolumn{7}{|c|}{ A. Safety Design } \\
\hline Ref & Category & Relevance & $\begin{array}{l}\text { International } \\
\text { Electrotechnical } \\
\text { Commission (IEC) }\end{array}$ & $\begin{array}{c}\text { IEC and European Union (EU) } \\
\text { Directives }\end{array}$ & United States & Certification \\
\hline A-1 & $\begin{array}{c}\text { Arc Flash/Arc } \\
\text { Blast Analysis } \\
\text { Arc Flash Labeling }\end{array}$ & $\begin{array}{l}\text { Turbines } \\
\text { and } \\
\text { Substations }\end{array}$ & $\begin{array}{l}\text { IEC 61482-2 } \\
\text { IEC TR 61641 } \\
\text { IEC 62271-200 } \\
\text { IEC 60909-0 }\end{array}$ & $\begin{array}{l}\text { Occupational Safety and Health (OSH) } \\
\text { Framework Directive 89/391/EEC } \\
\text { European Norm (EN) 50110-1 }\end{array}$ & $\begin{array}{l}\text { Institute of Electrical and } \\
\text { Electronics Engineers } \\
\text { (IEEE) } 1584 \\
\text { National Fire Protection } \\
\text { Association (NFPA) 70E } \\
\text { Canadian Standards } \\
\text { Association (CSA) Z462 }\end{array}$ & \\
\hline
\end{tabular}

\section{A-1 Comments}

- All listed standards have similar requirements, but IEC and IEC and EU do not include arc flash labeling requirements. ${ }^{\mathrm{i}}$

- The labeling requirement is standard for U.S. land-based wind, but perhaps new to offshore vendors in other markets. For other markets, hazards are addressed in design and lockout/tagout (LO/TO) instructions, but application of an arc flash sticker is not standard. A suggested approach for resolving this difference follows: IEC standards will yield a level of safety similar to that with the U.S. standards. Hence, use of IEC standards should be acceptable to justify compliance, and then the arc flash sticker can be applied per IEEE 1584/NFPA 70E. However, if a sticker is used on IECtested and -rated equipment, the boundary statement and other critical details should correlate to the IEC-defined levels. Although either system could be acceptable for safety, the boundary or class definitions should not be mixed.

- The Bureau of Safety and Environmental Enforcement (BSEE) recommends that developers utilize NFPA 70E or IEEE approaches on arc flash labeling requirements.

- Industry views IEEE 1584 and NFPA 70E as the most appropriate standards for the U.S. market.

- Arc flash labeling requirements can be aligned through BSEE's Safety Management System.

- The above IEC standards could be followed for wind applications, with proper justification.

- CSA Z462 is essentially the same as, and harmonized with, NFPA 70E.

- On labeling, but not for arc flash, IEEE and NFPA require breaker panels to include panel schedule labeling. The corresponding IEC standards do not. 


\begin{tabular}{|c|c|c|c|c|c|c|}
\hline Ref & Category & Relevance & IEC & IEC and EU Directives & United States & Certification \\
\hline$A-2$ & $\begin{array}{l}\text { Emergency Stop - } \\
\text { Design }\end{array}$ & $\begin{array}{l}\text { Turbines } \\
\text { and } \\
\text { Substations }\end{array}$ & IEC 60204-1 & $\begin{array}{c}\text { DS/EN Independent System Operator } \\
\text { (ISO) 13850 } \\
\text { DS/EN 61400-25-2 } \\
\text { ISO 13850; ISO 13849-1 } \\
\text { DNVGL-ST-0438 } \\
\text { EN/IEC 60204-1 } \\
\text { British Standard (BS) EN 60204-1 }\end{array}$ & $\begin{array}{c}\text { NFPA } 79 \\
\text { CSA C22.2 No. } 301\end{array}$ & $\begin{array}{l}\text { Certification } \\
\text { should be carried } \\
\text { out in accordance } \\
\text { with the design } \\
\text { standards used } \\
\text { and employ } \\
\text { nationally } \\
\text { recognized } \\
\text { testing laboratory } \\
\text { (NRTL) approval if } \\
\text { called for in those } \\
\text { standards. }\end{array}$ \\
\hline \multicolumn{7}{|c|}{$\begin{array}{l}\text { A-2 Comments } \\
\text { - The following standards are acceptable: ISO 13850, IEC 60204-1 (aka EN 60204-1), NFPA 79, and CSA C22.2 No.301. } \\
\text { - Addition of ISO 13849-1 is recommended because it is also heavily used for the design of the overall emergency stop systems. } \\
\text { - A new Canadian standard was published in 2016: CSA C22.2 No. 301. This standard draws heavily on several standards for core material, including } \\
\text { IEC 60204-1 and NFPA 79. CSA C22.2 No. } 301 \text { uses identical definitions for stop-function categories. }\end{array}$} \\
\hline
\end{tabular}




\begin{tabular}{|c|c|c|c|c|c|c|}
\hline Ref & Category & Relevance & IEC & IEC and EU Directives & United States & Certification \\
\hline A-3 & $\begin{array}{l}\text { Spaces Around } \\
\text { Cabinets and } \\
\text { Compartments } \\
\text { and Equipment } \\
\text { - Low Voltage } \\
\text { - High Voltage } \\
\text { (Adequate } \\
\text { Workspace) }\end{array}$ & $\begin{array}{c}\text { Turbines } \\
\text { and } \\
\text { Substations }\end{array}$ & $\begin{array}{l}\text { Low Voltage } \\
\text { IEC } 60364-7-729 \\
\text { IEC } 61439 \\
\frac{\text { High Voltage }}{\text { IEC } 61482} \\
\text { IEC } 60298 \\
\text { IEC } 62271-200\end{array}$ & $\begin{array}{l}\text { Low Voltage } \\
\text { EN 50110-1 } \\
\text { EU Directive } \\
\text { 2014/35/EU } \\
\frac{\text { High Voltage }}{\text { EN 50110-1 }}\end{array}$ & $\begin{array}{c}\text { Low Voltage } \\
\text { NEC (NFPA 70) } \\
\text { Article } 110.26 \\
\text { Article 110.34 } \\
\text { NFPA 70B; NFPA 70E } \\
\text { OSHA 29 CFR 1910.269 } \\
\text { OSHA 29 CFR 1910.305 } \\
\text { OSHA 29 CFR 1926.403 } \\
\text { High Voltage } \\
\text { IEEE C2 (National } \\
\text { Electrical Safety Code } \\
\text { [NESC]) }\end{array}$ & $\begin{array}{l}\text { Certification } \\
\text { should be carried } \\
\text { out in accordance } \\
\text { with the design } \\
\text { standards used } \\
\text { and employ NRTL } \\
\text { approval if called } \\
\text { for in those } \\
\text { standards. }\end{array}$ \\
\hline \multicolumn{7}{|c|}{$\begin{array}{l}\text { A-3 Comments } \\
\text { - The terms "high voltage" and "low voltage" are subjective. Actual voltage ranges should be used instead. } \\
\text { - EU directive (low voltage) and EN 50110-1 (high voltage) are acceptable because of their close alignment with OSHA } 29 \text { CFR } 1910.269 . \\
\text { - However, the following comments offer an alternative view. } \\
\text { - For cabinets with exposed live voltages, the EU/EN standards will usually require space around electrical cabinets to be increased to comply with } \\
\text { OSHA and IEEE-NESC. } \\
\text { - Going forward, it should be recognized that the NFPA, OSHA, and IEEE guidance primarily refers to work on or near exposed live parts. Exposed live } \\
\text { parts are generally prohibited in much of the IEC guidance. } \\
\text { Requirements from IEC } 60364, \text { IEC } 60204-1, \text { IEC } 60204-11 \text {, and IEC } 61936-1 \text { include measures to protect from electric shock, such as isolation of } \\
\text { hazardous energy and the use of protective barriers. } \\
\text { Because the distances around electrical cabinets from IEC standards take shock hazard into consideration, BSEE should consider accepting these } \\
\text { distances if exposed live parts are not present when the cabinets are opened. }\end{array}$} \\
\hline
\end{tabular}




\begin{tabular}{|c|c|c|c|c|c|c|}
\hline Ref & Category & Relevance & IEC & IEC and EU Directives & United States & Certification \\
\hline$A-4$ & $\begin{array}{c}\text { Electrical Safety } \\
\text { Equipment } \\
\text { (Ground Fault } \\
\text { Circuit } \\
\text { Interrupter [GFCI] } \\
\text { - Residual } \\
\text { Current Device } \\
\text { [RCD]) }\end{array}$ & $\begin{array}{c}\text { Turbines } \\
\text { and } \\
\text { Substations }\end{array}$ & $\begin{array}{l}\text { IEC } 60364 \\
\text { IEC } 61439 \\
\text { IEC 60204-1 }\end{array}$ & & $\begin{array}{c}\text { NFPA 70E } \\
\text { Underwriters } \\
\text { Laboratories (UL) 943; } \\
\text { UL } 1053 \\
\text { OSHA: } 29 \text { CFR } \\
\text { 1926.404(b)(1)(ii) }\end{array}$ & \\
\hline \multicolumn{7}{|c|}{$\begin{array}{l}\text { A-4 Comments } \\
\text { - } \text { OSHA regulations and NFPA 70E are acceptable because of corrosive environments. } \\
\text { - } \quad \text { IEC-60204-1, which refers to IEC-60364-4-41, has been added per industry recommendation for protection against electrical shock. } \\
\text { - } 943 \text { has been added per industry recommendation. } \\
\text { - the 4-6 mA point of a GFCl, so they are not interchangeable. This distinction is addressed in the following comment. } \\
\text { BSEE could consider allowing RCDs and residual current circuit breakers with overcurrent protection [RCBO] devices designed to IEC standards (e.g., } \\
\text { IEC 60364-6), as long as trip time vs. fault current as defined in UL } 943 \text { is fulfilled. Note that, while RCDs and RCBOs may have higher fault current } \\
\text { ratings, they often have faster trip times than GFCls. } \\
\text { Based on the NFPA 70/UL } 943 \text { selector guide, Class C protection is sufficient when all relevant tools are double isolated and/or grounded. } \\
\text { Commonly used } 30 \mathrm{~mA} \mathrm{RCBOs} \mathrm{designed} \mathrm{toward} \mathrm{IEC} \mathrm{standards} \mathrm{can} \mathrm{fulfill} \mathrm{the} \mathrm{trip} \mathrm{time} \mathrm{vs.} \mathrm{fault} \mathrm{current} \mathrm{requirements} \mathrm{as} \mathrm{defined} \mathrm{for} \mathrm{Class} \mathrm{C.}\end{array}$} \\
\hline
\end{tabular}




\begin{tabular}{|c|c|c|c|c|c|c|}
\hline Ref & Category & Relevance & IEC & IEC and EU Directives & United States & Certification \\
\hline A-5 & $\begin{array}{c}\text { Adjustable Speed } \\
\text { Drives }\end{array}$ & Turbines & $\begin{array}{c}\text { IEC 61800-1 (DC) } \\
\text { IEC 61800-2 (AC) } \\
\text { IEC 61800-4 } \\
\text { IEC 61800-5-1 } \\
\text { IEC 62477-1 }\end{array}$ & $\begin{array}{c}\text { BS EN 61800-1 (DC) } \\
\text { BS EN 61800-2 (AC) } \\
\text { BS EN 61800-3 (test methods) } \\
\text { BS EN 61800-4 } \\
\text { BS EN 61800-5-1 } \\
\text { BS EN 61800-5-2 } \\
\text { BS EN 61800-9-1 } \\
\text { Danish Standard (DS)/Cenelec } \\
\text { Technical Report (CLC/TR) 61800-6 }\end{array}$ & $\begin{array}{l}\text { UL 1741; UL 61800 } \\
\text { UL 61800-5-1 } \\
\text { UL 61800-5-2 } \\
\text { UL 62109 } \\
\text { National Electrical } \\
\text { Manufacturers } \\
\text { Association (NEMA) } \\
\text { Industrial Control and } \\
\text { Systems (ICS) 61800-1 } \\
\text { (DC) } \\
\text { NEMA ICS 61800-2 (AC) } \\
\text { NEMA ICS 61800-4 (AC) } \\
\text { CSA-C22.2 No. } 274 \\
\text { IEEE 1566 }\end{array}$ & $\begin{array}{l}\text { Certification } \\
\text { should be carried } \\
\text { out in accordance } \\
\text { with the design } \\
\text { standards used } \\
\text { and employ NRTL } \\
\text { approval if called } \\
\text { for in those } \\
\text { standards. }\end{array}$ \\
\hline A-5C & $\begin{array}{l}\text { mments } \\
\text { Acceptable standa } \\
\text { IEC } 61800-5-1 \text { and } \\
\text { more stringent in } \\
\text { Regarding certifica } \\
\text { standards, which c } \\
\text { UL } 508 \mathrm{C} \text { has been }\end{array}$ & $\begin{array}{l}\text { C } 62477-1 \text { c } \\
\text { ne areas. } \\
\text { n, frequenc } \\
\text { includes }\end{array}$ & $\begin{array}{l}\text { also be considered } \\
\text { ves used for motor } \\
\text { tandards. This is als } \\
\text { laced by UL } 61800\end{array}$ & $\begin{array}{l}1800 \text { series, and BS EN } 61800 \text { series. } \\
\text { cceptable standards, with suitable jus } \\
\text { d so on, are provided by the suppliers } \\
\text { case for the wind turbine main conv }\end{array}$ & $\begin{array}{l}\text { ation, even though BS sta } \\
\text { h certificates of compliar } \\
\text { rs. }\end{array}$ & $\begin{array}{l}\text { dards may be } \\
\text { with relevant }\end{array}$ \\
\hline
\end{tabular}




\begin{tabular}{|c|c|c|c|c|c|c|}
\hline Ref & Category & Relevance & IEC & IEC and EU Directives & United States & Certification \\
\hline A-6 & $\begin{array}{c}\text { Switchgear (High } \\
\text { Voltage) }\end{array}$ & $\begin{array}{c}\text { Turbines } \\
\text { and } \\
\text { Substations }\end{array}$ & $\begin{array}{l}\text { IEC } 62271 \text { Series } \\
\text { IEC 62271-1 } \\
\text { IEC 62271-100 } \\
\text { IEC 62271-102 } \\
\text { IEC 62271-103 } \\
\text { IEC 62271-106 } \\
\text { IEC 62271-200 } \\
\text { IEC 62271-203 } \\
\text { IEC 62271-205 } \\
\text { IEC TR 62271-307 } \\
\text { IEC TS 62271-210 }\end{array}$ & $\begin{array}{c}\text { BS 6867; BS EN 62271-104 } \\
\text { BS PD IEC/TR 62271-307 } \\
\text { German Institute for Standardization } \\
\text { (DIN) IEC/TR 62271-307 } \\
\text { DIN EN 62271-200 } \\
\text { DS/EN 62271-1; DS/EN 62271-100 } \\
\text { DS/EN 62271-106; DS/EN 62271-202 } \\
\text { DS/EN 62271-205 } \\
\text { DS/EN IEC 62271-102 } \\
\text { DS/IEC/IEEE 62271-37-013 } \\
\text { EN IEC 62271-205 } \\
\text { AS 62271.1; AS 62271.200 }\end{array}$ & $\begin{array}{c}\text { IEEE } 1547 \\
\text { IEEE C37 series } \\
\text { IEEE C37.100.1 } \\
\text { IEEE C37.20.2 } \\
\text { IEEE C37.301 } \\
\text { IEEE/IEC C37.60 } \\
\text { IEEE/IEC } 62271-37-013 \\
\text { IEEE/IEC } 62271-37-082\end{array}$ & $\begin{array}{l}\text { Certification } \\
\text { should be carried } \\
\text { out in accordance } \\
\text { with the design } \\
\text { standards used } \\
\text { and employ NRTL } \\
\text { approval if called } \\
\text { for in those } \\
\text { standards. }\end{array}$ \\
\hline . & $\begin{array}{l}\text { mments } \\
\text { Acceptable stand } \\
\text { IEC } 62271-203 \text {, ap } \\
\text { For }<52-\mathrm{kV} \text { produ } \\
\text { For }>52(72.5-\mathrm{kV}) \\
62271-200 \text { and/o } \\
\text { Regarding certific } \\
\text { standards by accr } \\
\text { recommend agair } \\
\text { regulations that } r \\
\text { for those standar } \\
\text { Applicable standa } \\
\text { States). For exam } \\
37.122 \text { (gas-insula }\end{array}$ & $\begin{array}{l}\text { licable for volt } \\
\text { ts, the switchg } \\
\text { roducts, the s } \\
\text { EC } 62271-203 \\
\text { ion, switchgea } \\
\text { dited laborato } \\
\text { t a requiremer } \\
\text { quire NRTL cer } \\
\text { may be accep } \\
\text { e, the followin } \\
\text { ed switchgear }\end{array}$ & $\begin{array}{l}\text { is designed and tes } \\
\text { chgear is designed } \\
\text { ems receive numer } \\
\text { For example, PEHL } \\
\text { or repeated testing } \\
\text { ation, then an NRTL } \\
\text { le. } \\
\text { switchgear with a } \\
\text { Sandards are applic }\end{array}$ & $\begin{array}{l}\text { are harmonized standards. } \\
\text { J), has been added per industry recomn } \\
\text { according to IEC } 62271-200 \text {. } \\
\text { tested according to IEC } 62271-203 \text {, with } \\
\text { type tests during their development. Sv } \\
\text { rovides type-testing services toward bo } \\
\text { in NRTL. However, others recommend t } \\
\text { ould be used to certify. If using IEC stan } \\
\text { uit breaker design (European) and not ir } \\
\text { having a circuit breaker design: IEEE St }\end{array}$ & $\begin{array}{l}\text { dation. } \\
\text { he internal arc classificatic } \\
\text { chgear are type tested to } \\
\text { IEC and IEEE standards. S } \\
\text { following approach: if us } \\
\text { ds, then tests with altern } \\
\text { rrupter design (mainly us } \\
37.100 \text { (Common), 37.04, }\end{array}$ & $\begin{array}{l}\text { according to IEC } \\
\text { ard IEC and IEEE } \\
\text { me participants } \\
\text { g U.S. codes and } \\
\text { tive accredited labs } \\
\text { din the United } \\
6 / 09 / 10 \text { (CB), }\end{array}$ \\
\hline
\end{tabular}




\begin{tabular}{|c|c|c|c|c|c|c|}
\hline Ref & Category & Relevance & IEC & IEC and EU Directives & United States & Certification \\
\hline A-7 & $\begin{array}{c}\text { Switchgear } \\
\text { (Medium } \\
\text { Voltage) }\end{array}$ & Substations & & & $\begin{array}{c}\text { IEEE C37.010 } \\
\text { IEEE C37.04 } \\
\text { IEEE C37.06 } \\
\text { IEEE C37.09 } \\
\text { IEEE C37.13 } \\
\text { IEEE C37.20.2 } \\
\text { IEEE C37.20.6 } \\
\text { IEEE C37.24 } \\
\text { American National } \\
\text { Standards Institute } \\
\text { (ANSI)/NEMA C37.54 } \\
\text { ANSI/NEMA C37.55 } \\
\text { NEMA SG 10 } \\
\text { National Electrical } \\
\text { Contractors Association } \\
\text { (NECA) National } \\
\text { Electrical Installation } \\
\text { Standards (NEIS) 430 } \\
\text { CSA-C22.2 No. } 31\end{array}$ & $\begin{array}{l}\text { Certification } \\
\text { should be carried } \\
\text { out in accordance } \\
\text { with the design } \\
\text { standards used } \\
\text { and employ NRTL } \\
\text { approval if called } \\
\text { for in those } \\
\text { standards. }\end{array}$ \\
\hline \multicolumn{7}{|c|}{$\begin{array}{l}\text { A-7 Comments } \\
\text { - IEEE harmonized standards are acceptable for addressing both medium- and high-voltage switchgear. } \\
\text { - Industry recommends that BSEE includes IEC standards for switchgear among acceptable standards. } \\
\text { Regarding certification, switchgear items receive numerous type tests during their development. Switchgear are type tested toward IEC and IEEE } \\
\text { standards by accredited laboratories. For example, PEHLA provides type-testing services toward both IEC and IEEE standards. Some participants } \\
\text { recommend against a requirement for repeated testing by an NRTL. However, others recommend the following approach: if using U.S. codes and } \\
\text { regulations that require NRTL certification, then an NRTL should be used to certify. If using IEC standards, then tests with alternative accredited labs } \\
\text { for those standards may be acceptable. }\end{array}$} \\
\hline
\end{tabular}




\begin{tabular}{|c|c|c|c|c|c|c|}
\hline Ref & Category & Relevance & IEC & IEC and EU Directives & United States & Certification \\
\hline A-8 & $\begin{array}{l}\text { Switchgear } \\
\text { (Low Voltage) }\end{array}$ & Substations & $\begin{array}{l}\text { IEC 60947-1\&2\&3 } \\
\text { IEC 60947-4-1 } \\
\text { IEC 60947-4-2 } \\
\text { IEC 60947-5-1 } \\
\text { IEC 60947-5-2 } \\
\text { IEC 60947-7-1 } \\
\text { IEC 60947-7-2 } \\
\text { IEC 60947-7-3 } \\
\text { IEC 60947-7-4 } \\
\text { IEC 61439-1 } \\
\text { IEC 61439-2 } \\
\text { IEC 61439-3 } \\
\text { IEC 61439-4 } \\
\text { IEC 60204-1 } \\
\text { IEC 60364-5-53 } \\
\text { IEC TR 61912-1 }\end{array}$ & $\begin{array}{c}\underline{\text { BS }} \\
\text { BS 6423 } \\
\text { BS EN 60947-4-1 } \\
\text { DS } \\
\text { DS/EN 61439-1 } \\
\text { DS/EN 61439-2 }\end{array}$ & $\begin{array}{c}\text { UL 60947-1 } \\
\text { UL 60947-4-1 } \\
\text { UL 60947-4-2 } \\
\text { UL 60947-5-1 } \\
\text { UL 60947-5-2 } \\
\text { UL 60947-7-1 } \\
\text { UL 60947-7-2 } \\
\text { UL 60947-7-3 } \\
\text { UL 60947-7-4 } \\
\text { (above items } \\
\text { harmonized with IEC } \\
\text { 60947 series) } \\
\text { IEEE C37 series } \\
\text { IEEE C37.20.1 } \\
\text { CSA-C22.2No.60947-4-1 } \\
\text { Low-Voltage } \\
\text { Switchboards } \\
\text { IEEE C37 series } \\
\text { NECA NEIS } 400 \\
\text { UL 891 }\end{array}$ & $\begin{array}{l}\text { Certification } \\
\text { should be carried } \\
\text { out in accordance } \\
\text { with the design } \\
\text { standards used } \\
\text { and employ NRTL } \\
\text { approval if called } \\
\text { for in those } \\
\text { standards. }\end{array}$ \\
\hline \multicolumn{7}{|r|}{$\begin{array}{l}\text { nmend against a } \\
\text { ations that require } \\
\text { hose standards }\end{array}$} \\
\hline
\end{tabular}




\begin{tabular}{|c|c|c|c|c|c|c|}
\hline Ref & Category & Relevance & IEC & IEC and EU Directives & United States & Certification \\
\hline A-9 & Transformers & $\begin{array}{c}\text { Turbines } \\
\text { and } \\
\text { Substations }\end{array}$ & $\begin{array}{l}\text { IEC } 60076 \text { series } \\
\text { IEC } 60076-1 \\
\text { IEC } 60076-11 \\
\text { IEC } 60076-13 \\
\text { IEC } 60076-3 \\
\text { IEC } 60076-5 \\
\text { IEC } 60076-8 \\
\text { IEC } 60076-16 \\
\text { IEC } 61936-1\end{array}$ & $\begin{array}{c}\text { EN 60076-16 } \\
\text { EN 61558-1 } \\
\text { EN 61558-2-16 } \\
\text { EN 61558-2-4 } \\
\text { EN 61558-2-6 } \\
\text { BS EN 60076-11 } \\
\text { BS EN 60076-16 } \\
\text { BS PD IEC TS 60076-20 } \\
\text { DS/EN 60076-16 } \\
\text { Austrian Standard (OVE/ONORM) } \\
\text { EN 60076-16 }\end{array}$ & $\begin{array}{l}29 \text { CFR part } 1910 \text { subpart S } \\
\text { Electrical section } 305 \text { (j) (5); } \\
\text { National Electric Code (NEC) } \\
\text { sections } 450.21 \text { through } \\
450.27 \text { and } 450 \text { Part III; } \\
\text { NESC Rule } 152 \text { Location and } \\
\text { arrangement of power } \\
\text { transformers and regulators, } \\
\text { and Rule } 124 \text { Guarding live } \\
\text { parts } \\
\text { UL } 1562 \\
\text { UL } 1561 \quad \text { IEEE/ANSI C57 Series } \\
\text { IEEE/IEC } 60076-16 \\
\text { IEEE } 4 \quad \text { IEEE } 259 \\
\text { IEEE } 1276 \quad \text { IEEE } 1538 \\
\text { IEEE C2 (NESC) } \\
\text { Low Voltage } \\
\text { UL 5085-1 UL } 5085-2 \\
\text { UL 5085-3 } \\
\text { CAN/CSA-C802.1 } \\
\text { CSA-C22.2 No. } 66.1 \& .2 \& .3\end{array}$ & $\begin{array}{l}\text { Certification } \\
\text { should be } \\
\text { carried out in } \\
\text { accordance with } \\
\text { the design } \\
\text { standards used } \\
\text { and employ } \\
\text { NRTL approval if } \\
\text { called for in } \\
\text { those standards. }\end{array}$ \\
\hline
\end{tabular}

\section{A-9 Comments}

- Acceptable standards include IEEE/IEC 60076 and/or BS EN 60076 harmonized standard.

- Note that when installed inside the tower or nacelle, a dry transformer or a transformer with nonflammable liquid should be used. There is also industry support for a "less-flammable" liquid rather than a "non-flammable" liquid. Liquids having a fire point higher than $300 \mathrm{C}$ meet the requirements for "less-flammable" liquid, as defined in NEC 450.23. This is equivalent to Class K liquid according to IEC 61039. Adequate justification would also be needed.

- IEC 61936-1, applicable for overall installation of transformers, has been added per industry recommendation.

- IEC 60076-16, because it is specific to wind turbines, has been added per industry recommendation.

- Regarding certification, type testing is often carried out on the transformer by IEC-accredited laboratories. Some participants recommend against a requirement for repeated evaluation and testing by an NRTL. However, others recommend the following approach: if using U.S. codes and regulations that require NRTL certification, then an NRTL should be used to certify. If using IEC standards, then tests with alternative accredited labs for those standards may be acceptable.

- Additional U.S. codes and regulations for transformer installation and protection have been added to the table. 


\begin{tabular}{|c|c|c|c|c|c|c|}
\hline Ref & Category & Relevance & IEC & IEC and EU Directives & United States & Certification \\
\hline A-10 & $\begin{array}{l}\text { Safety of } \\
\text { Machinery }\end{array}$ & $\begin{array}{c}\text { Turbines } \\
\text { and } \\
\text { Substations }\end{array}$ & $\begin{array}{c}\text { IEC 60204-1 } \\
\text { IEC 60204-11 } \\
\text { IEC } 62061 \\
\text { IEC } 62745 \\
\text { Note that voltage levels } \\
\text { above } 36 \mathrm{kV} \text { are not } \\
\text { covered by the above } \\
\text { standards. }\end{array}$ & $\begin{array}{c}\text { EN/IEC 60204-1, }-11 \\
\text { EN/IEC ISO } 12100 \\
\text { ISO } 12100 \quad \text { ISO } 13849-1 \\
\text { ISO } 13849-2 \quad \text { ISO } 14119 \\
\text { ISO } 14120 \quad \text { ISO } 14122-1 \\
\text { ISO } 14122-2 \quad \text { ISO } 14122-3 \\
\text { ISO } 14122-4 \\
\text { BS EN ISO } 13849-1 \\
\text { BS EN ISO } 13849-2 \\
\text { BS EN ISO } 14122-1 \\
\text { BS EN ISO } 14122-2 \\
\text { BS EN ISO } 14122-3 \\
\text { BS EN ISO } 14122-4 \\
\text { BS EN IEC } 60204-11 \\
\text { DS/EN ISO } 13850 \\
\text { EU Directive: } 2006 / 42 / E C \\
\text { DNVGL-ST-0361 } \\
\text { BS EN 50308 }\end{array}$ & $\begin{array}{c}\text { NFPA } 79 \\
\text { NFPA } 70 \\
\text { CSA-C22.2 No. } 301\end{array}$ & $\begin{array}{l}\text { Certification } \\
\text { should be } \\
\text { carried out in } \\
\text { accordance with } \\
\text { the design } \\
\text { standards used } \\
\text { and employ } \\
\text { NRTL approval if } \\
\text { called for in } \\
\text { those standards. }\end{array}$ \\
\hline$\frac{\mathrm{A}-10}{\bullet}$ & $\begin{array}{l}\text { ments } \\
\text { tandard CSA- } \\
\text { SEE will also } \\
s \text { part of thei } \\
\text { his is a very } b \\
\text { leasures to } p \\
\text { egarding cert } \\
\text { II, participant } \\
\text { IFPA is also re }\end{array}$ & $\begin{array}{l}\text { EN/IEC } 6020 \\
\text { fication proce } \\
\text { from rotatin } \\
\text { on, design fo } \\
\text { eve there sho } \\
t \text { and has bee }\end{array}$ & $\begin{array}{l}-1,-11 \text { and EN/IEC ISO } 12 \\
\text { esign for machine safety } f \\
\text { equipment, electrical sho } \\
\text { nachine safety is evaluate } \\
d \text { be no requirement for } r \\
\text { added to the table. }\end{array}$ & $\begin{array}{l}\text { l-aligned with NFPA } 79 . \\
\text { which are harmonized to th } \\
\text { ind turbines involves the ov } \\
\text { uids under pressure, and ma } \\
\text { d certified as part of the ove } \\
\text { ated testing by an NRTL. }\end{array}$ & $\begin{array}{l}\text { EN standards. Interte } \\
\text { ol and operation str } \\
\text { hazards. } \\
\text { le type certification }\end{array}$ & $\begin{array}{l}\text { both standards } \\
\text { as well as specific } \\
\text { s. Some, but not }\end{array}$ \\
\hline
\end{tabular}




\begin{tabular}{|c|c|c|c|c|c|c|}
\hline Ref & Category & Relevance & IEC & IEC and EU Directives & United States & Certification \\
\hline A-11 & $\begin{array}{l}\text { Lightning } \\
\text { Protection }\end{array}$ & $\begin{array}{l}\text { Turbines } \\
\text { and } \\
\text { Substations }\end{array}$ & $\begin{array}{l}\text { IEC } 61400-24 \\
\text { IEC } 62305-3 \\
\text { IEC } 62305-4\end{array}$ & $\begin{array}{c}\text { BS EN/IEC 62305 } \\
\text { BS EN 61400-24 } \\
\text { EN 61400-24 } \\
\text { DIN EN 61400-24 }\end{array}$ & $\begin{array}{l}\text { NFPA } 780 \\
\text { CSA IEC } 61400-24 \\
\text { ANSI/CAN/UL } 96\end{array}$ & \\
\hline \multicolumn{7}{|c|}{$\begin{array}{l}\text { - An acceptable standard is the CSA IEC 61400-24 harmonized standard. } \\
\text { - However, industry recommends using IEC 61400-24 rather than the CSA-harmonized version to avoid any potential deviations. }\end{array}$} \\
\hline Ref & Category & Relevance & IEC & IEC and EU Directives & United States & Certification \\
\hline A-12 & $\begin{array}{l}\text { Electrical } \\
\text { Enclosures/ } \\
\text { Control Panel } \\
\text { (Degrees of } \\
\text { Protection) }\end{array}$ & $\begin{array}{c}\text { Turbines } \\
\text { and } \\
\text { Substations }\end{array}$ & $\begin{array}{l}\text { IEC } 60529 \\
\text { IEC 61936-1 }\end{array}$ & $\begin{array}{c}\text { BS EN } 60529 \\
\text { AS } 60529\end{array}$ & $\begin{array}{c}\text { NEMA ANSI/IEC } 60529 \\
\text { NEMA } 250 \\
\text { UL } 50 \\
\text { UL 508A } \\
\text { UL 50E }\end{array}$ & $\begin{array}{l}\text { Certification } \\
\text { should be } \\
\text { carried out in } \\
\text { accordance with } \\
\text { the design } \\
\text { standards used } \\
\text { and employ } \\
\text { NRTL approval if } \\
\text { called for in } \\
\text { those standards. }\end{array}$ \\
\hline \multicolumn{7}{|c|}{$\begin{array}{l}\text { A-12 Comments } \\
\text { - An acceptable standard is the NEMA ANSI/IEC } 60529 \text { harmonized standard. } \\
\text { - Note that UL 50E "Type" ratings and IEC } 60529 \text { "Ingress Protection (IP)" ratings are acceptable, but there are some incompatibilities with the ratings } \\
\text { systems, especially with respect to protection from oil or hydraulic fluid. } \\
\text { - There should be a focus on IP terminology. }\end{array}$} \\
\hline
\end{tabular}




\begin{tabular}{|c|c|c|c|c|c|c|}
\hline Ref & Category & Relevance & IEC & IEC and EU Directives & United States & Certification \\
\hline A-13 & $\begin{array}{l}\text { Wind Turbine } \\
\text { Electrical Systems }\end{array}$ & Turbines & $\begin{array}{c}\text { IEC 61400-1 } \\
\text { IEC 61400-3-1 (fixed) } \\
\text { IEC 61400-3-2 (floating) } \\
\text { IEC System for } \\
\text { Certification to } \\
\text { Standards Relating to } \\
\text { Equipment for Use in } \\
\text { Renewable Energy } \\
\text { Applications (IECRE) } \\
\text { Operational Document } \\
\text { (OD)-502 } \\
\text { IEC 61936-1 }\end{array}$ & $\begin{array}{c}\text { DNVGL-ST-0076 } \\
\text { EU Directive 2006/42/EC } \\
\text { BS EN 50308 } \\
\text { DIN EN 61400-3 (superfluous) } \\
\text { EN IEC } 61400-3 \text { (superfluous) }\end{array}$ & $\begin{array}{c}\text { CAN/CSA-C22.2 No. } 272 \\
\text { CAN/CSA-C61400-1 } \\
\text { CAN/CSA-C61400-3 } \\
\text { NFPA } 70 \text { (NEC) } \\
\text { NFPA 70B } \\
\text { NFPA 70E } \\
\text { OSHA } 29 \text { CFR } 1910.269 \\
\text { UL } 6141\end{array}$ & $\begin{array}{l}\text { Certification } \\
\text { should be } \\
\text { carried out in } \\
\text { accordance with } \\
\text { the design } \\
\text { standards used } \\
\text { and employ } \\
\text { NRTL approval if } \\
\text { called for in } \\
\text { those standards. }\end{array}$ \\
\hline A-13 & $\begin{array}{l}\text { Oomments } \\
\text { Acceptable standa } \\
\text { Canadian (CAN)/C } \\
\text { Note that the abo } \\
\text { Some industry rep } \\
\text { Significant revisior } \\
\text { Others recommen } \\
\text { the United States. } \\
\text { In general, industr } \\
\text { For example, DIN } \\
\text { BS EN } 50308 \text { appli } \\
\text { added here. } \\
\text { If using U.S. codes } \\
\text { system. If somethi } \\
\text { been certified. } \\
\text { Regarding certifica } \\
\text { industry represent } \\
\text { following approacl } \\
\text { components of the } \\
\text { beyond what has }\end{array}$ & $\begin{array}{l}\text { standards ar } \\
\text { sentatives re } \\
\text { ind expansior } \\
\text { following U.S } \\
\text { recommends } \\
61400-3 \text { anc } \\
\text { more to A-1 } \\
\text { nd regulation } \\
\text { has already } \\
\text { on, the wind } \\
\text { if using U.S. } \\
\text { ivstem. If son }\end{array}$ & $\begin{array}{l}\text { harmonized and referenc } \\
\text { mmend focusing on IEC } \\
\text { f the Electrical Systems s } \\
\text { gainst und regulations stat } \\
\text { N IEC } 61400-3 \text { seem supe } \\
\text { han A-13. It has been adc } \\
\text { for the wind turbine elect } \\
\text { rbine electrical system is } \\
\text { hd against a requirement } \\
\text { des and regulations for th } \\
\text { thing has already been ce }\end{array}$ & $\begin{array}{l}72 \text { (which is similar to UL } 6141 \\
\text { ated version of IEC } 61400-3 \text {. } \\
\text { C } 61400-3 \text {. Intertek uses these } \\
00-3-1 \text { and IEC } 61400-3-2 \text {, and a } \\
\text { on is included in the } 2019 \text { revis } \\
\text { in this table as primary referen } \\
\text { en a corresponding IEC version } \\
\text { there. Also, EU Directive } 2006 \text { / } \\
\text { lation is needed unless it has be } \\
\text { e tested and certified as part of } \\
\text { repeated evaluation and testin } \\
\text { vind turbine electrical system, } t \\
\text { ied, then no reevaluation is nee }\end{array}$ & $\begin{array}{l}\text { ards as part of their certifi } \\
\text { IEC } 61400-1 \text { as an accept } \\
\text { the IEC } 61400-1 \text { wind turl } \\
\text { the design basis of offsh } \\
\text { s. } \\
\text { applies here as well as in } \\
\text { anged or there are details } \\
\text { ppe certification process ( } \\
\text { N NRTL. However, others } \\
\text { NRTL should be used to } \\
\text { nless it has been changed }\end{array}$ & $\begin{array}{l}\text { ion process. } \\
\text { e standard. } \\
\text { e design standard. } \\
\text { wind turbines in } \\
\text { 10. It has been } \\
\text { nponents of the } \\
\text { Rond what has } \\
\text { ommend the } \\
\text { there are details }\end{array}$ \\
\hline
\end{tabular}




\begin{tabular}{|c|c|c|c|c|c|c|}
\hline Ref & Category & Relevance & IEC & IEC and EU Directives & \multirow[b]{2}{*}{$\begin{array}{c}\text { United States } \\
\text { OSHA } 29 \text { CFR } 1926.24 \\
\text { OSHA 29 CFR } 1926.150 \\
\text { OSHA } 29 \text { CFR } 1926.151 \\
\text { NFPA } 72 \\
\text { NFPA } 850 \\
\text { NEMA SB } 11 \\
\text { NEMA SB } 23 \\
\text { UL } 864\end{array}$} & \multirow[b]{2}{*}{$\begin{array}{l}\text { Certification } \\
\text { Certification } \\
\text { should be } \\
\text { carried out in } \\
\text { accordance with } \\
\text { the design } \\
\text { standards used } \\
\text { and employ } \\
\text { NRTL approval it } \\
\text { called for in } \\
\text { those standards }\end{array}$} \\
\hline A-14 & $\begin{array}{c}\text { Fire Prevention } \\
\text { and Fire } \\
\text { Protection }\end{array}$ & $\begin{array}{c}\text { Turbines } \\
\text { and } \\
\text { Substations }\end{array}$ & & 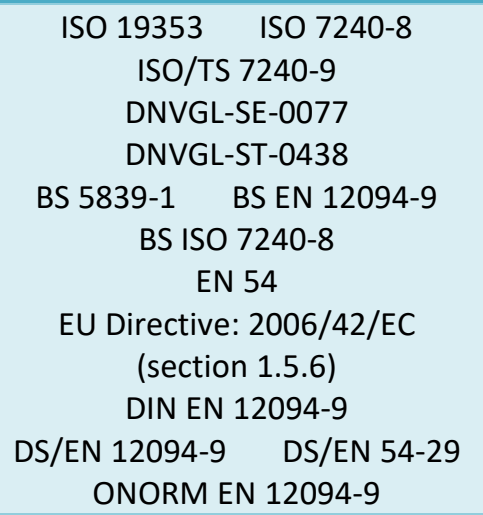 & & \\
\hline \multicolumn{7}{|c|}{$\begin{array}{l}\text { A-14 Comments } \\
\text { - Further assessment is needed to determine which IEC standards are compatible with U.S. regulations and standards. } \\
\text { - On an interim basis, the following standards are acceptable: OSHA regulations, NFPA 72, and NEMA standards. } \\
\text { - Industry recommends including ISO } 19353 \text { as an acceptable standard. } \\
\text { - } \text { reviewed during the certified verification agent process. } \\
\text { - Regarding certification, this topic is also covered in the wind turbine type certificate. Some industry representatives recommend against a } \\
\text { requirement for repeated certification by an NRTL. Others recommend the following approach: if using U.S. codes and regulations that require } \\
\text { - NRTL certification, then an NRTL should be used to certify. } \\
\text { - Evaluation of fire resistance and fire prevention are included in the IECRE-OD501 type certification process. } \\
\text { - See also comments on fire and smoke behavior under C-6. }\end{array}$} \\
\hline
\end{tabular}




\begin{tabular}{|c|c|c|c|c|c|c|}
\hline Ref & Category & Relevance & IEC & IEC and EU Directives & United States & Certification \\
\hline A-15 & $\begin{array}{l}\text { Converter/ } \\
\text { Inverter }\end{array}$ & $\begin{array}{l}\text { Turbines } \\
\text { and } \\
\text { Substations }\end{array}$ & $\begin{array}{l}\text { IEC 62477-1\&2 } \\
\text { IEC 62909-1 } \\
\text { IEC } 61800 \text { series }\end{array}$ & $\begin{array}{c}\text { BS PD IEC/TR 60146-1-2 } \\
\text { BS EN 61400-7 } \\
\text { DIN EN 62477-1 }\end{array}$ & $\begin{array}{c}\text { UL 347A } \\
\text { UL 508C } \\
\text { UL } 1741 \\
\text { UL 61800-5-1 } \\
\text { UL 61800-5-2 } \\
\text { UL 62109-1 } \\
\text { CAN/CSA-C22.2 No. } 14 \\
\text { CAN/CSA-C22.2 No } 107.1\end{array}$ & $\begin{array}{l}\text { Certification } \\
\text { should be } \\
\text { carried out in } \\
\text { accordance with } \\
\text { the design } \\
\text { standards used } \\
\text { and employ } \\
\text { NRTL approval if } \\
\text { called for in } \\
\text { those standards. }\end{array}$ \\
\hline
\end{tabular}

- The following standards are acceptable: UL 508C, CAN/CSA C22.2 No 107.1, UL 1741, UL 61800-5-1, UL 61800-5-2, UL 62109-1, and CAN/CSA-C22.2 No. 14.

- Industry recommends that converters comply to IEC 62477-1 and IEC 62477-2, respectively.

- Industry recommends including the IEC 61800 (series) of standards as acceptable. These are the leading standards for converter/inverter design and testing and have been included in the above list.

- For medium-voltage converters, UL 347A has been added to the table.

\begin{tabular}{|c|c|c|c|c|c|c|}
\hline Ref & Category & Relevance & IEC & IEC and EU Directives & United States & Certification \\
\hline A-16 & $\begin{array}{l}\text { Fixed Ladder } \\
\text { Inside Wind } \\
\text { Turbine }\end{array}$ & Turbines & & $\begin{array}{c}\text { ISO } 14122-1 \\
\text { ISO } 14122-4 \\
\text { BS EN ISO 14122-4 } \\
\text { EN50308 }\end{array}$ & $\begin{array}{c}\text { OSHA } 29 \text { CFR } 1910.23 \\
\text { OSHA } 29 \text { CFR 1910.269(h) } \\
\text { ANSI/American Society of } \\
\text { Safety Professionals (ASSP) } \\
\text { A1264.1 } \\
\text { American Ladder Institute } \\
\text { (ALI) ANSI Accredited } \\
\text { Standards Committee (ASC) } \\
\text { A14.3 }\end{array}$ & \\
\hline \multicolumn{7}{|c|}{$\begin{array}{l}\text { A-16 Comments } \\
\text { - Any of the listed standards are acceptable. } \\
\text { - Some industry representatives recommend compliance with the European standards, which they view as more practicable (EN50308). Others disagree. } \\
\text { - Nostricted clearance. } \\
\text { - An industry safety manager recommends that fixed ladders should comply with OSHA standards inside the United States and its waters. European } \\
\text { standards have not provided enough clearances for personnel and in the onshore industry OSHA will not give a variance for non-compliant ladders } \\
\text { from Europe. The fixed ladder standard in OSHA is well established and should be utilized in the United States. }\end{array}$} \\
\hline
\end{tabular}




\section{B. Safety Procedures}

\begin{tabular}{|c|c|c|c|c|c|c|}
\hline Ref & Category & Relevance & \multicolumn{2}{|r|}{$\begin{array}{l}\text { IEC and EU } \\
\text { Directives }\end{array}$} & United States & \multirow[t]{2}{*}{ Certification } \\
\hline B-1 & $\begin{array}{l}\text { Working On } \\
\text { or Near Live } \\
\text { Equipment }\end{array}$ & $\begin{array}{l}\text { Turbines and } \\
\text { Substations }\end{array}$ & $\begin{array}{c}\text { IEC 60364- } \\
5-52\end{array}$ & $\begin{array}{l}\text { BS } 6626 \text { BS } 7671 \\
\text { EU Directive } \\
\text { 2009/104/EC }\end{array}$ & $\begin{array}{l}\text { OSHA } 29 \text { CFR } 1926.960 \\
\text { OSHA } 29 \text { CFR } 1910 \text { Subparts R, S } \\
\text { NFPA 70E Ch. } 1 \text { Art.100-130 }\end{array}$ & \\
\hline \multicolumn{7}{|c|}{$\begin{array}{l}\text { B-1 Comments } \\
\text { - In BSEE's preliminary assessment, the following standards are acceptable: EU directive (2009/104/EC), BS standards, and IEC } 60364-5-52 \text {. } \\
\text { - However, one industry original equipment manufacturer (OEM) believes that further assessment is needed to determine which IEC standards anc } \\
\text { - A-3 comments also apply here. } \\
\text { - An industry safety manager recommends that OSHA and NFPA 70E should be the only allowable standards for the United States. These are } \\
\text { regulations that technicians and personnel are already trained in across all U.S. industries. These are well-established in the United States, and } \\
\text { manufacturers should not be allowed to dictate safety procedures. }\end{array}$} \\
\hline Ref & Category & Relevance & IEC & $\begin{array}{l}\text { IEC and EU } \\
\text { Directives }\end{array}$ & United States & Certification \\
\hline B-2 & $\begin{array}{l}\text { Personnel } \\
\text { Protective } \\
\text { Equipment } \\
\text { (PPE) }\end{array}$ & $\begin{array}{l}\text { Turbines and } \\
\text { substations }\end{array}$ & $\begin{array}{c}\text { IEC 61482- } \\
2 \\
\text { (European } \\
\text { Equivalent } \\
\text { to } \\
\text { American } \\
\text { Society of } \\
\text { Testing } \\
\text { Materials } \\
\text { [ASTM] } \\
\text { F1506) }\end{array}$ & $\begin{array}{l}\text { OSH Framework } \\
\text { Directive } \\
\text { 89/391/EEC }\end{array}$ & $\begin{array}{l}\text { ASTM F1506 NEMA ABP } 10 \\
\text { NFPA } 2112 \\
\text { NFPA } 70 \text { NEC - Art. } 110.16 \\
\text { NFPA 70B NFPA 70E } \\
\text { OSHA } 29 \text { CFR } 1910.137 \\
\text { - OSHA refers to Subpart I requirements, } \\
\text { which refer to ANSI and ASTM standards } \\
\text { - NFPA also refers to applicable ANSI and } \\
\text { ASTM standards }\end{array}$ & \\
\hline \multicolumn{7}{|c|}{$\begin{array}{l}\text { B-2 Comments } \\
\text { - In BSEE's preliminary assessment, the following standards are acceptable: OSH Framework Directive (89/391/EEC) and/or IEC } 61482-2 \text {. } \\
\text { - However, one industry OEM believes that further assessment is needed to determine which IEC standards and EU directives are compatible with } \\
\text { - Industry recommends enforcing NFPA 70E to address arc flash risk. } \\
\text { - Note that, relative to electrification risk, the European standards are more restrictive than the U.S. standards. }\end{array}$} \\
\hline
\end{tabular}




\begin{tabular}{|c|c|c|c|c|c|c|}
\hline Ref & Category & Relevance & IEC & $\begin{array}{l}\text { IEC and EU } \\
\text { Directives }\end{array}$ & United States & Certification \\
\hline B-3 & $\begin{array}{l}\text { Lockout- } \\
\text { Tagout } \\
\text { (LO/TO) }\end{array}$ & $\begin{array}{c}\text { Turbines and } \\
\text { Substations }\end{array}$ & $\begin{array}{c}\text { IEC 60204- } \\
1\end{array}$ & $\begin{array}{c}\text { EU Dir. 2009/104/EC } \\
\text { EU Dir. 2006/42/EC } \\
\text { EN ISO 14118 } \\
\text { AS } 4024.1603 \\
\text { ISO } 12100(6.2 .11 .1) \\
\text { ISO } 4413(5.4 .7 .2 .1)\end{array}$ & $\begin{array}{l}\text { NFPA } 70 \text { E NFPA 70B NFPA } 70 \\
\text { OSHA } 29 \text { CFR } 1910 \\
\text { ANSI/ASSP Z224.1 }\end{array}$ & \\
\hline \multicolumn{7}{|c|}{$\begin{array}{l}\text { B-3 Comments } \\
\text { - NFPA 7OE is an acceptable standard. } \\
\text { Industry recommends that IEC 60204-1 (e.g. } \S 5.4 \text { ) be included in the list of acceptable standards, because it addresses design of equipment for } \\
\text { - Industry recommends including ISO } 12100 \text { (see } \S 6.2 .11 .1 \text { ) and ISO } 4413 \text { (see 5.4.7.2.1) as additional standards applicable for LO/TO (often referred } \\
\text { to as "isolation of hazardous energy" internationally). The industry recommendations have been added to the above list. } \\
\text { - An industry safety manager recommends that only U.S. LO/TO standards and practices should be followed. As project owners, they will not allow } \\
\text { anyone to work on their project site who does not follow NFPA } 70 \mathrm{E} \text { and OSHA standards for control of hazardous energies and LO/TO. }\end{array}$} \\
\hline Ref & Category & Relevance & IEC & $\begin{array}{l}\text { IEC and EU } \\
\text { Directives }\end{array}$ & United States & Certification \\
\hline B-4 & $\begin{array}{l}\text { Equipment } \\
\text { Guarding } \\
\text { (Energized } \\
\text { Component) }\end{array}$ & $\begin{array}{l}\text { Turbines and } \\
\text { Substations }\end{array}$ & IEC 60204 & $\begin{array}{c}\text { EN ISO } 12100 \\
\text { ISO } 14120 \text { ISO } \\
13857 \\
\text { AS } 4024.1601 \\
\text { BS EN ISO } 14120 \\
\text { EN } 50308 \\
\text { ISO } 14119 \\
\text { ISO } 14122-3\end{array}$ & $\begin{array}{c}\text { OSHA } 29 \text { CFR } 1910.212 \text { (Sub.O) } \\
\text { NFPA } 70 \text { NFPA 70E NFPA } 79 \text { NFPA 70B } \\
\text { AMT ANSI B11.19 }\end{array}$ & \\
\hline \multicolumn{7}{|c|}{$\begin{array}{l}\text { B-4 Comments } \\
\text { - An acceptable standard is EN ISO } 12100 \text { harmonized for equipment guarding (energized component). } \\
\text { - EN 50308, ISO } 14119 \text {, and ISO } 14122-3 \text { (guard rails) have been added per industry recommendation. }\end{array}$} \\
\hline
\end{tabular}




\begin{tabular}{|c|c|c|c|c|c|c|}
\hline Ref & Category & Relevance & IEC & $\begin{array}{l}\text { IEC and EU } \\
\text { Directives }\end{array}$ & United States & Certification \\
\hline B-5 & $\begin{array}{c}\text { Work on } \\
\text { Submarine } \\
\text { Cables }\end{array}$ & Cable & & $\begin{array}{l}\text { Conseil } \\
\text { International des } \\
\text { Grands Réseaux } \\
\text { Électriques } \\
\text { (International } \\
\text { Council for Large } \\
\text { Electric Systems) } \\
\text { (CIGRE) TB } 773\end{array}$ & $\begin{array}{l}\text { IEEE } 1727 \\
\text { IEEE } 1234\end{array}$ & \\
\hline \multicolumn{7}{|c|}{$\begin{array}{l}\text { B-5 Comments } \\
\text { - CIGRE B1-115_2018 (conference paper) is also recommended for safe working practices in the presence of induced voltages. } \\
\text { - Consult Association of Diving Contractors International and International Marine Contractors Association for standards related to diving operations } \\
\text { near high-energy systems including submarine power cables. }\end{array}$} \\
\hline
\end{tabular}

\section{Reliability Design}

\begin{tabular}{|c|c|c|c|c|c|c|}
\hline Ref & Category & Relevance & IEC & IEC and EU Directives & United States & Certification \\
\hline C-1 & $\begin{array}{c}\text { Safety } \\
\text { (Testing/Fit } \\
\text { for Purpose) } \\
\text {-Acceptance } \\
\text { Testing }\end{array}$ & $\begin{array}{c}\text { Turbines } \\
\text { and } \\
\text { Substations }\end{array}$ & $\begin{array}{l}\text { IECRE OD-502 } \\
\text { IECRE OD-501 }\end{array}$ & $\begin{array}{l}\text { DNVGL-SE-0074 } \\
\text { DNVGL-SE-0441 } \\
\text { ISO } 9001\end{array}$ & $\begin{array}{l}\text { ANSI/International Electrical } \\
\text { Testing Association (NETA) } \\
\text { Acceptance Testing } \\
\text { Specifications (ATS) } \\
\text { CSA SPE-1000-13 } \\
\text { NFPA } 79\end{array}$ & $\begin{array}{l}\text { Certification per OD- } \\
501 \& 2 \text { should be done by } \\
\text { an IECRE-accepted } \\
\text { renewable energy } \\
\text { certification body). }\end{array}$ \\
\hline \multicolumn{7}{|c|}{$\begin{array}{l}\text { C-1 Comments } \\
\text { - In BSEE's preliminary assessment, the following standards are acceptable: DNV, CSA, or ANSI/NETA standards. However, one industry OEM believes } \\
\text { further assessment is needed. } \\
\text { BSEE recommends that developers conduct tests on electrical equipment to determine if it is fit for service before going live. This is routinely being } \\
\text { done by the industry. OEMs indicate that they do routinely carry out operational tests of wind turbine generators at the factory, including } \\
\text { generator and converter operation and operation of yaw motors fans, the pitch system, and so on. } \\
\text { - Standardized precommissioning and commissioning processes are also followed to ensure safe operation of all systems before startup. Also, service } \\
\text { manuals cover checks during lifetime. These manuals and checklists are required and reviewed as part of type certification according to IECRE OD- } \\
\text { 501. }\end{array}$} \\
\hline
\end{tabular}




\begin{tabular}{|c|c|c|c|c|c|c|}
\hline Ref & Category & Relevance & IEC & IEC and EU Directives & United States & Certification \\
\hline C-2 & $\begin{array}{l}\text { Wiring } \\
\text { Methods } \\
\text { High Voltage } \\
\text { (Submarine } \\
\text { Cable) }\end{array}$ & Cable & $\begin{array}{c}\text { IEC } 63026 \\
\text { Not specific to subsea } \\
\text { cable: } \\
\text { IEC } 62067 \\
\text { IEC } 60840 \\
\text { IEC } 60228\end{array}$ & $\begin{array}{l}\text { DNVGL-ST-0359 } \\
\text { CIGRE TB } 490 \\
\text { CIGRE TB } 610 \\
\text { CIGRE TB } 623 \\
\text { CIGRE TB } 784\end{array}$ & $\begin{array}{c}\text { OSHA_29 CFR1910.269 } \\
\text { IEEE C2 (NESC) }\end{array}$ & $\begin{array}{c}\text { The cable systems must } \\
\text { be covered by an existing } \\
\text { prequalification test and } \\
\text { type test that is } \\
\text { witnessed by a } \\
\text { competent witnessing } \\
\text { body or performed at an } \\
\text { independent test } \\
\text { laboratory. }\end{array}$ \\
\hline \multicolumn{7}{|c|}{$\begin{array}{l}\text { C-2 Comments } \\
\text { - IEC } 63026 \text { is the only internationally recognized standard covering both mechanical and electrical testing specifically adapted for submarine cable } \\
\text { systems up to } 60 \mathrm{kV}(\mathrm{Um}=72.5 \mathrm{kV}) \text {. } \\
\text { - Standards that are not specific to subsea cables should be used in combination with CIGRE TB } 490 \text { and CIGRE TB } 623, \text { which provide guidance on } \\
\text { testing for submarine applications. } \\
\text { - Information in DNVGL-ST-0359 is useful but it provides guidance, not a standard. } \\
\text { - Industry recommends consulting Appendix D4 of CIGRE TB } 610 \text { and CIGRE B1-303_2016 (conference paper) for information required to calculate } \\
\text { the current rating under dynamic loading. }\end{array}$} \\
\hline
\end{tabular}




\begin{tabular}{|c|c|c|c|c|c|c|}
\hline Ref & Category & Relevance & IEC & IEC and EU Directives & United States & Certification \\
\hline C-3 & $\begin{array}{l}\text { Wiring } \\
\text { Methods } \\
\text { Medium } \\
\text { Voltage } \\
\text { (Submarine) }\end{array}$ & Cable & $\begin{array}{c}\text { IEC } 63026 \\
\text { Not specific to subsea } \\
\text { cable: } \\
\text { IEC } 60840 \\
\text { IEC } 60502-2 \\
\text { IEC } 60228\end{array}$ & $\begin{array}{l}\text { DNVGL-ST-0359 } \\
\text { CIGRE TB } 490 \\
\text { CIGRE TB } 623\end{array}$ & IEEE 1120 & $\begin{array}{l}\text { The cable systems must } \\
\text { be covered by an existing } \\
\text { prequalification test and } \\
\text { type test according to IEC } \\
63026 \text {. See standards for } \\
\text { the description of the } \\
\text { range of approvals for } \\
\text { each of the tests. The } \\
\text { prequalification test and } \\
\text { type test must have been } \\
\text { witnessed by a } \\
\text { representative of a } \\
\text { competent witnessing } \\
\text { body or performed at an } \\
\text { independent test } \\
\text { laboratory. }\end{array}$ \\
\hline \multicolumn{7}{|c|}{ C-3 Comments } \\
\hline Ref & Category & Relevance & IEC & IEC and EU Directives & United States & Certification \\
\hline C-4 & $\begin{array}{l}\text { Wiring } \\
\text { Methods } \\
\text { Low Voltage } \\
\text { (Substation } \\
\text { and Wind } \\
\text { Turbine) }\end{array}$ & $\begin{array}{l}\text { Substations } \\
\text { Turbines } \\
\text { and Cable }\end{array}$ & & $\begin{array}{c}\text { DNVGL-ST-0359 } \\
\text { BS } 7671 \\
\text { Norme Francaise (NF) C15- } \\
100 \\
\text { DIN Verband der } \\
\text { Elektrotechnik (VDE) 0276- } \\
620 \\
\text { EU Directive: } 2009 / 104 / E C \\
\text { EU Directive: } 2006 / 42 / E C\end{array}$ & $\begin{array}{c}\text { NFPA } 70 \text { (NEC) } \\
\text { NFPA 70E } \\
\text { UL } 1277 \\
29 \text { CFR } 1910.305 \\
\text { ANSI/NEMA WC } 71 / \text { Insulated } \\
\text { Cable Engineers Association } \\
\text { (ICEA) S-96-659 } \\
\text { ANSI/NEMA WC 70/ICEA S-95- } \\
658\end{array}$ & \\
\hline $\mathrm{C}-4 \mathrm{C}$ & $\begin{array}{l}\text { nments } \\
\text { DNVGL-ST-03 } \\
\text { The following }\end{array}$ & is an accept & ctandard hecause it di & ly relates to the offshore wi & $\begin{array}{l}\text { industry. } \\
\text { DIN. }\end{array}$ & \\
\hline
\end{tabular}




\begin{tabular}{|c|c|c|c|c|c|c|}
\hline Ref & Category & Relevance & IEC & IEC and EU Directives & United States & Certification \\
\hline C-5 & $\begin{array}{c}\text { Wiring } \\
\text { Methods } \\
\text { (Marine } \\
\text { Shipboard } \\
\text { Cable) }\end{array}$ & Cable & IEC 60092-353 & $\begin{array}{c}\text { BS } 6883 \\
\text { ISO } 29400\end{array}$ & $\begin{array}{l}\text { IEEE } 1580 \\
\text { UL } 1309 \\
\text { Military Specification MIL- } \\
\text { DTL-24643C } \\
\text { MIL-DTL-24640C } \\
\text { CSA C22.2 No. } 245\end{array}$ & $\begin{array}{l}\text { Cables should be listed as } \\
\text { a marine shipboard cable } \\
\text { by an NRTL. }\end{array}$ \\
\hline \multicolumn{7}{|c|}{$\frac{\text { C-5 Comments }}{\text { - All of the }}$} \\
\hline Ref & Category & Relevance & IEC & IEC and EU Directives & United States & Certification \\
\hline C-6 & $\begin{array}{l}\text { Cable } \\
\text { Flammability } \\
\text { Testing }\end{array}$ & Cable & $\begin{array}{l}\text { IEC 60332-1-2 } \\
\text { IEC 60332-3-22 }\end{array}$ & $\begin{array}{c}\text { CIGRE TB } 720 \\
\text { EN 61034-2 (or IEC 61034- } \\
\text { 2-2005) for smoke visibility }\end{array}$ & $\begin{array}{l}\text { API Recommended Practice } \\
\text { (RP) } 14 f \\
\text { IEEE } 1202\end{array}$ & \\
\hline \multicolumn{7}{|c|}{$\begin{array}{l}\text { - All of the listed standards are acceptable. } \\
\text { - Some industry representatives recommend using API RP } 14 f \text { to identify fire protection needs and CIGRE TB } 720 \text { to select fire protection methods. } \\
\text { Others disagree. } \\
\text { - Note that the United States and Europe prioritize different hazards. Common practice in the United States suggests greater concern about smoke } \\
\text { than the toxicity of emissions. U.S. manufacturers make cables with halogen, whereas European designs are halogen-free. }\end{array}$} \\
\hline Ref & Category & Relevance & IEC & IEC and EU Directives & United States & Certification \\
\hline C-7 & Harmonics & $\begin{array}{l}\text { Turbines } \\
\text { and } \\
\text { Substations }\end{array}$ & $\begin{array}{l}\text { IEC } 61000-3-2 \text { IEC } 61000- \\
4-7 \text { IEC } 61000-4-15 \\
\text { IEC } 61000-4-30\end{array}$ & $\begin{array}{c}\text { EN IEC 61000-3-2 } \\
\text { EN } 50160\end{array}$ & IEEE 519 & \\
\hline C-7 C & $\begin{array}{l}\text { mments } \\
\text { The preventic } \\
\text { Requirements }\end{array}$ & re typically & $\begin{array}{l}\text { eeds to be discussed betu } \\
\text { by the transmission syste }\end{array}$ & $\begin{array}{l}\text { en the offshore wind farm d } \\
\text { operator/grid owner. }\end{array}$ & loper and grid owner. & \\
\hline
\end{tabular}




\begin{tabular}{|c|c|c|c|c|c|c|}
\hline Ref & Category & Relevance & IEC & IEC and EU Directives & United States & Certification \\
\hline C-8 & $\begin{array}{l}\text { Systems of } \\
\text { Insulating } \\
\text { Materials }\end{array}$ & Turbines & $\begin{array}{l}\text { IEC } 61857-31 \\
\text { IEC 60721-1 } \\
\text { IEC } 60071-1 \& 2 \\
\text { IEC } 60664-1 \& 3 \\
\text { IEC } 60085\end{array}$ & & $\begin{array}{l}\text { UL } 1446 \\
\text { IEEE } 1776\end{array}$ & $\begin{array}{l}\text { Certification should be } \\
\text { carried out in } \\
\text { accordance with the } \\
\text { design standards used } \\
\text { and employ NRTL } \\
\text { approval if called for } \\
\text { in those standards. }\end{array}$ \\
\hline \multicolumn{7}{|r|}{$\begin{array}{l}\text { address systems of } \\
0664-3, \text { have been } \\
\text { ommend against a } \\
\text { and regulations that } \\
\text { labs for those }\end{array}$} \\
\hline Ref & Category & Relevance & IEC & IEC and EU Directives & United States & Certification \\
\hline C-9 & $\begin{array}{l}\text { Uninterrupt } \\
\text {-able Power } \\
\text { Supplies }\end{array}$ & $\begin{array}{c}\text { Turbines } \\
\text { and } \\
\text { Substations }\end{array}$ & $\begin{array}{l}\text { IEC 62040-1 } \\
\text { IEC 61056-1 } \\
\text { IEC 60896-21 }\end{array}$ & $\begin{array}{c}\text { BS EN 62040-5-3 } \\
\text { BS EN 62040-1 }\end{array}$ & $\begin{array}{c}\text { UL } 1778 \text { UL } 62109-1 \\
\text { UL } 6141 \\
\text { CAN/CSA-C } 813.1 \\
\text { CAN/CSA-C381.2 } \\
\text { CSA-C22.2 No. } 60896-21 \\
\text { IEEE } 1106 \text { IEEE } 1184 \\
\text { IEEE } 1115 \\
\text { NECA NEIS } 411\end{array}$ & $\begin{array}{l}\text { Certification should be } \\
\text { carried out in } \\
\text { accordance with the } \\
\text { design standards used } \\
\text { and employ NRTL } \\
\text { approval if called for } \\
\text { in those standards. }\end{array}$ \\
\hline \multicolumn{7}{|c|}{$\begin{array}{l}\text { C-9 Comments } \\
\text { - The IEC and BS EN standards are acceptable. The UL } 6141 \text { standard references both as compatible. } \\
\text { Regarding certification, uninterruptable power supply (UPS) systems are provided by the supplier with type-test certification and documentation. } \\
\text { Some participants recommend against a requirement for repeated testing and/or evaluation by an NRTL. Others recommend the following } \\
\text { approach: if using U.S. codes and regulations that require NRTL certification, then an NRTL should be used to certify. If using IEC standards, then } \\
\text { tests with alternative accredited labs for those standards may be acceptable. }\end{array}$} \\
\hline
\end{tabular}




\begin{tabular}{|c|c|c|c|c|c|c|}
\hline Ref & Category & Relevance & IEC & IEC and EU Directives & United States & Certification \\
\hline C-10 & Slip Rings & Turbines & $\begin{array}{l}\text { IEC 60204-1 } \\
\text { IEC 60364-1 } \\
\text { IEC 60664-1 }\end{array}$ & AS $60204-1$ & $\begin{array}{c}\text { UL } 508 \\
\text { UL } 347 \\
\text { UL } 6141\end{array}$ & \\
\hline \multicolumn{7}{|c|}{$\begin{array}{l}\text { C-10 Comments } \\
\text { - The IEC slip rings standard IEC } 60204-1 \text { is acceptable. The UL } 6141 \text { standard accepts either IEC } 60204-1 \text { or UL } 508 \text { compliance. } \\
\text { UL } 6141 \text { explains that testing of the slip ring must consider the ratings/certifications of upstream overcurrent protection. A slip ring evaluated to UL } \\
\text { - IEC } 60364-1 \text { and IEC } 60664-1 \text { could be considered applicable. IEC } 60664-1 \text { focuses primarily on electromagnetic compatibility (EMC) requirements, } \\
\text { whereas IEC } 60364-1 \text { covers more general electrical requirements. These have been added to the above list per industry suggestion. }\end{array}$} \\
\hline Ref & Category & Relevance & IEC & IEC and EU Directives & United States & Certification \\
\hline C-11 & $\begin{array}{c}\text { Alternators, } \\
\text { Generators, } \\
\text { and } \\
\text { Motors }\end{array}$ & Turbines & $\begin{array}{l}\text { IEC } 60034 \text { Series } \\
\text { IEC } 60034-1 \text { IEC } 60034-2-1 \\
\text { IEC } 60034-2-2 \\
\text { Note: ANSI is harmonizing the } \\
\text { ANSI C50 series with IEC } \\
\quad 60034\end{array}$ & ISO 281 & $\begin{array}{l}\text { UL } 1004 \text { Series } \\
\text { UL } 4143 \quad \text { UL 1004-1\&4 } \\
\text { UL } 6141 \\
\text { ANSI/NEMA MG } 1 \\
\text { NEMA MG } 2 \\
\text { ANSI C50 series } \\
\text { IEEE } 1310\end{array}$ & $\begin{array}{l}\text { Certification should be } \\
\text { carried out in } \\
\text { accordance with the } \\
\text { design standards used } \\
\text { and employ NRTL } \\
\text { approval if called for } \\
\text { in those standards. }\end{array}$ \\
\hline \multicolumn{7}{|c|}{$\begin{array}{l}\text { C-11 Comments } \\
\text { - The IEC Alternators, Generators, and Motors series of standards are acceptable. The UL } 6141 \text { standard accepts compliance with either the UL } 1004 \\
\text { series or IEC } 60034 \text { series. } \\
\text { UL } 6141 \text { explains that testing of the item must consider the ratings/certifications of upstream overcurrent protection. An item evaluated to UL } 1004 \\
\text { may not be compatible with upstream equipment evaluated to IEC } 60034 \text {. } \\
\text { Regarding certification, generators go through extensive component certification testing. Motors are provided by the supplier with type-test } \\
\text { certification and documentation. Some participants recommend against a requirement for repeated testing and/or evaluation by an NRTL. Others } \\
\text { recommend the following approach: if using U.S. codes and regulations that require NRTL certification, then an NRTL should be used to certify. If } \\
\text { using IEC standards, then tests with alternative accredited labs for those standards may be acceptable. }\end{array}$} \\
\hline
\end{tabular}




\begin{tabular}{|c|c|c|c|c|c|c|}
\hline Ref & Category & Relevance & IEC & IEC and EU Directives & United States & Certification \\
\hline C-12 & $\begin{array}{l}\text { Cable } \\
\text { Testing }\end{array}$ & Cable & $\begin{array}{l}\text { IEC } 60230 \\
\text { IEC } 60229 \\
\text { IEC } 60287 \\
\text { IEC } 60811-501\end{array}$ & $\begin{array}{l}\text { CIGRE TB } 303 \\
\text { CIGRE TB } 490 \\
\text { CIGRE TB } 623 \\
\text { CIGRE TB } 722\end{array}$ & $\begin{array}{l}\text { ICEA P-32-382 } \\
\text { ICEA P-45-482 } \\
\text { ICEA T-24-380 } \\
\text { ICEA T-31-610 } \\
\text { ICEA T-32-645 } \\
\text { ICEA T-34-664 } \\
\text { Association of Edison } \\
\text { Illuminating Companies (AEIC) } \\
\text { CS8 AEIC CS9 }\end{array}$ & \\
\hline \multicolumn{7}{|c|}{$\frac{\text { C-12 Comments }}{\bullet \quad \text { Note tha }}$} \\
\hline Ref & Category & Relevance & IEC & IEC and EU Directives & United States & Certification \\
\hline C-13 & $\begin{array}{l}\text { Wiring } \\
\text { Within the } \\
\text { Turbine }\end{array}$ & Turbines & $\begin{array}{c}\text { IEC 60364-5-52 } \\
\text { IEC 60364-1 } \\
\text { IEC 60204-1 }\end{array}$ & BS 7671 & $\begin{array}{cc}\text { NFPA } 70 \text { (NEC) } & \text { NFPA } 79 \\
\text { UL } 6141 & \text { UL } 508 \\
\text { UL } 2277 \text { Outline } \\
\text { UL } 1651 \quad \text { UL } 1072\end{array}$ & \\
\hline \multicolumn{7}{|c|}{$\begin{array}{l}\text { C-13 Comments } \\
\text { - Both the IEC and U.S. standards are acceptable. As required by UL 6141, the OEM needs to state which set of standards is used and remain } \\
\text { consistent in the design. } \\
\text { - Note that the requirements for wiring in Section } 4.2 \text { of UL } 6141 \text { address wiring design, installation, and marking. NFPA } 70 \text { or IEC } 60364-5-52 \text { align } \\
\text { with UL requirements. } \\
\text { - Industry recommends that wiring be fully documented in electrical diagrams made available to technicians. This could be beneficial to addressing } \\
\text { differences between the NFPA and IEC; for example, wire color coding. } \\
\text { - Industry recommends using the NFPA standards, and that they be acceptable (technicians will be trained to these standards). } \\
\text { - Note that these standards apply only for voltages under } 1,000 \text { volts alternating current (VAC) (1,500 VDC). }\end{array}$} \\
\hline
\end{tabular}




\begin{tabular}{|c|c|c|c|c|c|c|}
\hline Ref & Category & Relevance & IEC & IEC and EU Directives & United States & Certification \\
\hline C-14 & $\begin{array}{l}\text { Surge } \\
\text { Protection/ } \\
\text { Suppression } \\
\text { Component }\end{array}$ & $\begin{array}{c}\text { Turbines } \\
\text { and } \\
\text { Substations }\end{array}$ & $\begin{array}{l}\text { IEC 61643-11 } \\
\text { IEC 60099-4 }\end{array}$ & $\begin{array}{l}\text { BS DD CLC TS 50539-22 } \\
\text { DIN CLC/TS 50539-22 }\end{array}$ & $\begin{array}{c}\text { UL } 1449 \\
\text { IEEE C62.23 } \\
\text { IEEE C62.21 }\end{array}$ & \\
\hline \multicolumn{7}{|c|}{$\begin{array}{l}\text { - In BSEE's preliminary assessment, the UL and IEEE standards, or the IEC standards, are acceptable. However, one industry OEM believes further } \\
\text { assessment is needed to determine which IEC standards are compatible with U.S. standards. }\end{array}$} \\
\hline Ref & Category & Relevance & IEC & IEC and EU Directives & United States & Certification \\
\hline C-15 & $\begin{array}{c}\text { Pitch, Yaw, } \\
\text { Other } \\
\text { Control } \\
\text { Panels }\end{array}$ & Turbines & IEC 61400-3 & $\begin{array}{l}\text { EN IEC 61400-3 } \\
\text { DS/EN 61400-3 }\end{array}$ & $\begin{array}{c}\text { UL 508A } \\
\text { CAN/CSA-C22.2 No } 14 \\
\text { CAN/CSA-C61400-3 }\end{array}$ & $\begin{array}{l}\text { Certification should be } \\
\text { carried out in } \\
\text { accordance with the } \\
\text { design standards used } \\
\text { and employ NRTL } \\
\text { approval if called for } \\
\text { in those standards. }\end{array}$ \\
\hline \multicolumn{7}{|c|}{$\begin{array}{l}\text { C-15 Comments } \\
\text { - In BSEE's preliminary assessment, the following standards are acceptable: UL 508A, CAN/CSA C22.2 No 14, and CAN/CSA C61400-3. However, one } \\
\text { industry OEM believes further assessment is needed to determine which IEC standards are compatible with U.S. standards. } \\
\text { - Note that Intertek certifies wind turbines to the above standards. } \\
\text { - Consider splitting this category into separate topics, given its broad coverage. Control panels are designed to comply with numerous IEC and ISO } \\
\text { standards on both electrical safety, ingress protection, EMC, adequate working space, guarding, and so on. } \\
\text { - Industry recommends including relevant IEC/ISO standards among acceptable standards. }\end{array}$} \\
\hline Ref & Category & Relevance & IEC & IEC and EU Directives & United States & Certification \\
\hline C-16 & Gearboxes & Turbines & IEC 61400-4 & $\begin{array}{l}\text { DS/EN 61400-4 } \\
\text { OVE/ONORM EN 61400-4 } \\
\text { DIN EN 61400-4 } \\
\text { BS EN 61400-4 }\end{array}$ & $\begin{array}{c}\text { ANSI/American Gear } \\
\text { Manufacturers } \\
\text { Association/American Wind } \\
\text { Energy Association 6006-A03 } \\
\text { UL } 508 \\
\text { UL } 73\end{array}$ & \\
\hline \multicolumn{7}{|c|}{ C-16 Comments } \\
\hline
\end{tabular}




\begin{tabular}{|c|c|c|c|c|c|c|}
\hline Ref & Category & Relevance & IEC & IEC and EU Directives & United States & Certification \\
\hline C-17 & $\begin{array}{l}\text { Wind } \\
\text { Turbine } \\
\text { Tower } \\
\text { Elevators }\end{array}$ & Turbines & & $\begin{array}{l}\text { EN 81-44 (in development) } \\
\text { 2006/42/EC (machinery) } \\
\text { EN } 1808\end{array}$ & $\begin{array}{l}\text { CSA B44.8/American Society } \\
\text { of Mechanical Engineers } \\
\text { (ASME) A17.8 } \\
\text { ASME A17.8 } \\
\text { ANSI/ASSP A10.4 }\end{array}$ & \\
\hline \multicolumn{7}{|c|}{$\begin{array}{l}\text { - In BSEE's preliminary assessment, any of the above standards are acceptable for wind turbine elevators. However, one industry OEM believes } \\
\text { further assessment is needed to determine which EN standards are compatible with U.S. standards. } \\
\text { - EN } 1808 \text { has been added to the listing per industry recommendation. }\end{array}$} \\
\hline Ref & Category & Relevance & IEC & IEC and EU Directives & United States & Certification \\
\hline C-18 & $\begin{array}{l}\text { Hoist, } \\
\text { Winch, and } \\
\text { Cranes }\end{array}$ & Turbines & IEC 60204-32 & $\begin{array}{c}\text { AS } 1418.2 \text { AS 2550.1 } \\
\text { BS EN 14492-1 } \\
\text { EN 13001-1\&2\&3 } \\
\text { IEC 60204-32 } \\
\text { EN 12999 } \\
\text { EN } 14492-1 \& 2 \\
\text { DIN 15400 } \\
\text { EN 12385-4 } \\
\text { EN13411-6 } \\
\text { EN1993-6 }\end{array}$ & UL 1340 & \\
\hline \multicolumn{7}{|c|}{$\begin{array}{l}\text { C-18 Comments } \\
\text { - UL } 1340 \text { is an acceptable standard. } \\
\text { - Some industry representatives recommend including the following as acceptable standards: EN 13001-1, EN 13001-2, and EN 13001-3 for general } \\
\text { crane requirements; IEC 60204-32 for electrical requirements toward hoisting machines; EN 12999 for specific requirements toward hydraulic } \\
\text { powered cranes; EN 14492-1 and EN 14492-2 for winches and hoists; DIN } 15400 \text { for lifting hooks; EN 12385-4 and EN 13411-6 for steel wire ropes; } \\
\text { and EN 1993-6 for crane rail systems. } \\
\text { - All of these additional standards have been added to the above list. } \\
\text { - However, one industry OEM believes further assessment is needed to determine which EN standards are compatible with U.S. standards. }\end{array}$} \\
\hline
\end{tabular}




\begin{tabular}{|c|c|c|c|c|c|c|}
\hline Ref & Category & Relevance & IEC & IEC and EU Directives & United States & Certification \\
\hline C-19 & Lighting & $\begin{array}{c}\text { Turbines } \\
\text { and } \\
\text { Substations }\end{array}$ & & $\begin{array}{l}\text { BS EN 12464-2 } \\
\text { Proposed additions for } \\
\text { consideration: } \\
\text { EN } 50308 \\
\text { EN } 12464-1 \\
\text { EN1838 } \\
\text { EN1837 }\end{array}$ & $\begin{array}{c}\text { OSHA } 29 \text { CFR } 1926.26 \\
\text { OSHA } 29 \text { CFR } 1926.56 \\
\text { ANSI/IES RP-7-17 } \\
\text { IEEE C2 (NESC) - minimum } \\
\text { illumination intensities for } \\
\text { different areas of operation } \\
\text { UL } 1598\end{array}$ & $\begin{array}{l}\text { Internal lighting } \\
\text { fixtures - NEMA } 4 \\
\text { protection (IP } 65 \text { can } \\
\text { be accepted) } \\
\text { External lighting } \\
\text { fixtures - NEMA } 6 \\
\text { protection (IP } 67 \text { can } \\
\text { be accepted) }\end{array}$ \\
\hline \multicolumn{7}{|c|}{$\begin{array}{l}\text { C-19 Comments } \\
\text { - In BSEE's preliminary assessment, any of the originally listed standards are acceptable for lighting. Proposed additions need to be considered. } \\
\text { indoor lighting and EN } 1838 \text { for emergency lighting; and EN 1837, as the more general lighting standard. } \\
\text { - However, one industry OEM believes further assessment is needed to determine which EN standards are compatible with U.S. standards. } \\
\text { - Another recommended addition is UL 1598, the safety standard for luminaires. It is added to the above list. }\end{array}$} \\
\hline Ref & Category & Relevance & IEC & IEC and EU Directives & United States & Certification \\
\hline C-20 & $\begin{array}{l}\text { Illumination } \\
\text { Levels for } \\
\text { Emergency } \\
\text { Evacuation }\end{array}$ & $\begin{array}{c}\text { Turbines } \\
\text { and } \\
\text { Substations }\end{array}$ & & $\begin{array}{l}\text { Australian Standard/New } \\
\text { Zealand Standard (AS/NZS) } \\
2293.1 \\
\text { EN } 50308 \\
\text { EN } 1838\end{array}$ & $\begin{array}{c}\text { NFPA } 110 \\
\text { NFPA } 111 \\
\text { NESC }\end{array}$ & \\
\hline \multicolumn{7}{|c|}{ C-20 Comments } \\
\hline
\end{tabular}




\begin{tabular}{|c|c|c|c|c|c|c|}
\hline Ref & Category & Relevance & IEC & IEC and EU Directives & United States & Certification \\
\hline C-21 & $\begin{array}{l}\text { Emergency } \\
\text { and } \\
\text { Standby } \\
\text { Power } \\
\text { Systems }\end{array}$ & $\begin{array}{c}\text { Turbines } \\
\text { and } \\
\text { Substations }\end{array}$ & $\begin{array}{c}\text { IEC } 62034 \\
\text { IEC } 61892-2 \\
\text { IEC } 62040-1 \& 2 \& 3 \& 4\end{array}$ & & $\begin{array}{l}\text { CSA-C282 } \\
\text { CSA-C22.2 No. } 141 \\
\text { NFPA } 110 \\
\text { NFPA } 111\end{array}$ & \\
\hline \multicolumn{7}{|c|}{ C-21 Comments } \\
\hline Ref & Category & Relevance & IEC & IEC and EU Directives & United States & Certification \\
\hline C-22 & $\begin{array}{l}\text { Power } \\
\text { Sockets and } \\
\text { Plugs }\end{array}$ & $\begin{array}{c}\text { Turbines } \\
\text { and } \\
\text { Substations }\end{array}$ & IEC 60309 & & $\begin{array}{c}\text { UL } 498 \\
\text { NFPA } 70 \text { (NEC) }\end{array}$ & $\begin{array}{l}\text { Receptacle NEMA } 4 \mathrm{X} \\
\text { protection. }\end{array}$ \\
\hline \multicolumn{7}{|c|}{$\begin{array}{l}\text { - The UL, NFPA, and NEMA standards listed above are acceptable. } \\
\text { - Industry recommends adding IEC 60309, which would be used for special OEM equipment operating at higher voltages (400 V, } 690 \text { V); } 120-\mathrm{V} \\
\text { sockets and plugs are likely to use NEMA 5-20R. } \\
\text { - Occasionally, European outlets have been mistakenly installed in some turbines for simple } 110-\mathrm{V} \text { circuits. }\end{array}$} \\
\hline Ref & Category & Relevance & IEC & IEC and EU Directives & United States & Certification \\
\hline C-23 & Cable Trays & $\begin{array}{l}\text { Turbines } \\
\text { and } \\
\text { Substations }\end{array}$ & $\begin{array}{c}\text { IEC } 61537 \\
\text { IEC 60364-5-52 }\end{array}$ & $\begin{array}{l}\text { DS/EN } 61537 \\
\text { BS EN } 61537\end{array}$ & $\begin{array}{l}\text { UL } 2277 \text { Outline } \\
\text { UL } 6141 \\
\text { NEMA VE } 1 \\
\text { NFPA } 70 \text { (NEC) Art.320 } \\
\text { CSA C22.2 No. } 230 \text { \& No.126.1 }\end{array}$ & \\
\hline \multicolumn{7}{|c|}{$\begin{array}{l}\text { C-23 Comments } \\
\text { - In BSEE's preliminary assessment, any of the standards listed above are acceptable. However, one industry OEM believes further assessment is } \\
\text { needed to determine which EN standards are compatible with U.S. standards. } \\
\text { Note that routing of cables can be done according to IEC 60364-5-52. This may relate to the configuration of cable trays, but not necessarily to the } \\
\text { cable trays themselves. }\end{array}$} \\
\hline
\end{tabular}




\begin{tabular}{|c|c|c|c|c|c|c|}
\hline Ref & Category & Relevance & IEC & IEC and EU Directives & United States & Certification \\
\hline C-24 & $\begin{array}{l}\text { Cable Cleats } \\
\text { for } \\
\text { Electrical } \\
\text { Installations }\end{array}$ & $\begin{array}{l}\text { Turbines } \\
\text { and } \\
\text { Substations }\end{array}$ & $\begin{array}{l}\text { IEC } 61914 \\
\text { Proposed additions: } \\
\text { IEC } 61238-1-1 \& 2 \& 3\end{array}$ & $\begin{array}{l}\text { BS EN } 61914 \\
\text { DS/EN } 61914 \\
\text { DIN EN } 61914\end{array}$ & $\begin{array}{l}\text { UL } 1565 \\
\text { UL } 6141 \\
\text { NFPA } 70\end{array}$ & \\
\hline \multicolumn{7}{|c|}{$\begin{array}{l}\text { - In BSEE's preliminary assessment, the standards originally listed above are acceptable. However, one industry OEM believes further assessment is } \\
\text { needed to determine which IEC standards are compatible with U.S. standards. } \\
\text { - Industry recommends adding IEC 61238-1-1, IEC 61238-1-2, and IEC 61238-1-3 to the list of acceptable standards. }\end{array}$} \\
\hline Ref & Category & Relevance & IEC & IEC and EU Directives & United States & Certification \\
\hline C-25 & $\begin{array}{l}\text { Cathodic } \\
\text { Protection }\end{array}$ & $\begin{array}{l}\text { Turbines } \\
\text { and } \\
\text { Substations }\end{array}$ & & $\begin{array}{l}\text { DNVGL-RP-B401 } \\
\text { DS/EN } 12473 \\
\text { EN } 12495 \\
\text { ISO } 12473 \\
\text { BS/EN } 13173\end{array}$ & $\begin{array}{c}\text { National Association of } \\
\text { Corrosion Engineers (NACE) } \\
\text { RP-01 }\end{array}$ & \\
\hline \multicolumn{7}{|c|}{ C-25 Comments } \\
\hline Ref & Category & Relevance & IEC & IEC and EU Directives & United States & Certification \\
\hline C-26 & $\begin{array}{l}\text { Grounding } \\
\text { and } \\
\text { Bonding }\end{array}$ & $\begin{array}{l}\text { Turbines } \\
\text { and } \\
\text { Substations }\end{array}$ & $\begin{array}{l}\text { IEC 60364-5-54 } \\
\text { IEC 60204-1 } \\
\text { IEC 60364-5-4 }\end{array}$ & IEC/BS EN 62305-3 & $\begin{array}{c}\text { NFPA } 70 \text { (NEC)- Art. } 250 \\
\text { CSA C22.2 No. } 0.4 \text { \& No. } 41 \\
\text { UL } 467 \\
\text { IEEE } 3003.2\end{array}$ & \\
\hline $\mathrm{C}-26 \mathrm{C}$ & $\begin{array}{l}\text { In BSEE's prel } \\
\text { assessment is } \\
\text { IEC-60204-1 } \mathrm{r} \\
\text { Industry reco }\end{array}$ & $\begin{array}{l}\text { eeded to det } \\
\text { meen added addin }\end{array}$ & $\begin{array}{l}\text { which IEC standards a } \\
\text { ustry recommendatio } \\
364-5-4 \text { to the list of a }\end{array}$ & $\begin{array}{l}\text { otable: NFPA 70, CSA, UL, } \\
\text { tible with U.S. standards. } \\
\text { e standards because it is }\end{array}$ & $\begin{array}{l}\text { EEE. However, one industry } \mathrm{OE} \\
\mathrm{f} \text { the design basis and is well-es }\end{array}$ & $\begin{array}{l}\text { believes further } \\
\text { blished in the industry. }\end{array}$ \\
\hline
\end{tabular}

NOTE: Arc flash does not apply only to transformer and high-voltage equipment, as low-voltage circuits have the potential for arc flash as well. Protection against electrical shock and arc flash are not equivalent.

ii NOTE: ANSI/NETA ATS-2017 (Standard for Acceptance Testing Specifications for Electrical Power Equipment and Systems) is an acceptable method for ensuring electrical equipment and systems are operational, are within applicable standards and manufacturer's tolerances, and are installed in accordance with design specifications prior to going live. 